\title{
The Aboriginal Material Culture of the Wellesley Islands and Adjacent Mainland Coast, Gulf of Carpentaria: Social and Environmental Factors Affecting Variations in Style
}

\author{
Anne Best \\ Aboriginal Environments Research Centre, The University of Queensland, Brisbane, QLD 4072, Australia
}

\begin{abstract}
Similarities and differences in aspects of the culture of the Aboriginal people of the Wellesley Islands, has been noted by European writers. This remote island group is situated in the southern region of the Gulf of Carpentaria, northwest Queensland. Observed differences appear to demonstrate dissimilarities in certain cultural manifestations between the North Wellesley Islands (Mornington and Forsyth) and the South Wellesley Islands (Bentinck and Sweers). These include language, social organisation, land-use, ritual and ceremonial practices and manufactured objects of material culture. However, other cultural practices, namely an economy based on marine resources, are shared throughout the region. The data used here focus on items of portable material culture used by the people of the Wellesley Islands and the adjacent mainland coast at a time before intensified social disruptions to Aboriginal people in the area was brought about by increased European occupation and by the establishment of missions in the region in the first quarter of the twentieth century. All items are from museum collections and were collected no later than 1916. Using a relational database, the morphological variations present in the objects are quantified and analysed. The study area is divided into three regional zones; the North Wellesley Islands, the South Wellesley Islands and the Adjacent Mainland Coast. In the region, four different languages are spoken and the data are also analysed by language group. The aim of the study is to determine whether quantifiable regional variation can be demonstrated. This article intentionally focuses narrowly on portable objects of material culture. For references to wider cultural aspects of the study area, see Roth $(1897,1901,1903)$, Tindale (1977), Trigger (1987), Robins et al. (1998), Evans (2005), Memmott (2010), whose work has previously explored similarity and difference in the culture of the region as well as theoretical discussions of the reasons for these differences.
\end{abstract}

\section{Introduction}

This study quantifies and analyses the spatial distributions and morphological similarities and differences within the material culture of the Wellesley Islands, Queensland, Australia, and that of the adjacent mainland Gulf of Carpentaria coast. Findings are set against the contemporary observations of Roth, and those of later workers in the region, in particular Tindale (1949, 1962, 1977), Trigger (1987), Memmott (2010) and Memmott et al. (2006). Results are also correlated with the environmental and social model of variation within the regional style of Aboriginal material culture in Queensland proposed by Best (2003).

In order to do this, a dataset of early contact period artefacts from the study area was assembled. For the purposes of analysis the area is divided into three geographical zones, namely the Mainland Coast (Geographical Zone 1), the North Wellesley Islands (Geographical Zone 2) and the South Wellesley Islands (Geographical Zone 3), and four language zones, namely Ganggalida (Language Zone 1), Lardil (Language Zone 2), Kaiadilt (Language Zone 3) and Yangkaal (Language Zone 4). The aim is to determine if style similarities and differences exist between the identified geographical and language zones; to see if interisland artefact differences exist; and to determine which island group/s shares most characteristics with the adjacent mainland coast. If regional spatial patterns are demonstrated, the reason for these will be discussed in order to understand the likely influence of social and environmental factors as a cause for variations in the style of objects of material culture. It should be noted that the material culture on which this study is based is at least a century old and that the intense social changes in the Aboriginal populations of the region during the past hundred years have resulted in attendant change both within the types of artefacts that are made now and in their regional distribution.

\section{The Study Area}

The study area comprises a group of offshore islands, collectively known as the 'Wellesley Islands', situated in the southern region of the Gulf of Carpentaria, northwest Queensland, Australia, and the adjacent mainland coast (Figure 1). The Wellesley Islands are further subdivided geographically into a northern group and a southern group with Mornington Island the largest in the northern group and Bentinck Island the largest in the southern group. A group of 'stepping stone' islands - Denham, Forsyth and Bayley - lie between Mornington Island and the coast. Clear visibility exists between these 'stepping stone' islands. During the period when the data used here were collected, the islands populated were Forsyth, Mornington, and Bentinck. Mornington Island is home to Lardil speakers, Bentinck to Kaiadilt speakers and Forsyth to Yangkaal speakers. Groups occupying the immediately adjoining coastal region are Ganggalida speakers (Note: this dialect is referred to in the literature by some as Yugulda).

The area lies within the tropics. Weather patterns are defined by a dry (April-November) and wet (DecemberMarch) season. Heavy monsoonal rainfall, flooding and cyclones are a feature of the wet season. The topography is flat. The sea is shallow and shorelines are fringed with saltpans, sand ridges, mangroves and mud flats, rocky cliffs and beaches, presenting an environment rich in marine resources of fish, shellfish, sea mammals and turtles. Mornington Island is the largest of the group and covers $1000 \mathrm{~km}^{2}$ (Tindale 1974). Bentinck covers an area 


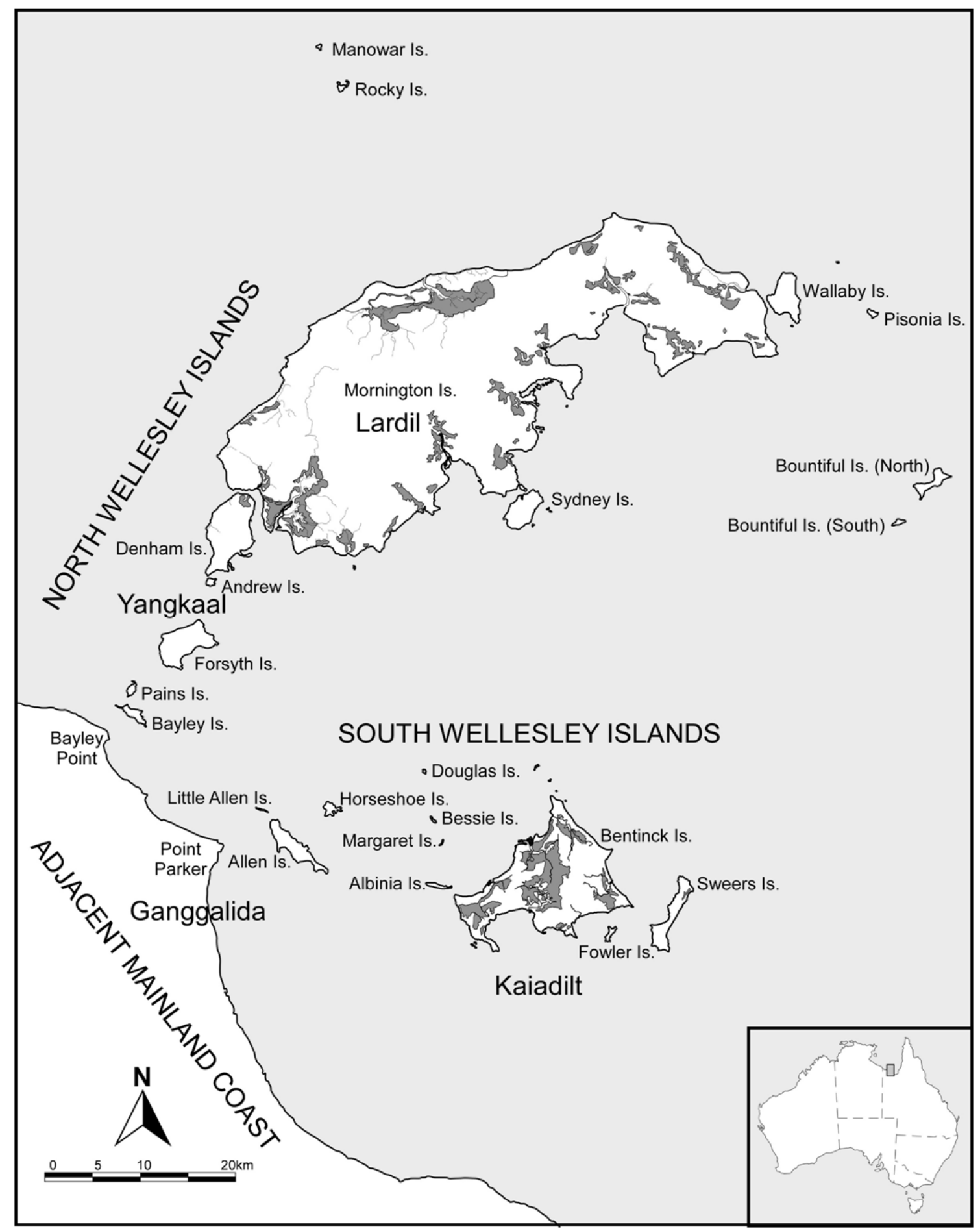

Figure 1. The Wellesley Islands and adjacent mainland coast, southern Gulf of Carpentaria, Queensland. 
of $180 \mathrm{~km}^{2}$, but, according to Tindale (1974), was more densely populated. The region was occupied by Aboriginal fisher-hunter-gatherers defined as 'Saltwater People' by Trigger (1987). The archaeology of shell middens in the coastal area indicates occupation spanning the past 3000 years (Robins et al. 1998; Rosendahl 2012; Ulm et al. 2010). Inshore rafting is widely-documented (Roth 1910:4-6, Plate III). However, in his detailed account of transport by water, Roth makes no mention of canoes in this area (Roth 1910:2-19), although canoe transport is reported in areas of the west coast of Cape York.

A coastal feature of the Wellesley Islands and the adjacent mainland coast are constructed rock-wall fish traps of undetermined age. The greatest density of traps is found in the South Wellesley Islands while Mornington Island has the lowest density. Rock-wall traps are evidence of local exploitation of fish, where a variety of species could be caught easily within the trap at the receding tide (Memmott et al. 2008). Shell middens are also a feature (Robins et al. 1998).

Terrestrial resources were more varied on Mornington than on Bentinck with macropods and dingoes present on Mornington and absent on Bentinck.

In summary, geographical links in the form of stepping-stone islands between the mainland and Mornington Island provide less difficult access between the populations of the northern Wellesleys and the adjacent coast. Bentinck Island is geographically more isolated.

\section{Previous Studies}

European chroniclers and academics have noted that cultural differences exist between the populations of the Wellesley Islands. Below is a quick glance at selected work which contributes to our understanding of the content and distribution of objects of material culture within the study area.

Roth visited the Wellesleys three times between 1901 and 1903, and recorded his findings. He postulated that the occupants of Bentinck lived largely in isolation from other peoples in the region and writes:

\section{The timidity of the Bentinck natives is such that only on one occasion, during the course of three visits, have I been able to come in direct touch with them. They neither communicate with the mainland and neighbouring islands, nor speak the same language as the Mornington and Forsyth blacks ... in fact they appear to have been isolated from the outside world long prior to the time when the present inhabitants first occupied the neighbouring islands of the group (Roth 1904:23).}

The premise that the Bentinck Island population existed in extreme isolation was taken up by Tindale to explain the differences in the material culture repertoires present within the wider Wellesley Islands. Subsequently work has focused on understanding the chronology of the colonisation of the islands. Two hypothesises exist. One, Tindale's (e.g. 1977), has the South Wellesley population as being ancient and isolated, whilst more recent research such as Trigger's (1987) anthropological work in the region, Evan's (2005) ongoing work in linguistics and others' in archaeology (Robins et al. 1998; Ulm et al.
2010) suggest a more recent date. However, whatever date is established for the antiquity of the population on Bentinck Island, observations to date suggest that a simpler repertory is present in terms of styles of material culture from the South Wellesleys than in the rest of the island group and mainland.

Tindale (1962:267, 268) writes 'Systematic efforts by Mornington Island Mission Officers to come into contact with Bentinck Islanders began in October 1925' and goes on to claim 'Prior to 1927 the Lardil had not met any Kaiadilt people at close quarters'. Tindale's hypothesis is that Kaiadilt speakers of Bentinck Island represent a relict population who have remained in situ and in isolation since 7000-5000 years ago employing subsistence strategies largely unchanged 'since the first colonisation of Australia' (1977:254, my emphasis). Cultural evidence for this premise, believes Tindale, is presented in such Kaiadilt traits as distinct language; physical characteristics and blood type; distinct territorial organisation; lack of a subsection system; raft travel; unique Kaiadilt male initiation rituals; and unique and impoverished material culture.

Trigger (1987) reviews Tindale's hypothesis. Trigger suggests that economies, social organisation and linguistics indicate that cultural connections exist between the peoples of the study area who he names 'Saltwater People'. Trigger proposes a relatively recent isolation for the population of the South Wellesleys of 1000-500 years ago. Using objects from museum collections, he explores specific manifestations of material culture (fluting, shell, spear throwers, spears, fishing technology and watercraft) and concludes that the Wellesley Islands and adjacent coast form a cultural area which excludes inland populations in the Gulf region and states that a 'Substantial degree of similarity between coastal mainland and island societies, compared with nearby inland society to the west and southwest' is demonstrated and that 'As 'saltwater people' occupying 'saltwater country', the coastal mainlanders can be regarded as part of the island cultural bloc in significant respects'. The author concludes that 'If further aspects of material culture were to be studied closely, a number of differences between mainland coast and the islands could well become evident' (Trigger 1987:81).

Tindale's assumptions were again reviewed by Memmott et al. (2006). The authors question the antiquity of the isolation of Bentinck Islanders, suggesting that genetic divergence may be the result of a small, but more recent founder population.

The four languages present in the study area (Lardil/Mornington Island, Kaiadilt/Bentinck Island, Yangkaal/Forsyth Island and Ganggalida/Mainland Coast), known as Tangkic languages, have been identified as sharing a common root (Proto-Tangkic) from which Lardil is believed to have diverged first and is therefore considered the oldest. Evans (2005, see also Memmott et al. 2006:35) notes that the Lardil language contains the greatest number of changes and suggests that Yangkaal and Kaiadilt both separated from Ganggalida and are two dialects of the same language. Linguistic evidence, therefore, does not support a long isolation of the population of Bentinck Island and Evans proposes that the Kaiadilt migrated to the South Wellesleys c.1000-500 years ago. 
Social organisation is different. The people of the North Wellesleys share initiation customs with the adjacent mainlanders (circumcision and subincision and the restricted language, Demiin), while on Bentinck Island, ceremonies are public and social organisation simpler and more flexible (Memmott 2010; Memmott et al. 2006:37). Without defining recent, however, Evans (2005:34, Table 5) proposes a 'Recent adoption of subsection, patrimoiety, distinction, ceremonial song cycles linking to mainland' on Mornington Island (see also Memmott et al. 2006:41, Table 1).

Land-use systems also vary regionally. Whilst on Mornington Island a clear division of territory into clan estates was the custom (Memmott 2010:3), a more fluid system of clan membership associated with birthplace with no discrete clan estates was practiced on Bentinck Island (Evans 2005:32).

Tindale's 'impoverished Bentinck Island material culture' theme is explored by Memmott (1982, 2010:94; Memmott et al. 2006:37) who states that a broader repertoire of objects of material culture (c.65 objects) are present in the North Wellesleys than in the South Wellesleys (c.28 objects). Shared objects, writes Memmott, are the raft, paddle, bark torch, shell knife, stone hammer, spearthrower, bark dish. Exclusively Lardil (Mornington Island) artefacts include the dugong net, large fishing nets, message stick, hand ball, septum ornaments and dancing artefacts. While Kaiadilt items comprise a round-shafted throwing stick, larger-headed pronged spears with greater numbers of barbs and a double shaft and pronged spear.

Best (2003) in a study of regional variation within the material culture of Queensland, examined regional differences and spatial patterning of six categories of object (bags and baskets, boomerangs, message sticks, shields, spears and spear throwers) in six geographical regions (Cape York, Rainforest, Southeast, Riverina, Eyre and Gulf). Geographical regions followed Queensland drainage division boundaries. The author examined the environmental model proposed by Peterson (1975, 1976) in Australia, and Kroeber (1947) in North America where drainage divisions can be seen to present cultural boundaries. In the Queensland study, Best discussed the spatial distributions of stylistic variation within the context of the hypothesis that cultural identity can be transmitted through the visible variation of objects of material culture. A similar methodology testing the theory that styles of artefacts transmit social information was put forward in the work of Wobst $(1977,1999)$, and elaborated by others such as Wiessner $(1983,1984)$ and Hodder (1982). Quantification of spatial patterns within the Queensland data demonstrates that objects associated with ceremony - and males in particular - carried the deepest layers of social information and were more likely to present clear spatial boundaries than objects associated with subsistence and/or with females. Items associated with documented exchange networks in central Queensland were distributed across the Gulf/Eyre drainage division boundary. The current research represents an opportunity to test the earlier panQueensland findings on a larger range of artefacts in a finer-grained study. If the twin theories of 'style as visual communication' and 'drainage divisions as cultural areas' apply to the current data, then a number of predictions can be made of the material culture of the Wellesley Islands and adjacent coast, namely:

- $\quad$ Objects associated with personal identity are likely to be bounded geographically.

- Objects associated with ceremony are likely to be bounded geographically.

- Objects associated with subsistence are likely to be less bounded geographically.

- Objects associated with exchange will traverse their culture area.

In summary, this report sets out to examine an expanded object repertory than that observed by Trigger (1987) and to establish whether quantification of style within the data will endorse Tindale's (1977) assertion of an 'impoverished' material culture tradition in the South Wellesleys. The antiquity of the populations of the study area is not a concern of this study.

It is anticipated that the data will reveal answers to the following research queries:

- $\quad$ Can the data be said to represent a Saltwater material culture (Trigger 1987)?

- Do spatial stylistic patterns suggest more than one cultural unit within the study area?

- What stylistic traits are common within the area and what are intraregionally unique?

- Can the Wellesley Islands be said to display an 'island style' which is different from a 'mainland style'?

- What are the contexts of those items which are common and those which are spatially bounded?

- What social and environmental factors can be said to affect the answers to the above?

\section{Definition of Key Terms}

A deliberately broad definition of style is adopted here. For the purposes of this study, all recurring formal variations which distinguish an artefact of one type, such as a spear, from another type of spear are considered expressions of style. Technical practices such as knotting, incising, the use of motifs and colours, the presence of which may be shared by different objects, are also considered manifestations of style. A consideration of style as a means of transmitting social information draws on models presented by, among others, Hodder (1982), Morphy (1977), Wiessner (1983, 1984), and Wobst (1977, 1999).

I use the term culture as a descriptive term, not as a noun, to describe the spatial presence of clusters of common, learned, practices of human behaviour which occur as a result of frequent social interaction. In this study, these practices involve the production, design and use of objects of material culture. The term 'culture' is not used to identify ethnicity or language. Past studies have demonstrated that the spatial distribution and boundaries of traits at a regional level, when compared with tribal or language boundaries, show a larger unit, which, following the ecological model of Peterson (1975, 1976) and those presented by Clarke (1968) and Kroeber (1947) is referred to here as a culture area. A culture area is a spatial entity where more traits are expected to be shared within the area than with another area. 
Universality of traits is not implied. Core features are predicted to be shared widely, while variations of core traits are likely to be demonstrated spatially at a subregional scale. In this study, the Gulf drainage division, represents a culture area and the subdivisions of the study area (i.e. North Wellesley Islands, South Wellesley Islands, Adjacent Mainland Coast) represent intraculture areas or culture units.

The term material culture is used to refer to manifestations of culture expressed through the human production of things. Here, easily portable objects are used as the primary data through which to understand the traditions of a population at a given time or place. My concern is to understand how variations in the style of objects can be linked to the social and ecological conditions of the populations who produced them (see Lubar and Kingery 1993).

\section{Methodological Issues Arising from the Use of Museum Data}

The issue of collection bias is an important one that has to be addressed when using objects from museum collections. It is argued that it was the curiosity of the collector, or the interest of the museum director, which largely determined the composition of any given collection. For example, one might expect a heavy bias towards objects used by males as in most cases - and in all cases here - the collectors were European and male. Robins (1990) writes that male, dangerous or spectacular artefacts will be emphasised. However, this prediction is not borne out by the current dataset where objects used and made by women are well-represented. Other influences which may skew the content of a collection include the ease of access to an area. For example, the remoteness of the Wellesley Islands has resulted in a small number of objects being collected there compared with objects from the mainland. The density of the population from whom the artefacts are collected is another factor as well as the research interests of museum personnel. However, are museum collections as a source of data intrinsically more biased than, for example, excavated archaeological material? Archaeological data populations at source are affected by preservation and post-depositional factors. Data are further influenced by the excavation location decisions made by the archaeologist, which, in turn, may be led by issues of time and funding, as well as personal research preference. Politics and law play an important role in archaeological research through excavation and therefore in the composition of available archaeological data.

In the section below, I set out the current data collection decisions, which, it is hoped, will go some way to minimise collection bias in this study. It is accepted that ethnographic data represents a snapshot in time, but the enquiry here is spatial and not temporal.

\section{The Data}

The data used here are from soundly-documented museum collections only. These are considered the most reliable source available, due to the quality of museum records accompanying each object. The data comprise 309 objects from the collections of The British Museum, London, The Australian Museum, Sydney and The Queensland Museum, Brisbane (Appendix A). The objects included in the set are those which would have been easily portable. Most objects are made from organic materials which would not routinely survive in archaeological contexts. Excavated material was excluded, as were unmodified raw materials (e.g. lumps of ochre). All objects were collected between 1888 and 1916 which represents a period of minimal European impact and pre-dates the major cultural and social disruptions to the populations in the region which followed the setting up of the mission on Mornington Island in 1914. While these disruptions were not uniformly intense throughout the study area, nevertheless, the impact on the populations of the Wellesley Islands and therefore on the material culture produced there was substantial. Only objects with 'safe' museum documentation have been included in the set and in order to help neutralise the effect of collector bias, objects from a number of collector and donor sources were selected. The number and range of collection sources is intentional. I feel that the likelihood of collection bias is reduced when a substantial number of collectors are involved, rather than, for example, if this study were to focus on a single collection such as that of Roth. The set comprises objects from 13 collectors (Table 1 ). The geographical set with the greatest number of collectors (10) is the Mainland Coast region. Four collectors provide objects from the North Wellesleys and two from the South Wellesleys. Roth is the only collector with objects from each of the geographical zones. Roth's objects are numerically the largest, representing 169 objects in total or $55 \%$ of the dataset (Figure 2).

Although the overwhelming majority of objects were donated to the museums by the collectors, the acquisition of 31 objects involved five further donors (represented in the Figure 2 as 'Unknown' collectors) (Table 2). In summary, the objects used in this study come from three museums and involve 18 different acquisition sources.

The likelihood of any objects being flotsam has been discounted. The objects included in this study are fragile and none bear evidence of water-logging or tumbling.

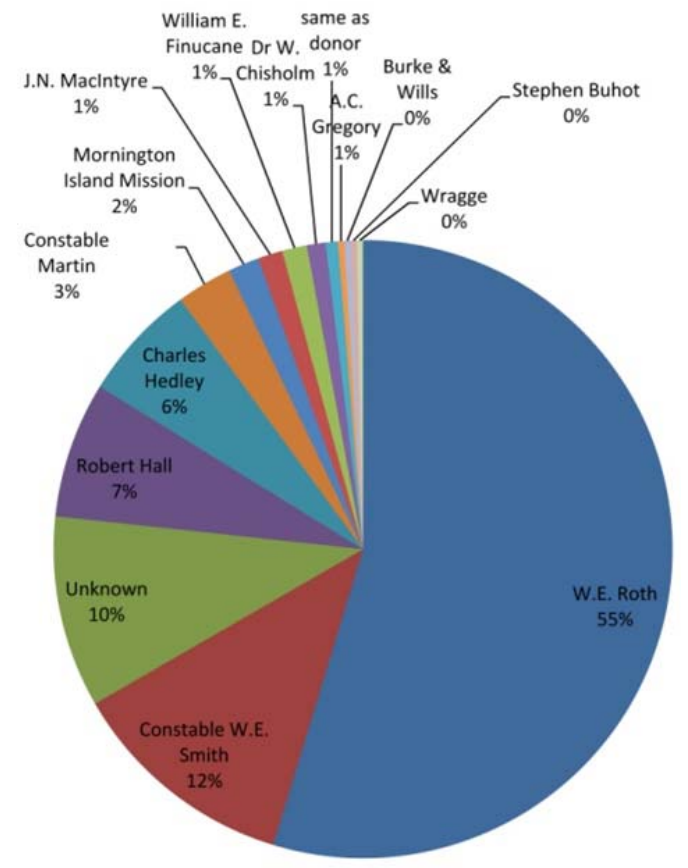

Figure 2. Composition of the dataset by collector (Donors are represented in the 'Unknown' category). 
Table 1. Collectors, date of collection, biographical notes.

\begin{tabular}{|c|c|c|}
\hline Collector & $\begin{array}{c}\text { Date of } \\
\text { Collection }\end{array}$ & Biographical Notes \\
\hline A.C. Gregory & $1855-1856$ & $\begin{array}{l}\text { British surveyor and explorer. } 1859 \text { became first Commissioner for } \\
\text { Crown Lands and Surveyor-General of Queensland. }\end{array}$ \\
\hline R.O. Burke \& W.J. Wills & $1860-1861$ & $\begin{array}{l}\text { Led expedition intended to cross Australia from Melbourne to Gulf of } \\
\text { Carpentaria. }\end{array}$ \\
\hline Charles Hedley & 1903 & $\begin{array}{l}\text { Naturalist. } 1908 \text { joined staff of Australian Museum, Sydney. } \\
\text { Accompanied W.E. Roth to the Wellesley Islands. }\end{array}$ \\
\hline Constable Martin & 1915 & 1867 appointed Constable of Native Police, Turn Off Lagoon. \\
\hline Constable W.E. Smith & 1911 & $\begin{array}{l}1888 \text { appointed Constable of Native Police. In charge of Turn Off } \\
\text { Lagoon 1905-11. }\end{array}$ \\
\hline Dr W. Chisholm & 1888 & $\begin{array}{l}\text { Sydney doctor. Family resided at Wollogorang Station in the Gulf } \\
\text { country. }\end{array}$ \\
\hline J.N. MacIntyre & 1916 & $\begin{array}{l}\text { Burketown resident and author of, among others, White Australia: The } \\
\text { Empty North, the Reasons and Remedy (MacIntyre 1920). }\end{array}$ \\
\hline Mornington Island Mission & 1914 & Objects collected by the mission. \\
\hline Robert Hall & 1916 & $\begin{array}{l}1914 \text { set-up Presbyterian mission on Mornington Island. Murdered } \\
\text { there } 1917 .\end{array}$ \\
\hline Stephen Buhot & 1898 & $\begin{array}{l}\text { Stock Inspector with the Department of Agriculture and Stock based } \\
\text { in northwest Queensland. }\end{array}$ \\
\hline W.E. Roth & 1903-1905 & Northern Protector of Aborigines. \\
\hline William E. Finucane & 1897 & $\begin{array}{l}\text { Joined Lands Department, Brisbane. In } 1866 \text { transferred to } \\
\text { Normanton. Was among those responsible for opening up Burketown } \\
\text { and Normanton districts. }\end{array}$ \\
\hline Clement Lindley Wragge & 1900 & $\begin{array}{l}\text { Meteorologist. } 1887 \text { appointed Government Meteorologist for } \\
\text { Queensland. }\end{array}$ \\
\hline
\end{tabular}

Table 2. Donors, date of donation, biographical notes.

\begin{tabular}{|c|c|c|}
\hline Donor to Museum & Date of Donation & Biographical Notes \\
\hline Sir A.W. Franks & 1874 & $\begin{array}{l}\text { Antiquarian, employed at British Museum from 1851, } \\
\text { becoming Keeper of British and Medieval Antiquities and } \\
\text { Ethnography. Donated objects to the British Museum. }\end{array}$ \\
\hline R. Christison & 1901 & $\begin{array}{l}\text { Pioneering pastoralist, Queensland, donated to British } \\
\text { Museum. }\end{array}$ \\
\hline Ethnological Committee & 1908 & $\begin{array}{l}\text { Operated between 1902-1909, comprised of } 8 \text { citizens } \\
\text { concerned about fate of Aboriginal Australians; Robert } \\
\text { Etheridge, Chairman; Colin J. MacMaster, Robert } \\
\text { McDonald, Hugh Langwell, Commissioners for Western } \\
\text { Lands; John Vernon; W.A. Gullick, Government Printer; } \\
\text { J.R. Holding; Percy E. Williams. Donated to Australian } \\
\text { Museum. }\end{array}$ \\
\hline Manchester Museum & 1891 & Donated collection to British Museum via Christy Fund. \\
\hline J.R. Elsey & 1857 & $\begin{array}{l}\text { Surgeon, naturalist, explorer. Appointed surgeon and } \\
\text { naturalist to the North Australian Exploring Expedition, } \\
\text { led by Gregory. Donated objects to the British Museum. }\end{array}$ \\
\hline
\end{tabular}


Table 3. Khan's terms - used for Object Groups in the dataset - with the corresponding Memmott terms.

\begin{tabular}{|l|l|}
\hline Terms used by Khan (2003) & Corresponding Terms used by Memmott (2010) \\
\hline Containers & Travel, Transport and Communication \\
\hline Dress and Ornament & Clothing, Ornamentation and Body Decoration \\
\hline Fire-Making Tools & Manufacture and Use of Fire \\
\hline Fishing Gear & ? \\
\hline Message Sticks & Travel, Transport and Communication \\
\hline Musical Instruments & ? \\
\hline Raw Material & Curation of Artefacts and Resources \\
\hline Tools & ? \\
\hline Weapons & Fighting and Duelling \\
\hline
\end{tabular}

\section{Methodology}

Each object has a unique identifier, its museum acquisition or registration number. I have added to the acquisition number a museum abbreviation AM (Australian Museum), BM (British Museum) and QM (Queensland Museum). Thus the museum origin of all items referred to or illustrated in the text is distinguishable.

A set of variables was devised which enabled the standardisation of museum documentation and ensured that objects from different sources were analysed using identical criteria. Variables relate to the objects' collection history, provenance and morphology (Appendix B).

The morphology of an artefact is set out in a hierarchy of terms, the most general being Object Group (e.g. weapons), followed by Object Category (e.g. boomerang), Object Form (e.g. hook) and Object Type (e.g. fluted and painted). Additional information is recorded concerning the social context, materials, dimensions, decoration techniques and decorative motifs of the artefact.

Museum documentation for identical objects varies often within the same museum. For example, an object worn at the waist may be identified as 'belt', 'skirt', 'apron', 'pubic cover', 'waistlet', 'waist band' and so on. In order that objects can be analysed using uniform criteria, decisions were taken on the terms used for objects. The most objective of terms were selected. For example in the case of the Object Group: Dress and Ornament, the position on the body that the item would have been worn is the chosen identifier. Thus I have used general terms such as 'waist ornament' and 'head ornament' to classify Object Categories within the metagroup Dress and Ornament, and employ additional variables - namely Object Form and Object Type - to further explore the morphology of each artefact. Khan's (2003) meta-category system has been adopted here for the Object Group divisions over Memmott's (2010) system for the following reasons (Table 3):

- Khan's system is widely published and itemises objects in descriptive terms.

- Memmott's system categorises objects by actions/activities.

In the context of this analysis, descriptive terms are considered safer than terms which require identification of an activity. The reasons for this are that:
- Aboriginal objects are likely to be multipurpose items and used for more than one activity.

- Conclusive identification of contextual use may be unavailable given that the data were collected over a century ago.

Detailed information on each artefact was recorded at the museums by hand on a datasheet, the contents of which were subsequently entered into a specially designed relational database (Microsoft Access) and later analysed (see Appendix B).

Throughout this article I have referred extensively to the ethnographies of W.E. Roth. I use Roth's reports as a form of 'control' to correlate the types of artefacts and their likely distribution with objects found in the dataset. Although a sizeable part of the dataset is from Roth's collection, as noted above, the assemblage includes objects from 18 acquisitions sources.

\section{Introduction to the Data: Object Groups}

Artefacts from eight of Khan's meta-categories are present as Object Groups in the dataset - namely Containers, Dress and Ornament, Fire-Making Tools, Fishing Gear, Message Sticks, Musical Instruments, Tools and Weapons. There follows a brief descriptive introduction to the Object Groups which are further subdivided into Object Categories. Where possible, I have cross-referenced object styles with Roth's contemporary accounts.

Aboriginal names are known for a range of these artefacts and included in the work of others (see Memmott 2010; Trigger 1987). I have deliberately omitted inclusion of linguistic terms. The description of objects here is fine-grained and I am not confident that I am qualified to assign Aboriginal names correctly. The inclusion of incorrect Aboriginal terms might be offensive to present-day language speakers. 


\section{Containers}

This group is made up of objects used to contain or carry other items or resources. Included are artefacts such as shell containers, bark containers, bags and coolamons.

Roth (1904:29) records the manufacture and use of 'trumpet' (Syrinx arianus) and 'melon' (Melo diadema) shell containers in the Wellesley Islands: 'On the Wellesley Islands, the ventral surface of the last whorl of the melon shell is pierced for insertion of the thumb during transport. On the Bentinck and Allen Islands, the last whorl of the Megalatractus was found to be similarly treated' (Figure 3). He (1904:30) describes the production of pleated bark containers with their diagnostic 'Wellesley Island' pleat fixing. 'The pleated ends of the Meleleuca bark are maintained in position by a supporting loop of fibre-strip attached to the top corners of the sides of the vessel ... whence the fibre passes outside and below the bunched-up ends to be finally rove through the opposite corner from inside out' (Figure 4). Typically, this group of artefacts has a subsistence context. However, exceptions would be pituri bags and carved wood coolamons.

Pituri bags are a distinctive bell shape, commonly woven to form circular, radiating, coloured bands (Figure 5). These mesh-weave bags are fabricated with string made from vegetable fibre, hair, or wool originating from government blankets (usually an arrangement of strings from different origins are applied in combination). Roth (1897:103) notes that materials used are 'white-fellow's' twine and blanket-thread, opossum string, human hair mixed with twine etc. or plant-fibre (i.e. flax twine).' Colours include reds, blues, and bright green European dyes, as well as black and natural beiges. Roth (1897:104) discusses the transmission of new mesh weaving techniques to women in the southern Gulf region as originating from southern and eastern neighbours, noting that it was a recent innovation, replacing a former tradition of grass bags. The bags are specific to an important harvest/exchange system originating in the Eyre Basin to the south of the Gulf region from where the drug-filled bags were exchanged. The pituri plant produced a psychoactive drug with high nicotine content, four times the strength of common tobacco. The leaves and small stems were dried and mixed with ash. The end user, reported to be usually elderly men, would chew a ball of the substance (see Keogh 2011). Roth (1897:100) describes the pituri exchange system. The plant, a small shrub, grows in the Carlo district on the Upper Mulligan River and flowers in January. By March, the narcotic in its rough state of harvested leaves is bagged. In exchange for items such as spears, boomerangs, government blankets and nets, the pituri is distributed north up the Georgina and Burke Rivers as well as south down the Diamantina. There is no record in Roth's reports that pituri reached the Wellesley Islands.

Shallow carved wood containers, or coolamons (Figure 6), are another example of extensively exchanged objects. Coolamons are commonly embellished with parallel linear grooves (fluting) to the external surface which may also be pigmented with red (see Roth 1897:101). Roth notes that their usage includes transportation of food, tools, water, and babies, for soaking yams in food preparation as well as providing a dish for pituri preparation (Roth 1897:100, 1904:31).

8 | 2012 | Vol. 15 | q a r

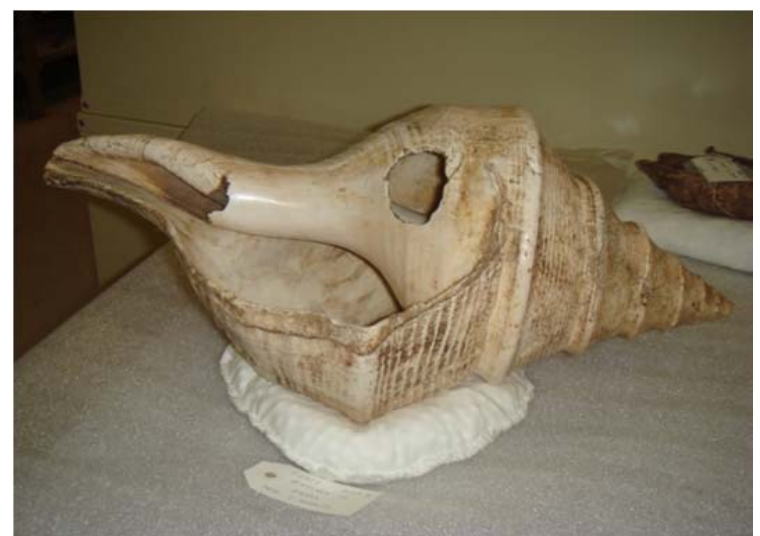

Figure 3. Shell container (AM E11822, Bentinck Island).

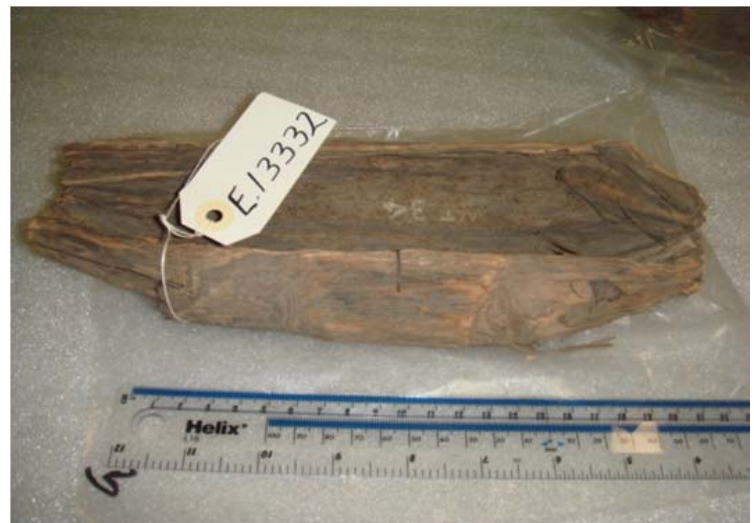

Figure 4. Bark container (AM E13332, Forsyth Island).

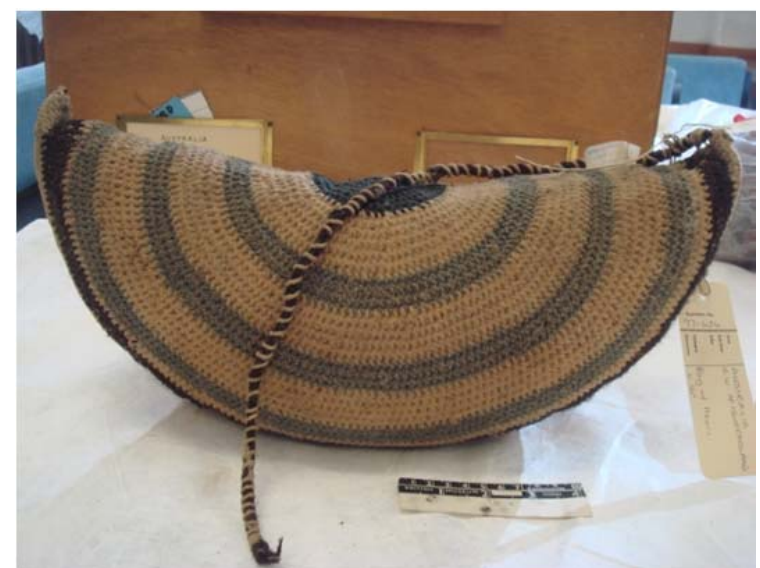

Figure 5. Pituri bag (BM 97-634, Burke district).

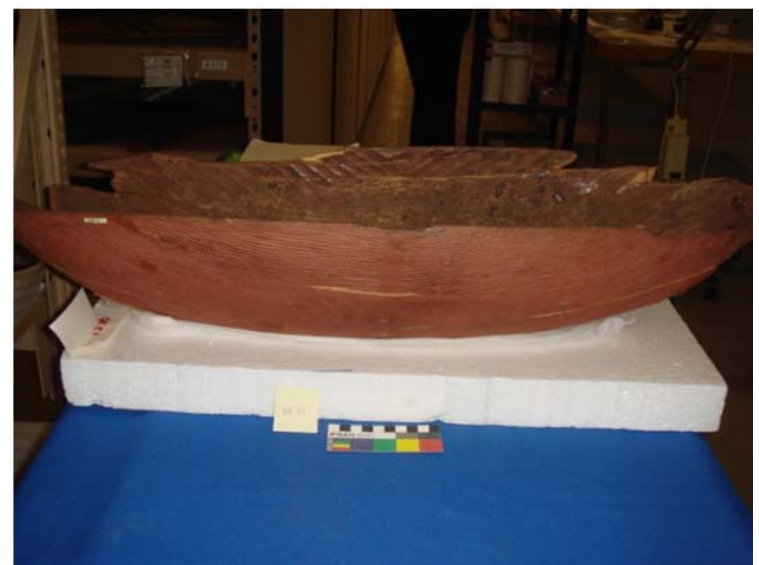

Figure 6. Painted and fluted coolamon (QM QE51, Turn Off Lagoon).

Aboriginal Material Culture of the Wellesley Islands 


\section{Dress and Ornament}

This Object Group incorporates all items worn on the body. Objects in this group are closely associated with personal identity, personal status and ceremony. Significantly many are connected with particular initiation systems present in the Gulf region (Tindale 1974) and in the North Wellesley Islands. While the majority of objects in this group would have been worn by men, some were worn by women.

Head ornaments include circlets which encompass the head and head bands which cover the front of the head and incorporate ties.

Circlets - apart from a single anomalous iron and macropod tooth object from Mornington Island - are formed with single strands of bound and wound opossum string (Figure 7). 'Single opossum-string circlets are also common along the Lower Gulf of Carpentaria coast-line ... like the fillets of the same material elsewhere, they are made by men only, but here also used by men alone' (Roth 1910:27).

Two styles of head band exist in the region. One is flat, of fine net, made by men, but could be worn by men and women. A second style is of similar flat shape but constructed using several coils of pigmented bound and wound opossum string. These objects are signifiers of final initiation. Materials include opossum hair, vegetable fibre and red or white pigment. An example from Mornington Island is further decorated with macropod tooth pendants (Figure 8). Of the first style Roth writes 'The forehead net ... is a spindle-shaped piece of fine netting ... worn over the forehead ... the two strings passing above the ears and tied together at the back of the head ... an exquisite piece of workmanship, woven after the style of an ordinary fishing net ... in some examples, each individual mesh is only about $1 / 8$ inch in size, its regularity calls both for wonder and for admiration ... One of the badges of the last of the initiation ceremonies ... can be worn by both men and women. It is made by males only.' Of the second style he notes 'The opossumstring fillet is made of four separate circlets bound together flat by means of four 'ties' ... the extremities of this composite band are looped into the two tying strings to be knotted at the back of the head ... all opossum string ornaments indeed are invariably coloured red' (1897:109, Figs 256-269, Plate XIII, 1910:23, Figs 4-5, Plate VIII).

Neck ornaments are various (Figures 9-10). This group incorporates single- or double-strand bound, wound and pigmented string necklets, multiple-strand grass bead necklaces, a group of bound, wound and pigmented pendants and a single example of a shell pendant.

'There are two varieties of the ring or circlet, according as they are single or double: both are made with opossum-string. In the former case, according as the central core is thick or thin, around which the string is spirally and closely wound, the diameter varies for different examples. In the latter, the two circlets are fixed together with two ties, at places more or less opposite; when measure out each ring in it continuous length is about 16 inches. As usual, coloured red and greased' (Roth 1897:110, Fig. 260, Plate XIII).

Roth (1910:33-34) writes of multiple-strand grass bead necklaces that 'on the Lower Gulf Coast, the ornament is made and worn only by the female portion of the community.'

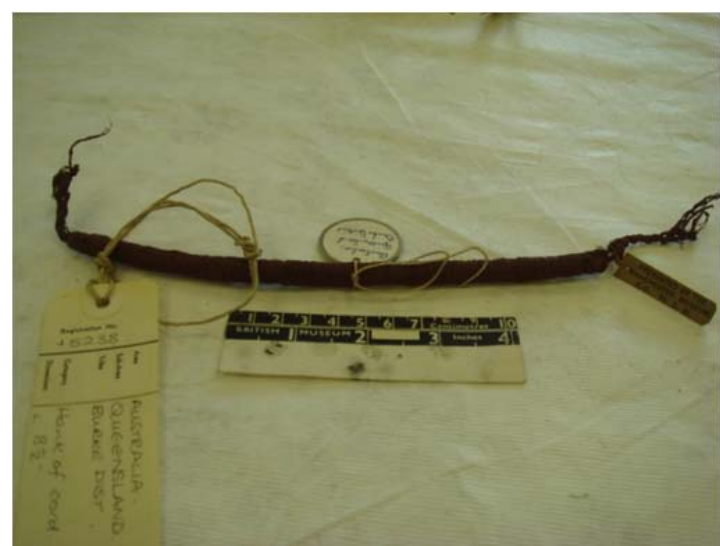

Figure 7. Head ornaments, circlet $(\mathrm{BM}+5238$, Burke district).

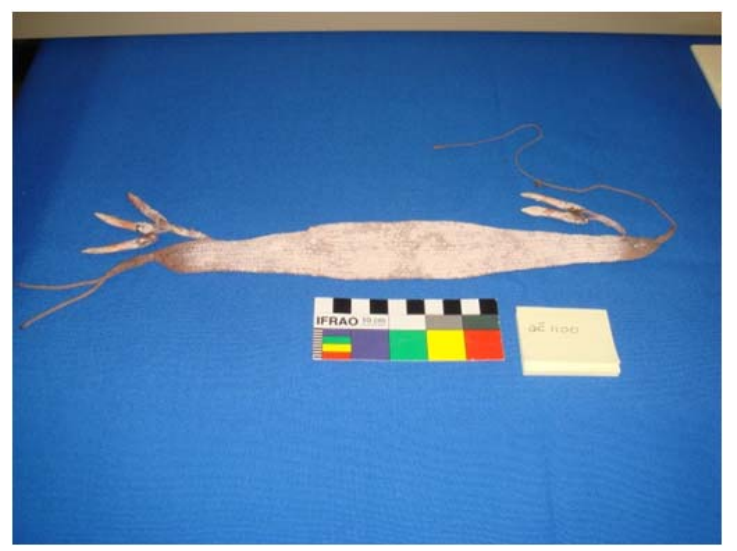

Figure 8. Headband (QM QE1100, Mornington Island).

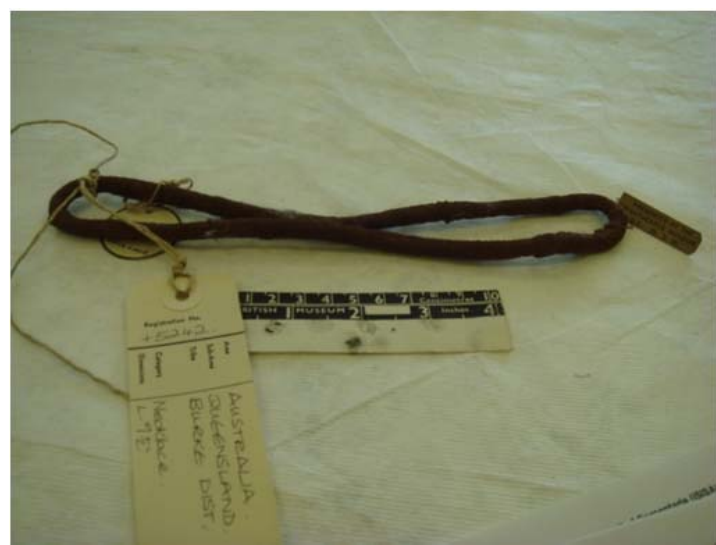

Figure 9. Opossum string neck ornament $(\mathrm{BM}+5242$, Burke district).

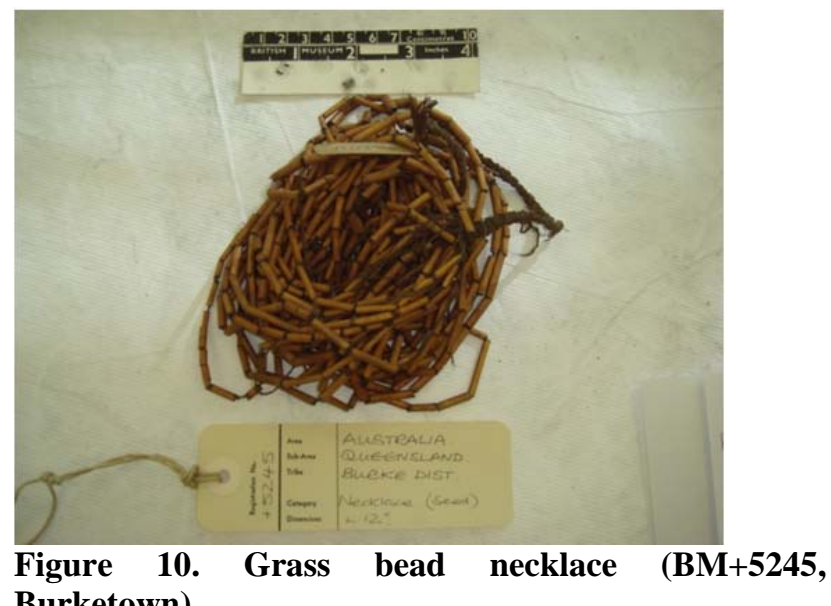


Pendants worn at the neck include a cluster of macropod teeth set in pigmented gum mounted on string (Figure 11) and a group of tapered cylindrical bound, wound and pigmented objects. According to Roth these are powerful objects, used 'throughout the whole of North-West Queensland', worn as an amulet and 'used to relieve obscure pains, a troublesome cough, etc., and, as a survival, may still be utilised for collecting aid in case of warfare' (1897:163, Fig. 404, Plate XXIII, 1903:37, Fig. 35).

Arm ornaments are of two main styles, one is soft, ochred, made of bound and wound opossum hair sometimes with added fringing (Figure 12) and the other is rigid, manufactured with plaited plant fibre (Figure 13). Of the first type, Roth writes 'In the neighbourhood of Burketown, whence they may have been obtained further westwards, the circlets often have tassels, etc. hanging from them' (1910:43) and that in the Gulf region this form of armlet signifies the first stage of male initiation (1897:172-173).

The dataset contains a number of waist ornaments of differing styles. These include human hair belts (Figure 14), a flat belt of similar manufacture to the opossum hair head band (Figure 15), fringed pubic covers with ties, tassel pubic covers without ties (Figure 16) and 'skirts' with all-round fringing (Figure 17). Apart from the human hair belts, these items are commonly pigmented red.

Roth (1903:7) writes that human hair belts were bartered into Mornington Island from the mainland. He notes that these objects are associated with the first initiation ceremony and were widely exchanged between mainland groups as far south as Boulia (Roth 1897:118, Fig. 293, Plate XV, 1897:170, Fig. 409, Plate XXIV, 1910:37). Fringed skirts were worn by women. Roth describes the manufacture of these objects. 'Fringes are met with on all apron belts. There are three stages in the construction of an apron-belt - the making of the topstring, the formation of the loops and the rolling of each loop upon the outer thigh to form a tassel' (1901:12, Figs 3-5, Plate VII, 1910:39, 119, Figs 23, 287, Plate XV).

A final category of body ornaments are feather tufts, worn either tucked into a circlet, arm band or waist band as part of a corroboree costume: 'in times of corrobboree and other occasions for rejoicing, certain ornaments are fixed or rather suspended from this hair belt in the case of males only ... a bunch of eagle-hawk feathers tied tightly round at their shafts into a form of a 'feather duster' (Roth 1897:113, Fig. 275, 294).

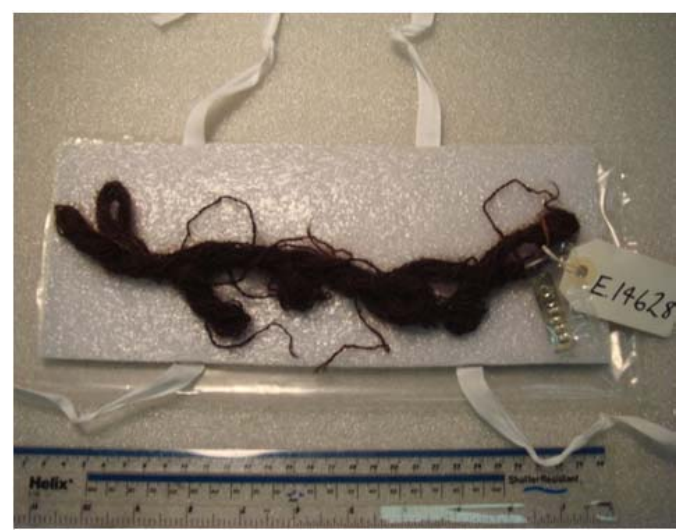

Figure 14. Human hair waist ornament (AM E14628, Mornington Island).

10 | 2012 | Vol. 15 | q a r

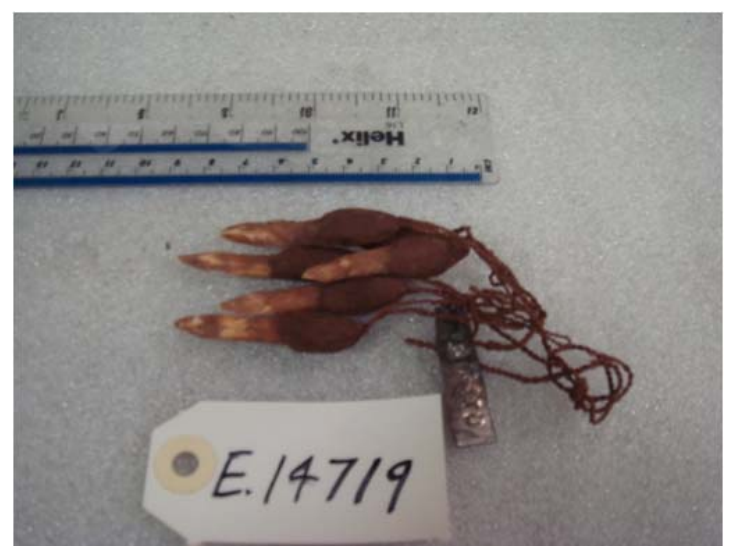

Figure 11. Macropod tooth pendant (AM E14719, Burketown).

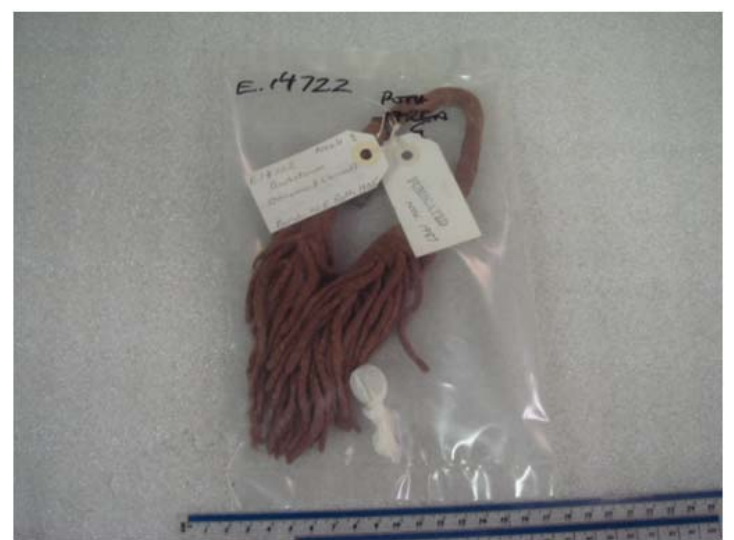

Figure 12. Fringed opossum hair arm ornament (AM E14722, Burketown).

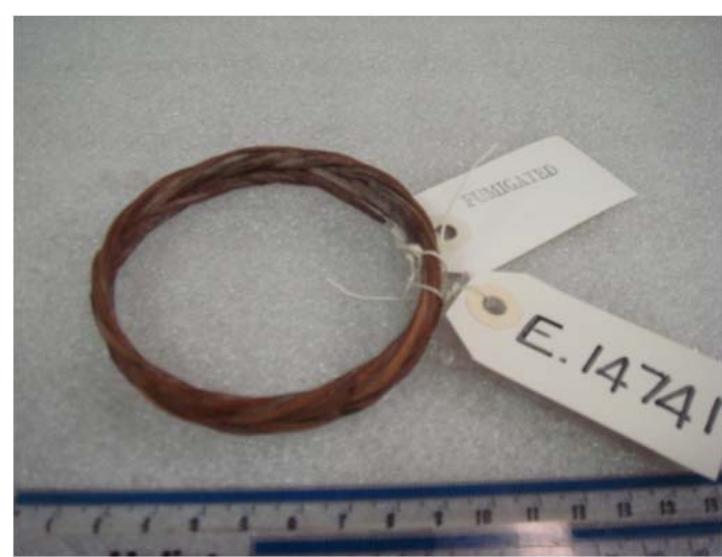

Figure 13. Plant fibre arm ornament (AM E14742, Burketown).

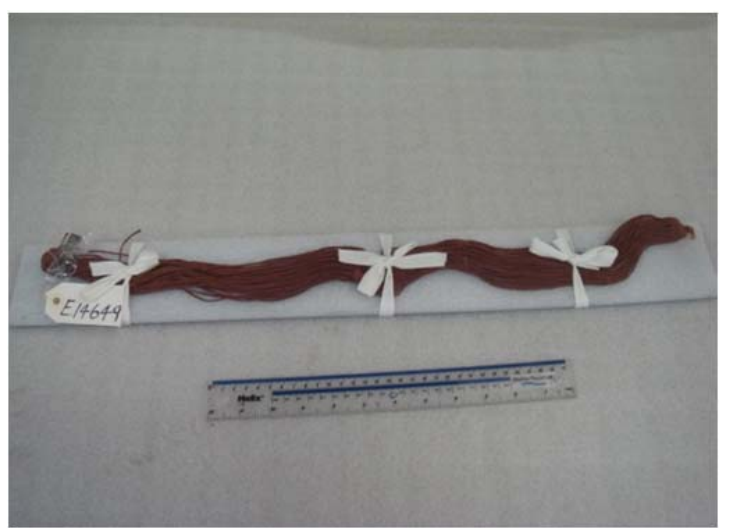

Figure 15. Ochred waist ornament (AM E14649, Burketown).

Aboriginal Material Culture of the Wellesley Islands 


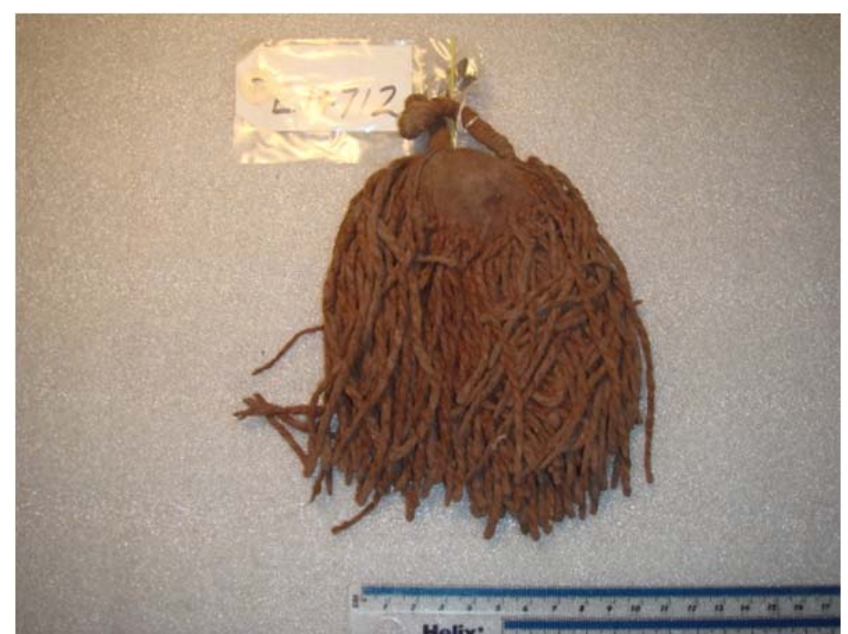

Figure 16. Tassel pubic cover (AM E14712, Mornington Island).

\section{Fire-Making Tools}

Following Khan (2003), fire-making artefacts are not included in the Tools category but form a category of their own (Figure 18). Fire is created using two sticks to generate friction and a spark. 'A very dry piece of wood is selected, a little nick or concavity cut into it, and fixed with the legs or feet lengthways on the ground in front of the operator. Another long stick of the same material is taken ... and its roughly-sharpened extremity placed vertically upon the nick already cut on the fixed piece. The vertical one is now twirled ... as rapidly as possible, between the flat opened palms ... Smoke, followed by a spark or two soon appears: with some very dry grass and a little blowing this is soon fanned into flame' (Roth 1897:10). These objects are associated with everyday life and subsistence practices. Roth (1897:105) writes 'Firesticks are thrown aside or discarded after use; they are made only as they are wanted and ... are certainly not carried about for future use.' Included in this category is a bark bundle 'torch' from Bentinck Island (Figure 19), collected by Charles Hedley. Roth (1901) observes that the Bentinck Islanders fish at night with torches on the reefs.

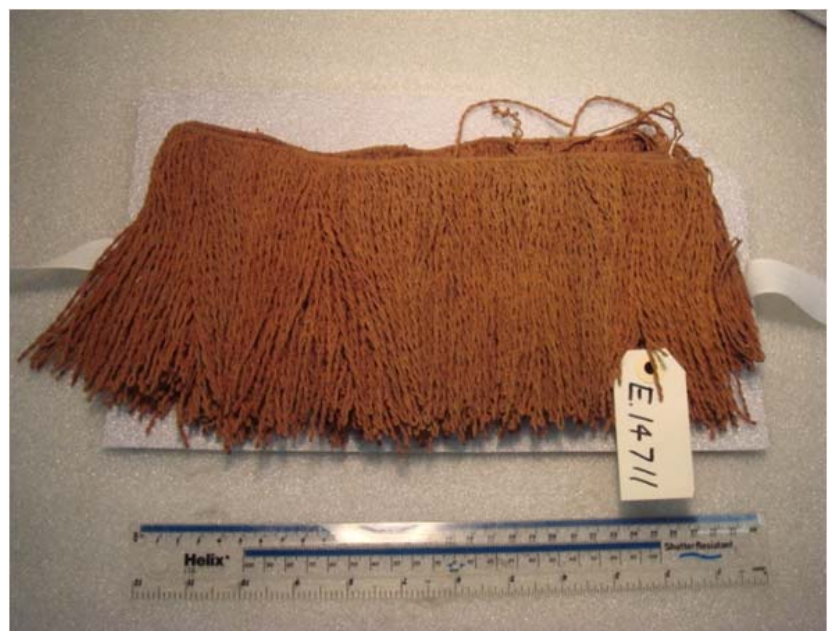

Figure 17. Fringed 'skirt' (AM E14711, Mornington Island).

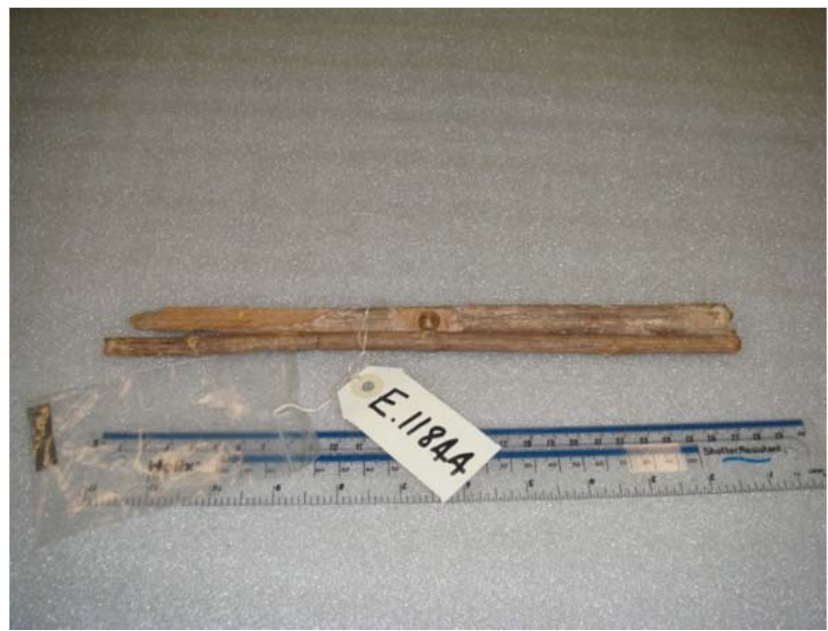

Figure 18. Fire-making tools (AM E11844, Forsyth Island).

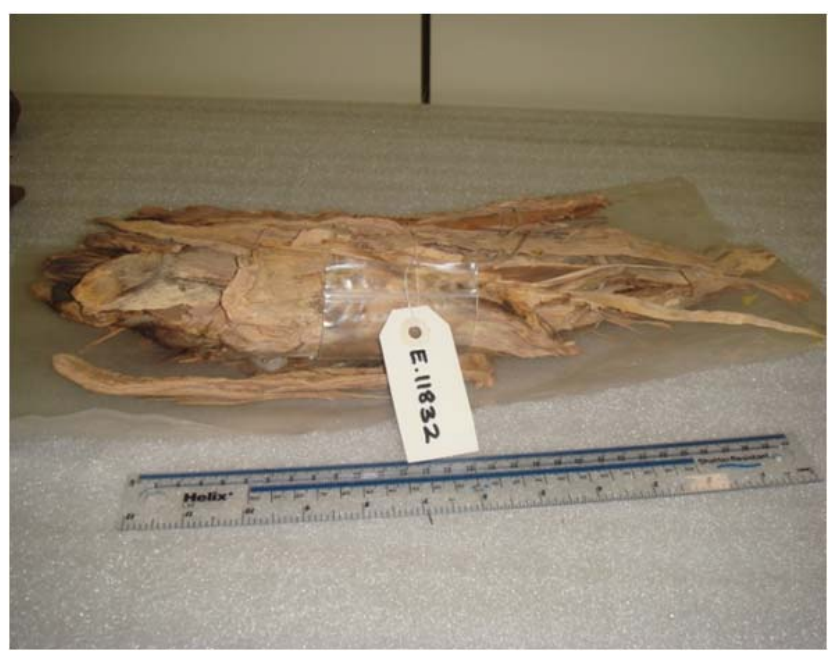

Figure 19. Bark torch (AM E11832, Bentinck Island). 


\section{Fishing Gear}

Fishing, or the acquisition of marine resources, was central to the economy of populations in the study area. Included in this artefact group are paddles, nets, rods, cordage, lines and hooks, all of which were used by men in a subsistence context.

Two forms of paddle propel V-shaped mangrove log rafts in the Wellesley Islands (Roth 1901, 1910:9, Fig. 8), a fan-shaped paddle made by flattening a mangrove root (Figure 20) and a carved, ovate paddle (Figure 21). Vegetable fibre nets of variable form use a knotted technique (Figure 22). Hooks of iron are attached to vegetable fibre twined string and rods are also existent (Figure 23). Roth (1903:3) writes that the fish hook as an object was never made with other materials (unlike, for example, the iron-bladed scraper which was also made with a stone blade) and is an example of an appropriated European object. Roth remarks that small nets are used in shallow water and larger nets in deep water (1897:94-95, Fig. 223, Plate XI), that iron fish hooks were bartered from the mainland to Forsyth and Mornington Islands (Roth 1903) and that fishing nets from the North Wellesleys form part of the outward exchange network where objects, as well as customs, language and beliefs, are transmitted between groups throughout northwest Queensland where communication is facilitated by regional river systems (1897:135-136). Quantities of cordage form part of this group of objects. Some examples of heavy rope from Mornington and Forsyth were possibly associated with hunting of dugong (Roth 1903:2).

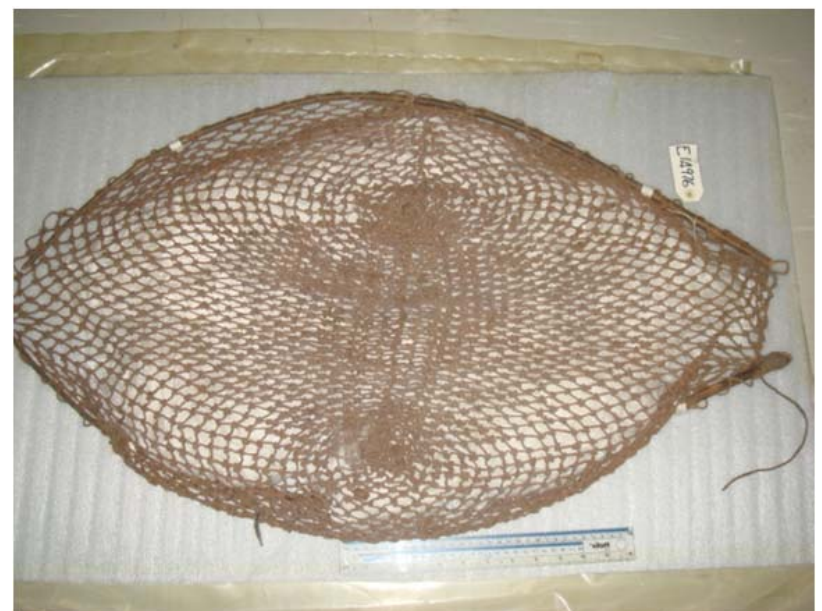

Figure 22. Hand-held knotted fishing net (AM E14979, Bentinck Island).

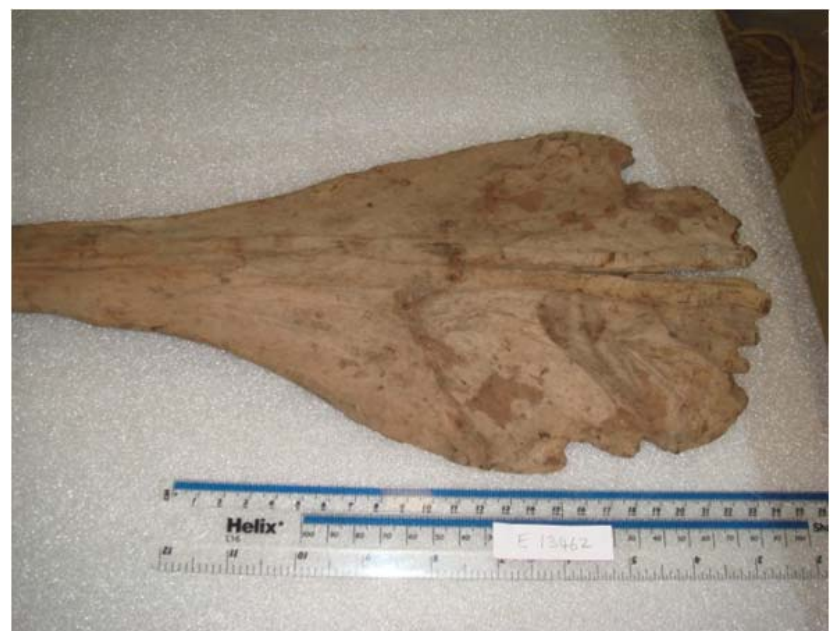

Figure 20. Fanned paddle (AM E13462, Bentinck Island).

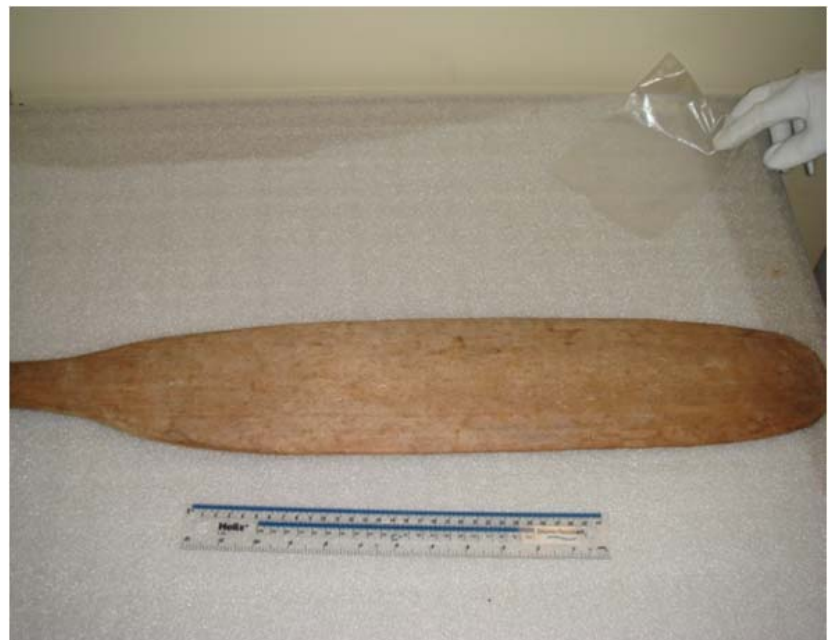

Figure 21. Ovate paddle (AM E13464, Forsyth Island).

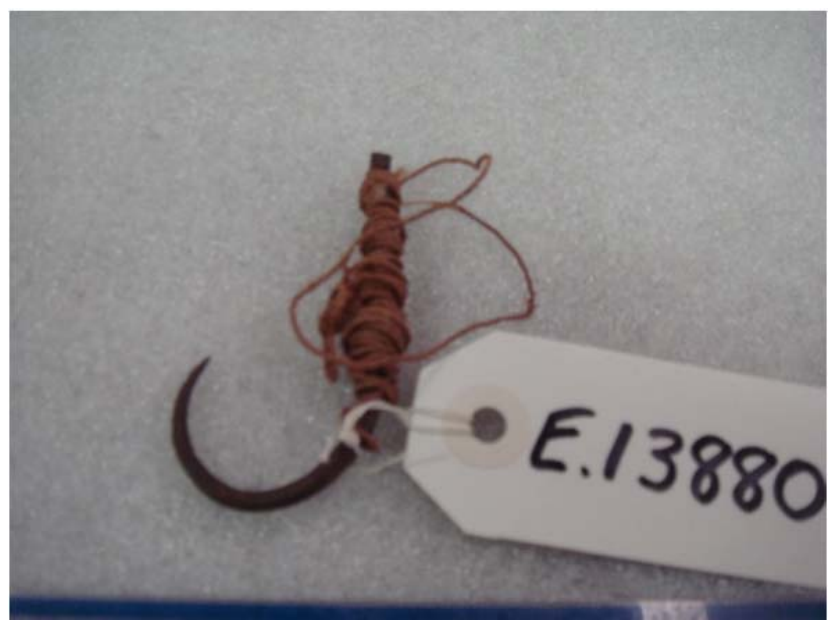

Figure 23. Iron fish hook with vegetable fibre twined string line (AM E13880, Mornington Island). 


\section{Message Sticks}

Message sticks are carved, incised or notched artefacts, most commonly of wood, some with the addition of pigments or other materials. They are small in size, usually measuring $10-15 \mathrm{~cm}$, and may be of a round, oval or flat form (Figures 24-25).

According to historical reports such as those of Howitt (1904:691-710), Roth (1897:136-138, 1905:9-10), and Hamlyn-Harris (1918:13-36), message sticks were borne by an individual and sent as a type of intergroup 'invitation' or 'request' to hunt, to attend a ceremony or an initiation, to announce death, or to undertake an economic transaction. Hamlyn-Harris (1918:15) writes, 'In Queensland they are carried by men only, and whilst hunting they are usually twisted into the hair and concealed therein; unless the messenger happens to have a belt, in which case the stick might be placed there for a time.'

Their small dimensions mean that they are visible only upon close inspection, enabling the target audience to be selected by the bearer. Message sticks, in the view of Hamlyn-Harris, could be more accurately described as memory sticks. The stick acted as protection - a form of passport - to the owner on his journey into the territory of others and provided a means of establishing an introduction to the group to be visited. The seemingly abstract designs incised on these sticks were explained by the bearer. Designs are roughly carved and include motif categories such as straight lines, zigzags, crosses, diagonal cross-hatch, and chevrons. In some, the edges of the object are deeply notched. It has been suggested that these simple motifs represented multiple meanings. Thus, a number of straight lines or notches may represent a group of individuals or spears. Crescents may be boomerangs or indicate lunar dates. Zigzags, may represent mountains. The vertical incised lines which can divide motifs on the stick into 'zones' may divide the message into different components, indicate a time frame, or separate 'out' and 'back' exchanges of goods. In this way, motifs may be read as a map of a meeting place, indicate the size of the intended gathering, or act as a 'ledger' of items to be exchanged.

\section{Musical Instruments}

Only one object from this category is present in the dataset. This is a pair of clap sticks, or sounding sticks (Figure 26) collected by Constable W.E. Smith from Turn Off Lagoon in the Gulf region. Made up of two cylindrical wooden objects, these would have been struck together to provide rhythm for singing and dancing in a ceremonial context (Roth 1902:24, Figs 1-3, Plate XXXIX).

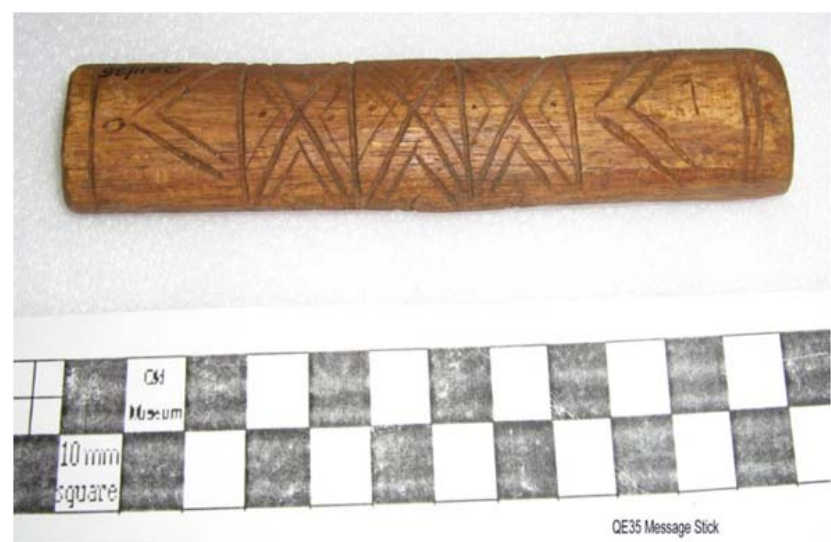

Figure 24. Oval form message stick (QM QE35, Turn Off Lagoon).

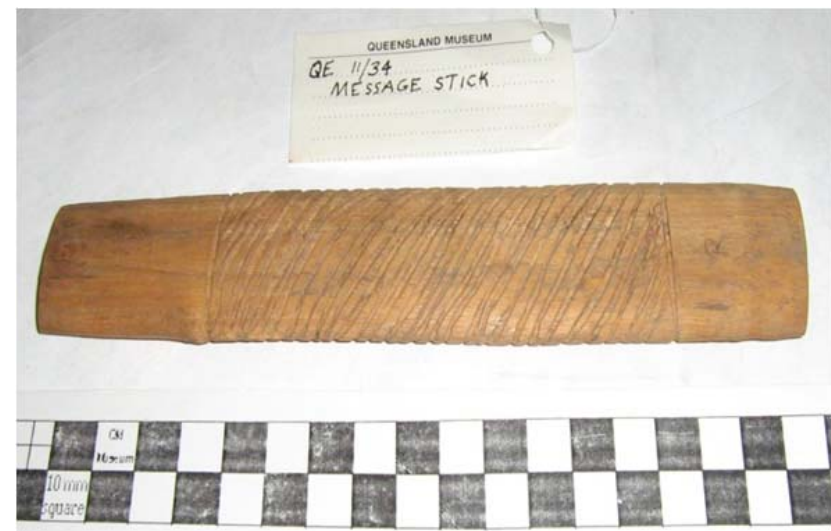

Figure 25. Flat form message stick (QM QE34, Turn Off Lagoon).

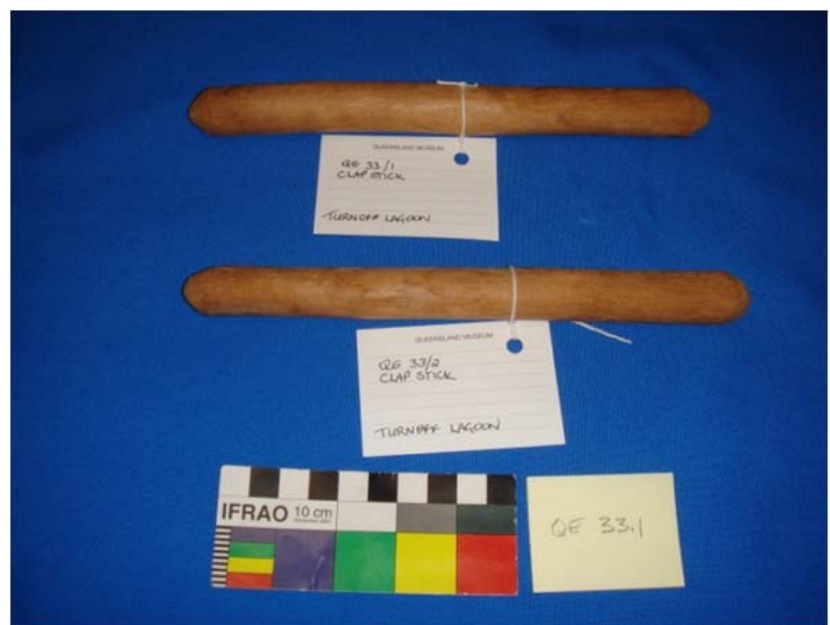

Figure 26. Clap sticks (QM QE33.1 and QM QE33.2, Turn Off Lagoon). 


\section{Tools}

As an Object Group, tools can be subdivided further into stick tools, points, pounders, stone points, and others such as plane-like iron-bladed scrapers. I have included in this category a group of fish mandibles (identified as Sphyraena barracuda or Sphyraena obtusata) and a bark bundle, also with fish mandibles from Bentinck Island. These items are of undetermined function, although Roth (1901) refers to the fish mandibles as combs as human hair strands were found attached to the teeth when the objects were collected by him.

A quantity of wood, cylindrical, pointed implements are present within the set. Museum records variously catalogue these as digging sticks, fighting sticks, yam sticks, and throwing sticks. I have named the group Stick Tools and have sorted these implements by size into those measuring $>100 \mathrm{~cm}$ which are entered as fighting/digging sticks, and those measuring $>25-100 \mathrm{~cm}$ which are classified multipurpose tools (Figure 27). A feature of the longer $(>100 \mathrm{~cm})$ sticks is the addition of a roughly incised area added near the end of the object which would function as a 'grip' to prevent the hand from slipping while in use (Figure 28). This feature is absent in the group of smaller $(>25-100 \mathrm{~cm})$ implements. The group of smaller implements comprises various forms and does not represent a homogeneous set. Included here is a single 'waisted' digging stick from Forsyth Island as well as a boomerang-shaped stick tool with fire-hardened ends from Bentinck Island (AM E14272) (see Roth 1901).

A quantity of smaller tools, measuring $<25 \mathrm{~cm}$, some made of bone, are categorised as points (Figure 29).

Stone tools include finely worked blades/knives, often with gum added to the proximal end, present on the mainland (Figure 30) and rough hammers/picks found on Mornington Island (Figure 31) (Roth 1903, 1904:23, Figs 144-149). Speaking of the former, Roth writes 'The stone knife consists of a chipped blade fixed into a rounded or oval handle made of cementing-substance ... along with the implement there is very often a sort of sheath made of fine strips of bark' (1897:151, Figs 386-390) and states that such objects were part of the Gulf region exchange system (1897:134-135).

Wooden pounders come in two distinct forms. All are carved from a single piece of wood. One form is roughly carved from a massive block with an integrated tapering handle and is found in the North Wellesleys (Roth 1904:24, Figs 162-164). The second type, present on Bentinck, takes the form of a roughly cylindrical object. Roth reports on the likely multipurpose function of the latter type: 'Another very primitive type of implement is met with on Bentinck Island, in the form of a mucronatepointed stick up to 2 feet in length ... It is used for hammering, digging, and perhaps also for knocking over birds, iguanas, etc. Evidence for the use of these implements for hammering or pounding was afforded the presence of adherent particles of vegetable fibre and debris’ (1904:23, Fig. 160).

Two final tool types are wood-handled scraper tools from the North Wellesleys, manufactured to take a metal blade - which would have been exchanged into the islands from the mainland - and two unmodified Placuna placenta shell tools from Turn Off Lagoon.

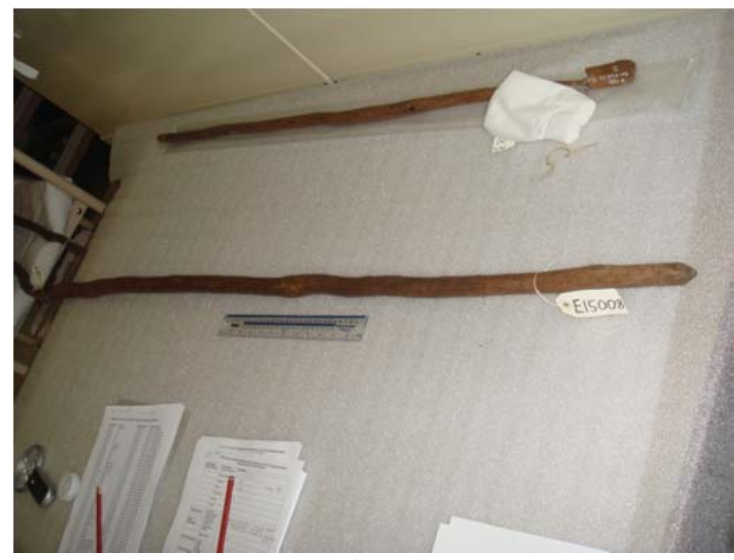

Figure 27. Fighting/digging stick (AM E15008, Bentinck Island).

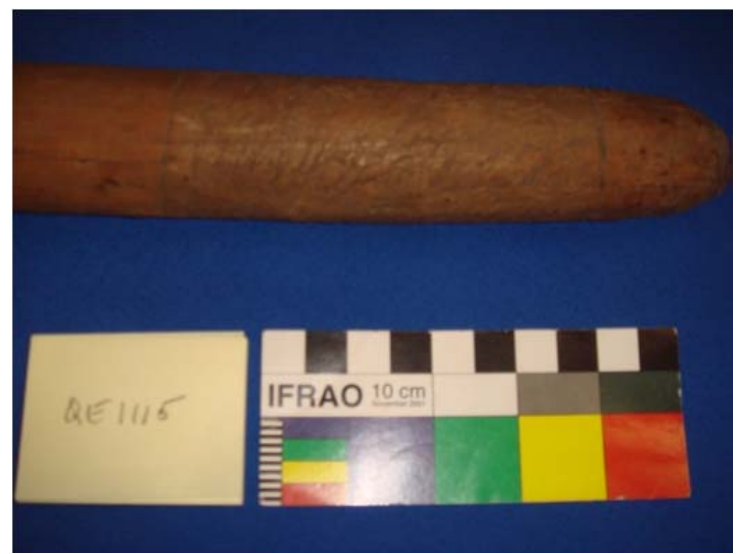

Figure 28. Fighting/digging stick showing incised feature (QM QE1115, Mornington Island).

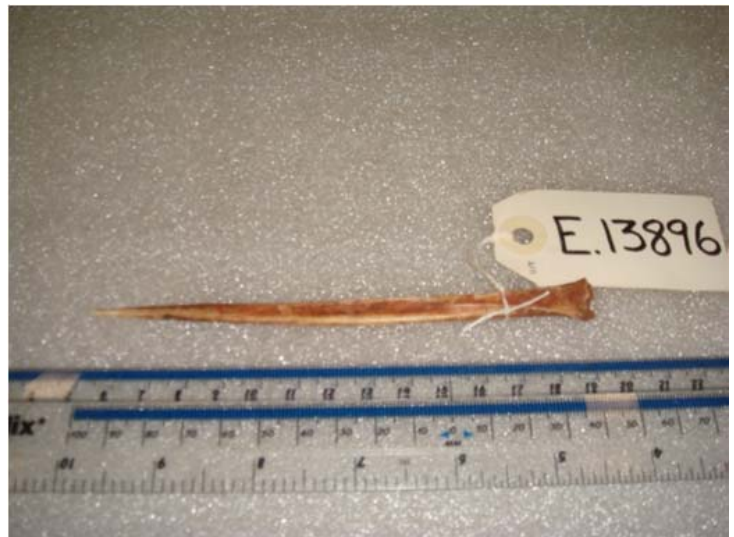

Figure 29. Bone point (AM E13896, Mornington Island).

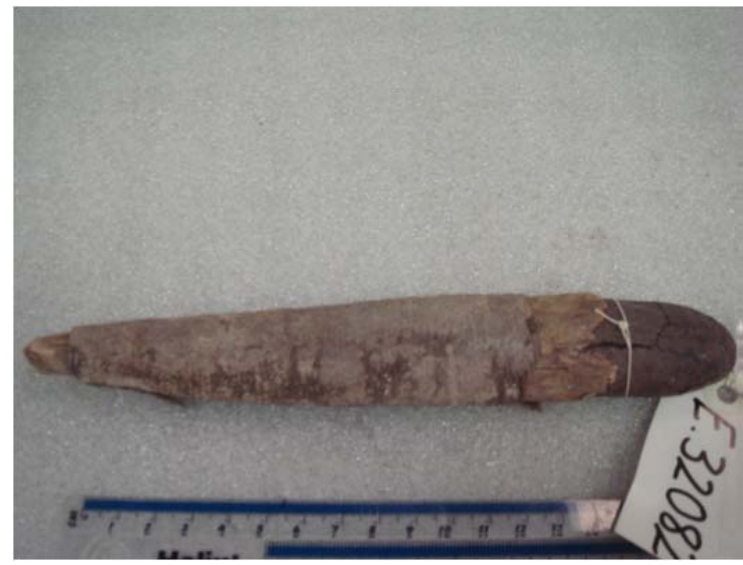

Figure 30. Stone blade (AM E32082, Burketown). 


\section{E. 13494}

Figure 31. Stone point (AM E13494, Mornington Island).

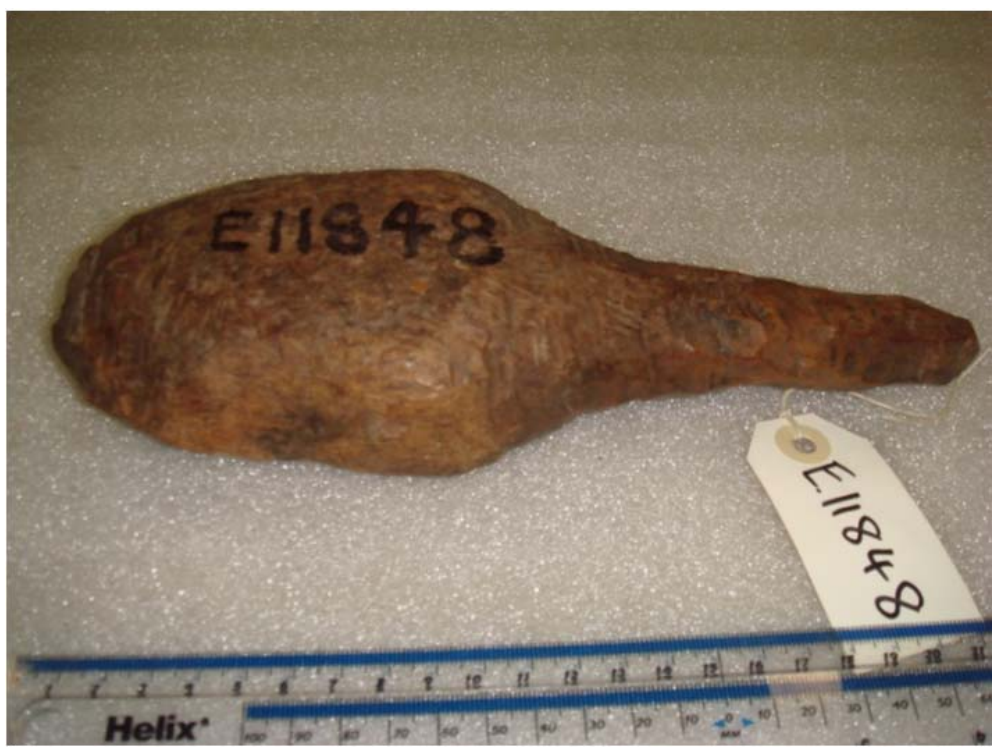

Figure 32. Pounder (AM E11848, Forsyth Island).

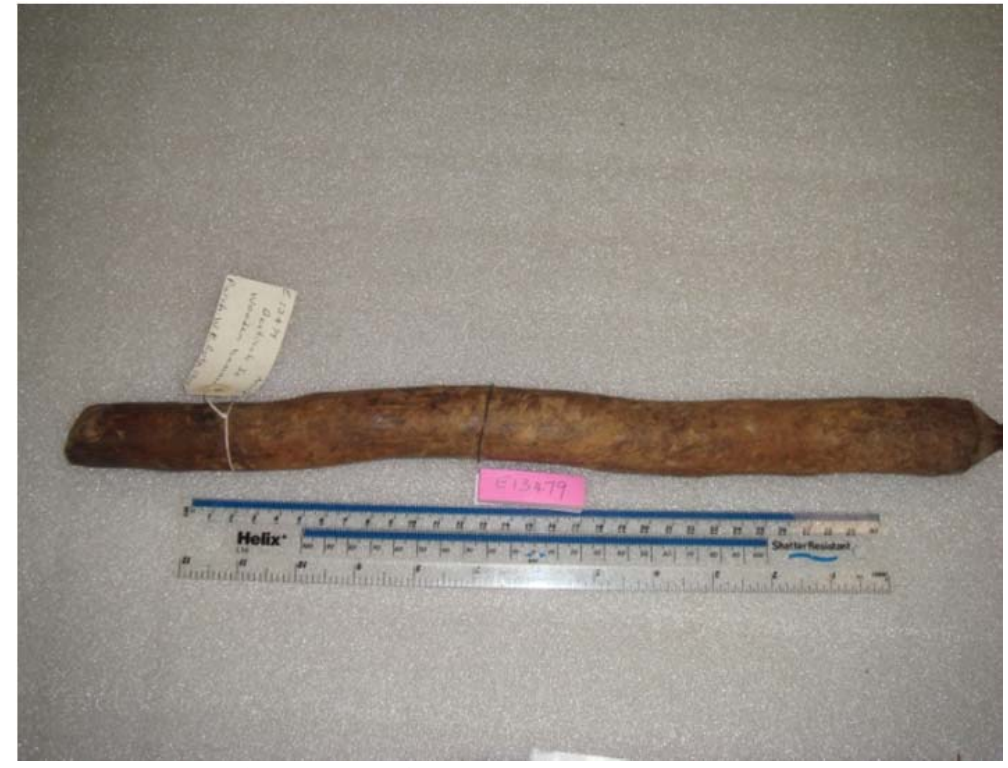

Figure 33. Pounder (AM E13479, Bentinck Island). 


\section{Weapons}

Following Khan's (2003) system, this category comprises boomerangs, spears, spear throwers and clubs. Although classified as 'weapons' not all forms were used in fighting. All are made and used by men. Some objects combine ceremonial and subsistence contexts, whilst others may be considered as having primarily a ceremonial (painted boomerang) or subsistence (fishing spear) function. Roth notes that a range of object forms found in this category would have been exchanged with groups from the south of the study area (e.g. fluted boomerangs, hook boomerangs) 'The Fluted Boomerang ... for the purposes of exchange and barter, travels both up and down the Georgina: in the former case branching on the way eastwards across to the Mitakoodi of the Cloncurry district, in the latter making its way to the Mulligan and the Burke ... The Hook Boomerang ... is made chiefly in the Upper Georgina Districts' (Roth 1897:145-146, Figs 352-353, Plate XX).

Boomerangs, in a number of forms are present in the coastal area, although are unlikely to have all been manufactured locally (e.g. hook boomerang, fluted asymmetrical boomerang; see Roth 1897:145). Roth remarks on the shallow angle of the 'knee' of boomerangs from the Gulf coast and the weightiness of boomerangs from this region (Figures 34-35). Simplified versions of a restricted repertoire of boomerang forms are present in the North Wellesleys, whilst this category is absent in the South Wellesleys. Note that the 'broken boomerang' found by Roth on Bentinck Island (1901) (AM E14272) is here classified as Stick Tool. Upon examination, it is unlikely to be a boomerang which confirms Roth's comments that 'no other specimens (boomerangs) were found in any of the local camps (on Bentinck)' (Roth 1901).

Gulf region spears are commonly made to be used with a spear thrower and spear throwers are present throughout the study area. Whilst different spear thrower morphologies exist to the east (Normanton) and to the south (southern Gulf country), one form is uniquely represented in the Burketown region (Best 2003:138148). This has a cylindrical shaft with the addition of a wooden peg hafted to the terminal end and is regularly pigmented red. Additional embellishments might include fluting or the addition of a human hair tassel (Figure 36). The Wellesley Island spear thrower also incorporates a cylindrical shaft. However, in the island form (found in both the North and South Wellesleys, as well as in Burketown) the peg element is integrated into the shaft as a carved component and is not affixed as in the coastal forms from Burketown (Figure 37). Pigment is absent in the island form. Roth (1909:200, Plate LVIII) comments 'I must draw attention to a very primitive form of implement met with in the Wellesley Islands (Mornington group), and on the adjoining mainland in the neighbourhood of Burketown. It is a straight stick in one piece, two feet five inches long, obtusely pointed at the proximal end, and round throughout the entire length'.

Spear styles are variable, with the greatest number of different forms found in the coastal area. These commonly incorporate hafted, carved, multiple-barbed points decorated with coloured pigments. Red, white, yellow and black pigments are present. On mainland spears decoration is commonly added to the carved

16 | 2012 | Vol. 15 | q a r
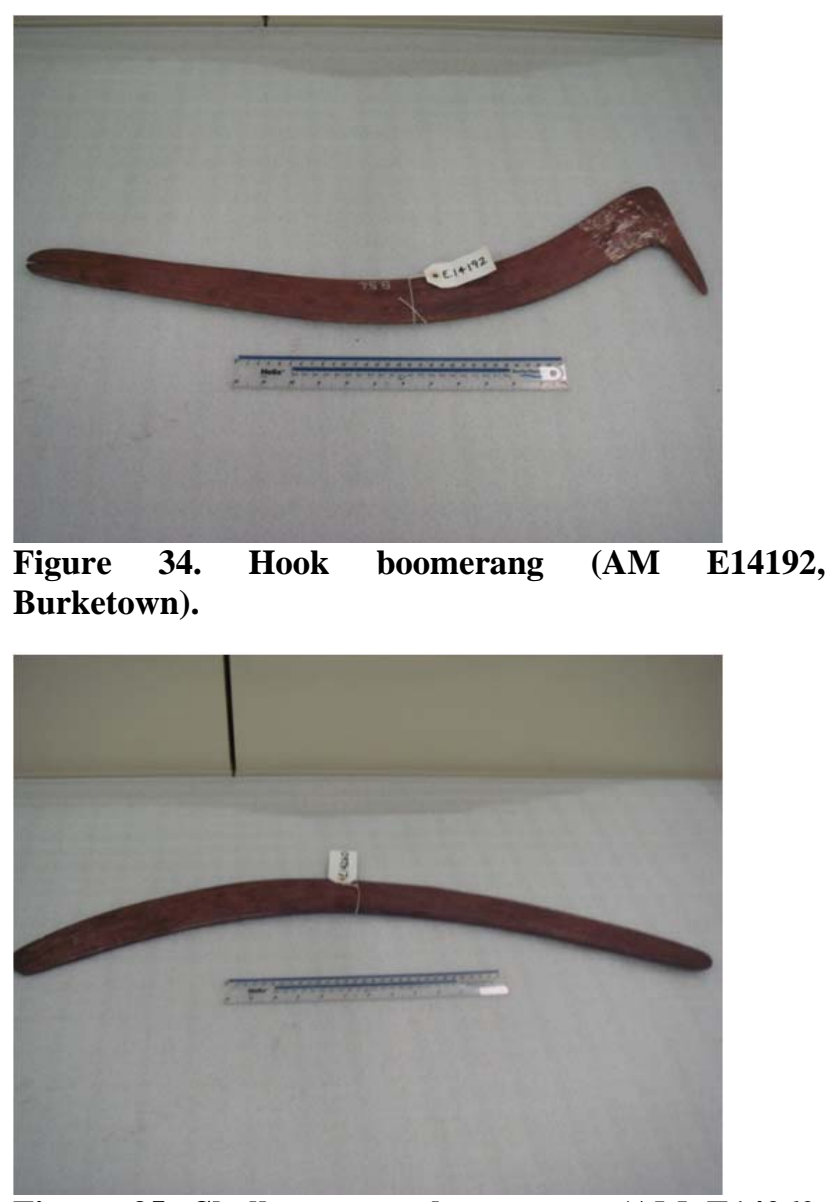

Figure 35. Shallow curve boomerang (AM E14260, Burketown).

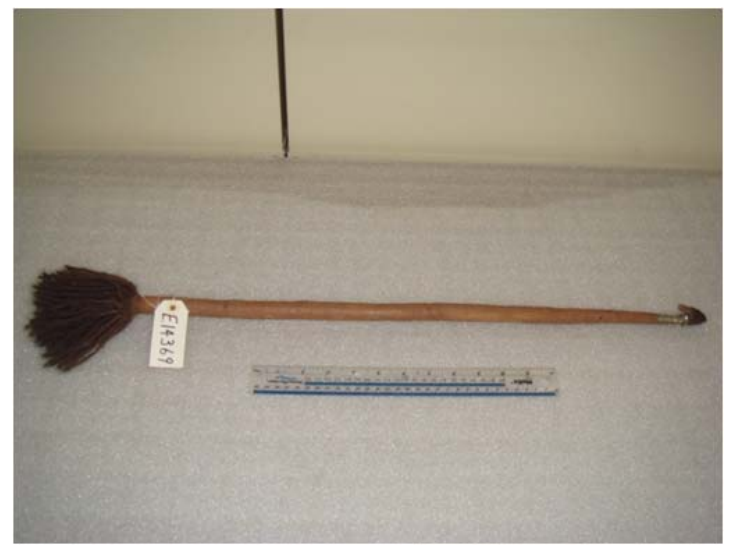

Figure 36. Cylindrical shafted spear thrower with added peg and tassel (AM E14369, Burketown).

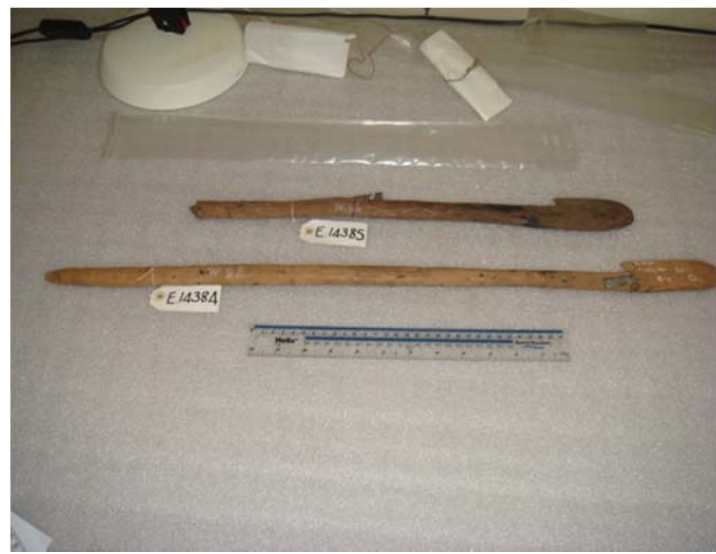

Figure 37. Cylindrical shafted spear thrower with integrated carved peg (AM E14385, Forsyth Island). 
barbed point, while on Bentinck Island, simple black bands decorate the shaft of pronged spears. Spears with stone points are typical of the Burketown area (Best 2003:131-136) (Figure 38). Numerically, the largest group in the set are barbed and pronged forms from Bentinck Island (Figure 39). A 'javelin' form with a hafted point is present in the coastal region and North Wellesleys and used to spear large marine animals (Trigger 1987:78).

With the exception of a single anomalous spear with integrated carved barbs (AM E15100) all spears are made of one or more hafted components. Hafting technique in the Burketown and Wellesley Islands is regionally distinctive. In other Queensland regions, the method by which two elements are joined to form the spear shaft involves carving the distal section into a point which is set into the hollowed tip of the proximal section. The two pieces are then bound and fixed with string and resin. In the study area, the two sections are laid side by side and bound (Figure 40).

Bentinck Island spears have a further diagnostic feature where the twine that binds two shaft components is 'returned' to form a diagonal outer thread (Figure 41). Resin is not used in the production of Wellesley Island spears. In the case of pronged spears, the distal end of the shaft is 'grooved on three faces to receive the basal ends of the prongs, the whole union ... being again bound round or whipped with native twine. The blunt barbs are cut out of the solid (prong), one behind the other, and all facing inwards' (Figure 42) (Roth 1909:190).

Two clubs only are present in the dataset, both from Burketown (Figures 43-44). Roth writes that clubs are 'not so much a hand implement as a throwing implement i.e. it is used more for throwing at short distances than for hitting at close quarters ... The distal extremity is enlarged and tapers to a point. A good one is usually incised with some circular bands at the proximal end, and with a longitudinal fluting which either reaches the tip or ceases abruptly about an inch from it (1897:150-151, Fig. 385, Plate XXII) (see also Roth 1909:207-209, Figs 1-15, Plate LXI).

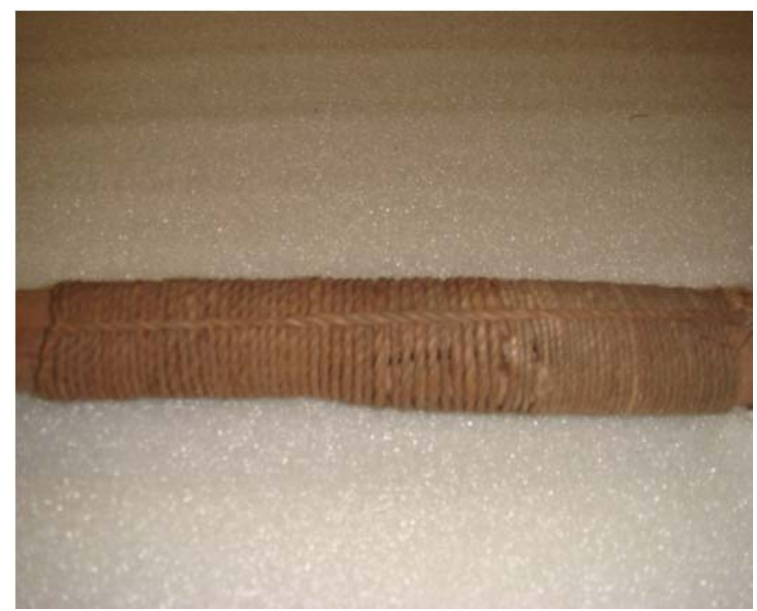

Figure 41. South Wellesley spear hafting technique showing 'return' thread (AM E15135-001, Bentinck Island).

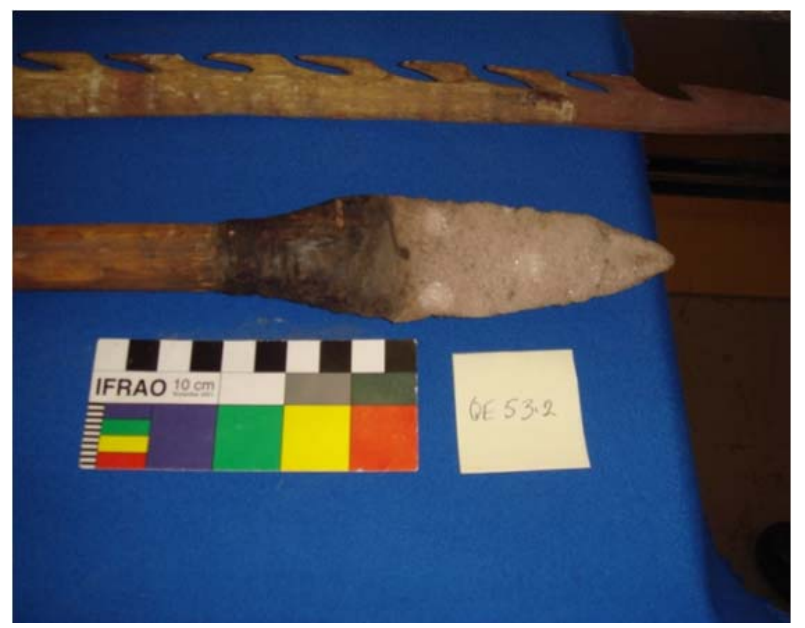

Figure 38. Stone-pointed spear (QM QE53.2, Turn Off Lagoon).

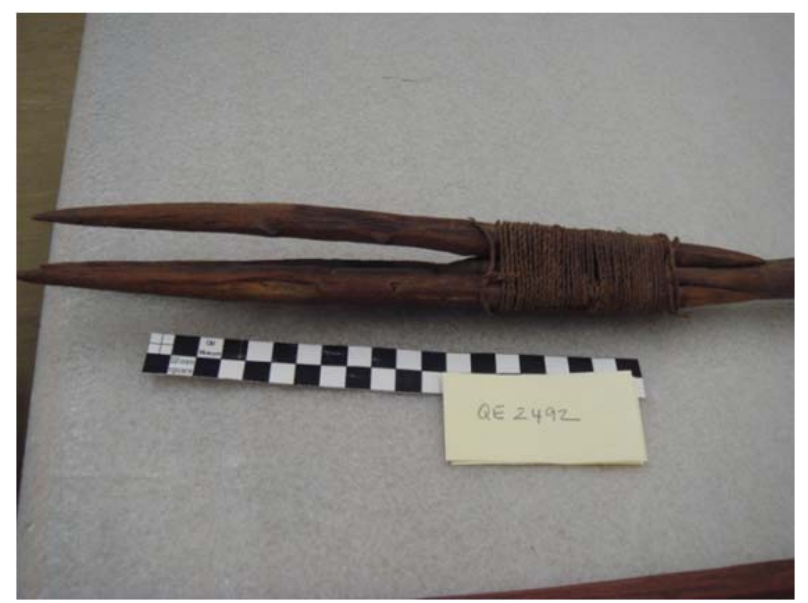

Figure 39. Pronged spear (QM QE2492, Bentinck Island).

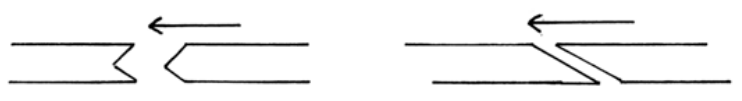

Figure 40. Diagram showing the common Queensland hafting technique of two spear sections (left) and the Burketown district hafting technique (right) (Best 2003:134, Fig. 6.33).

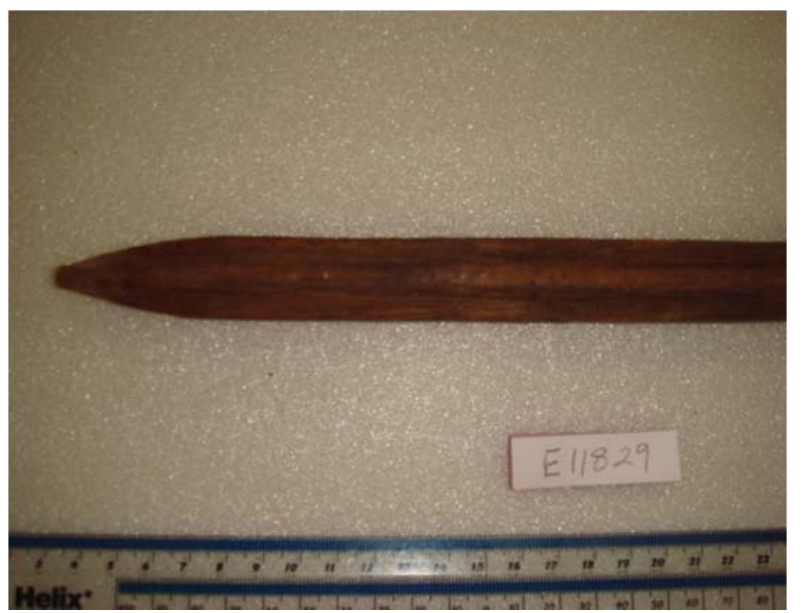

Figure 42. Carved distal end of spear shaft showing grooves to receive barbed prongs (AM E11829, Bentinck Island). 


\section{Data Analysis}

The data are examined using a hierarchy of steps which begin at the most broad-scale consideration of the composition and quantification of the set. Next I look at the distribution of Object Groups by Geographical Zone and then by Language Zone - to see if any obvious presences/absences are apparent at this level. This is followed by similarly-constructed enquiries into the spatial distributions of Object Categories. Finally I look at the distribution of more detailed artefact morphological variables of shape, colour, materials, manufacturing techniques and decorations.

As mentioned previously, the data are divided into three geographical zones with Zone 1 being the mainland Gulf coast, Zone 2, the North Wellesleys and Zone 3, the South Wellesleys.

The data comprise 164 objects from Zone 1 (Mainland Coast); 94 objects from Zone 2 (North Wellesleys) and 51 objects from Zone 3 (South Wellesleys) (Table 4). When broken down into Object Groups, the composition of the database is set out in Table 5. Of the Object Groups present, Dress and Ornament and Weapons represent the largest numbers, followed by Tools, Fishing Gear and Containers. With the exception of the Musical Instruments, each Object Group is well-represented in the set.

Table 4. Composition of dataset by Geographical Zone.

\begin{tabular}{|c|l|r|r|}
\hline Zone & Geographical Zone & \# Objects & \% Dataset \\
\hline 1 & Mainland Coast & 164 & 53 \\
\hline 2 & North Wellesley Islands & 94 & 30 \\
\hline 3 & South Wellesley Islands & 51 & 17 \\
\hline Total & & $\mathbf{3 0 9}$ & $\mathbf{1 0 0}$ \\
\hline
\end{tabular}

Table 5. Composition of the dataset by Object Group (following Khan's meta-categories).

\begin{tabular}{|l|r|r|}
\hline \multicolumn{1}{|c|}{ Object Group } & \# Objects & \multicolumn{1}{c|}{ \% } \\
\hline Containers & 31 & 10 \\
\hline Dress \& Ornament & 94 & 30 \\
\hline Fire-Making Tools & 5 & 2 \\
\hline Fishing Gear & 36 & 12 \\
\hline Message Sticks & 12 & 4 \\
\hline Musical Instruments & 1 & 0 \\
\hline Tools & 47 & 15 \\
\hline Weapons & 83 & 27 \\
\hline Total & $\mathbf{3 0 9}$ & $\mathbf{1 0 0}$ \\
\hline
\end{tabular}

\section{Object Group by Geographical Zone}

When sorted by Geographical Zone - Mainland Coast (Zone 1), North Wellesleys (Zone 2) and South Wellesleys (Zone 3) - at the coarsest stage of the analysis hierarchy, differences are visible both in terms of which categories are present, but significantly in numbers present (Figure 45). Seven Object Categories feature in the Mainland Coast zone, where all but Fire-Making Tools are present. Six categories are found in the North Wellesley and five in the South Wellesley set. Present throughout the region are Containers, Fishing Gear, Tools and Weapons. Dress and Ornament (47\%) and Weapons (29\%) comprise the largest percentage of the Mainland

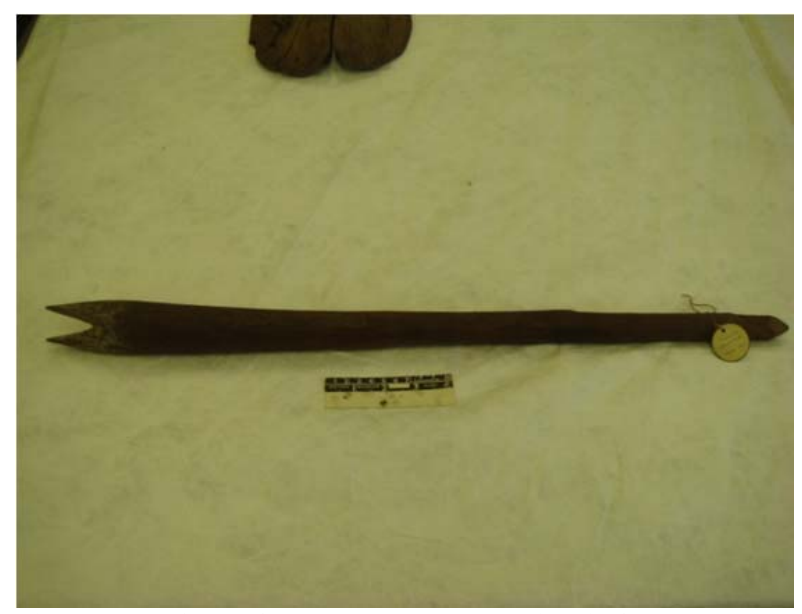

Figure 43. Club (BM 5250, Burke district).

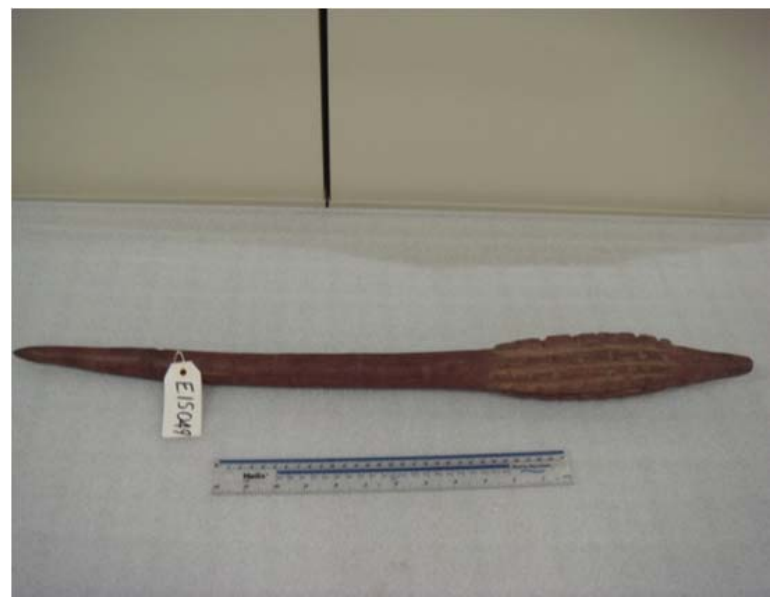

Figure 44. Club (AM E15049, Burketown).

Coast set while Tools are more prominent in the island sets. Message sticks are a mainland feature. The absence of message sticks in the Wellesleys is confirmed in a letter from Robert Hall, the first missionary on Mornington Island, who, when asked by Hamlyn-Harris (Director of the Queensland Museum 1910-1917) if message sticks were in use on Mornington Island, wrote on 8 August 1916 'During my two years on this island, I have seen nothing of message sticks' (Queensland Museum Library Correspondence Archive). Dress and Ornament is absent from the South Wellesleys. Weapons present $40 \%$ of the Bentinck Island set. However, as mentioned previously, all spears fall into this category even if the function of the artefact is for subsistence rather than fighting. Tools and Fishing Gear are similarly represented in the North Wellesley (28\% and 20\%) and South Wellesley (31\% and 18\%) sets.

In summary, analysis of Object Groups demonstrates a wider range of artefact groups are present on the mainland than on the islands and that Dress and Ornament are a shared category between the mainland and North Wellesleys but absent in the South Wellesleys. 


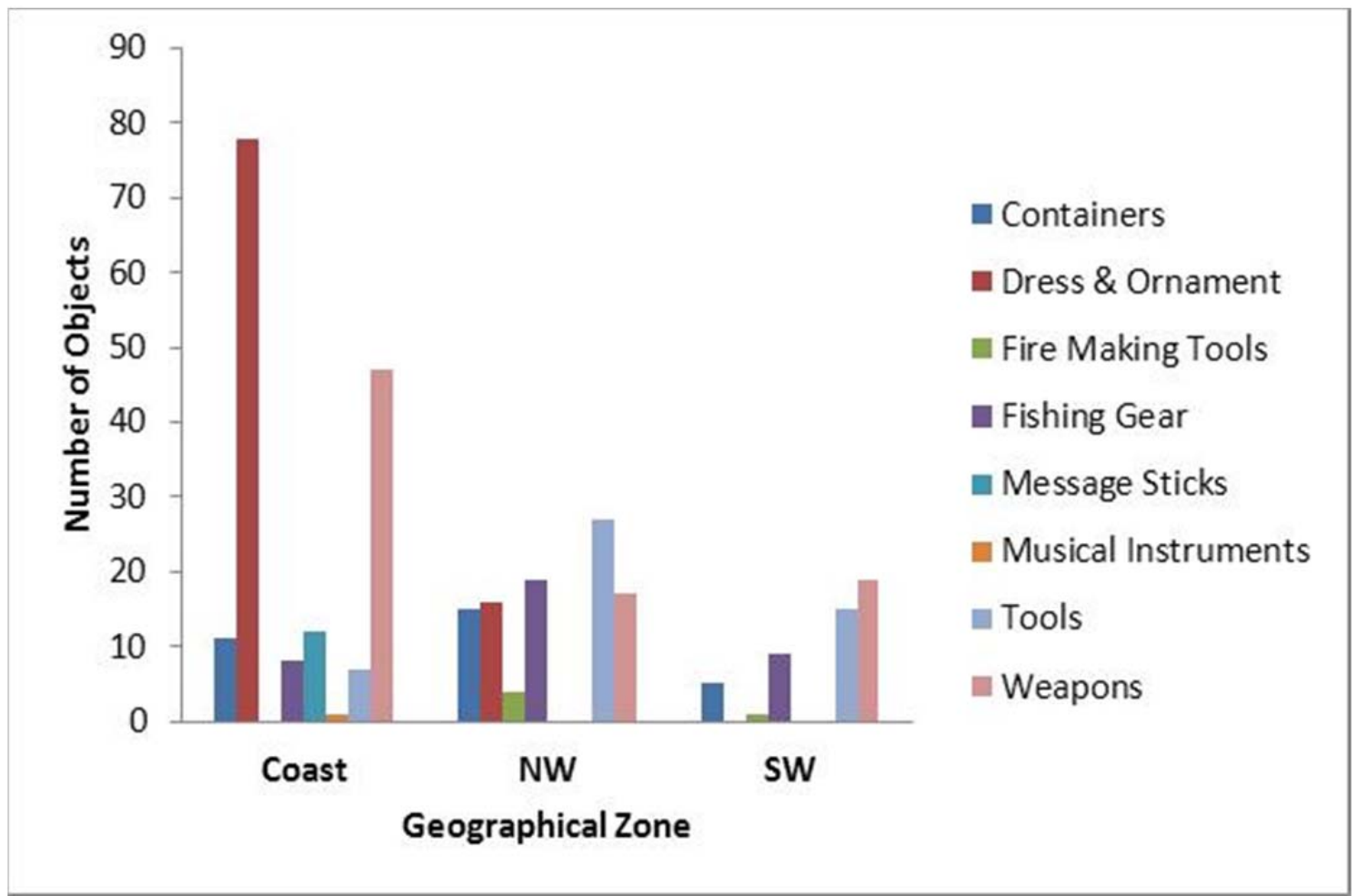

Figure 45. Object Groups by Geographical Zone.

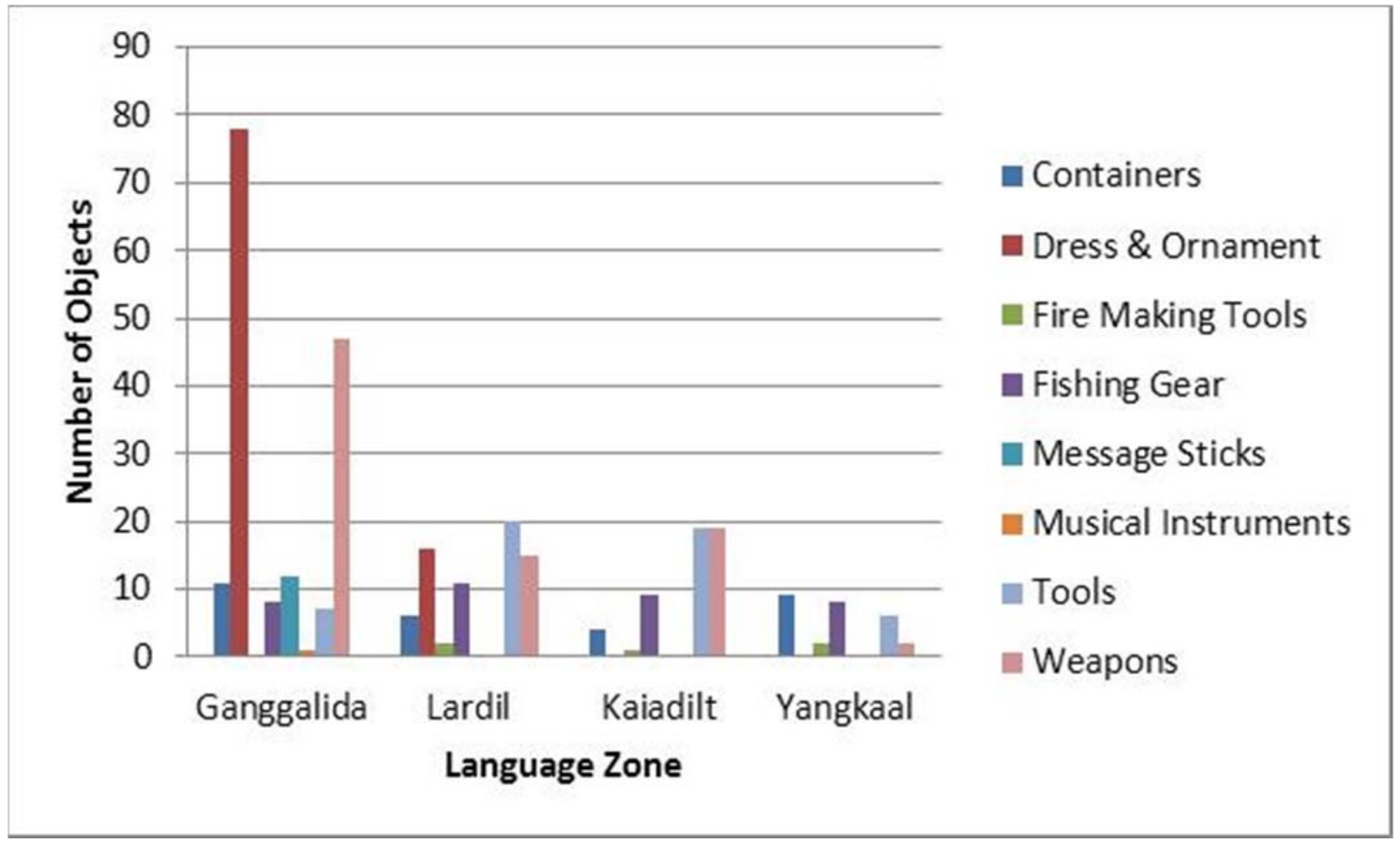

Figure 46. Object Groups by Language Zone. 


\section{Object Group by Language Zone}

The study area is divided into four Language Zones namely - Ganggalida (Zone 1) which geographically equates the coast; Lardil (Zone 2) which geographically equates Mornington Island; Kaiadilt (Zone 3) which geographically equates Bentinck Island and Yangkaal (Zone 4) which geographically equates Forsyth Island (Tindale 1974). A single object from Allen Island (a Syrinx arianus shell container AM E13346) is not assigned a Language Zone.

When Object Groups are examined by Language Zone, the Mainland Coast and South Wellesley sets remain unchanged, but the North Wellesley set is subdivided in two (Lardil and Yangkaal). Once this is done, it can be shown that all groups present in Zone 4 (Yangkaal) are also present in Zone 3 (Kaiadilt) (Containers, Fire-Making Tools, Fishing Gear, Tools and Weapons) although in percentage terms, the emphasis is different (Figure 46).

$30 \%$ of the Yangkaal set is Fishing Gear (an Object Group which includes, nets, lines, paddles, hooks etc but not spears), which is almost double the percentage found in the Lardil (16\%) and Kaiadilt (17\%) sets. However, one Object Group (Dress and Ornament) is absent in Forsyth Island and Bentinck Island but present from the Coast (Ganggalida) and Mornington Island (Lardil). Two Object Groups (Message Sticks and Musical Instruments) are restricted to the coast (Ganggalida).

In summary, the Yangkaal and Kaiadilt Object Group sets show similarities in composition and an absence of Dress and Ornament. The emphasis on fishing gear in the Yangkaal set may suggest a different subsistence focus in Forsyth Island with less spearing of marine resources. The Object Groups which are absent from the Yangkaal and Kaiadilt Language Zones (Dress and Ornament, Message Sticks and Musical Instruments) are all objects associated with specific social contexts.

\section{Object Categories by Geographical Zone}

As discussed earlier, each Object Group is further divided into Object Categories. For example the Dress and Ornament Group contains Object Categories such as Waist Ornament, Head Ornament, Armlet, Necklet, and so on. In all the set has been divided into 31 Object Categories (Appendix C). Quantifying Object Categories and seeing where these Object Categories are distributed and in what percentages show similarities and differences within the material culture of the study area.

Figures 47-29 set out the Object Category breakdowns of the data from each Geographical Zone. At this stage of the analysis, in numerical terms, Zone 1 (Coast) has 21 categories (Figure 47); Zone 2 (North Wellesleys) has 21 categories (Figure 48) and Zone 3 (South Wellesleys) has 12 categories (Figure 49). Quantification of the categories would confirm those writers who have observed that the material culture of the North Wellesleys includes a wider repertoire than that of the South Wellesleys (e.g. Roth, Tindale, Memmott). However, the 21 categories present in the mainland region and the North Wellesleys are not the same categories.
Five categories are present throughout the study area: cordage, nets, paddles, spears and spear throwers all of which have a subsistence context.

Seven categories are present on the coast but not in the Wellesleys: armlets, bags, clap sticks, clubs, message sticks, necklets, stone blades. A majority of these objects are items associated with exchange, personal identity and ceremony. Some objects in this set have stylistic origins from further afield (e.g. hook boomerangs). Some incorporate materials of European origin (e.g. bags).

Eight categories are found on both the mainland and the North Wellesleys, but are absent in the South Wellesleys: boomerangs, coolamons, feather tufts, hair string skeins, head ornaments, pendants, non-stone points, waist ornaments. A glance at the distribution of categories, demonstrates that 5/8 objects which are shared with the mainland and North Wellesleys relate to body ornament. The categories which link these two geographical zones are connected with personal identity and ceremony. Styles in objects, if not the objects themselves, were exchanged within these zones.

Four categories are present in the Wellesley Island sets but not in the mainland set: fire-making tools, pounders, shell containers, and stick tools. Most of these objects are connected with subsistence practices although a subset of stick tools may have been associated with ceremony ('fighting sticks').

Three categories are present only in the North Wellesley set: bark containers, line fishing, and stone point.

Fish mandibles and the mixed media (bark and fish mandible) bundle are only present in the Bentinck Island set while two examples of unmodified shell are present in the coast and Bentinck Island sets.

While those categories distributed throughout the study area are connected to subsistence practices, pounders and shell containers exhibit an interisland tradition which is absent on the adjacent coast.

Quantifying the numbers of artefacts present in the various categories, Figures 47-49 show that no single category significantly dominates the Mainland Coast or North Wellesley sets. However, the South Wellesley set is dominated by spears which represent $33 \%$ of that set. In fact $55 \%$ of the Bentinck Island set comprises objects directly associated with fishing (cordage, paddles, nets, spears and spear throwers). Categories in the South Wellesley set are associated with subsistence. None are obviously associated with ceremony, status or personal identity, although items are differentially used by men and women.

In summary, the Mainland Coast and North Wellesleys have a greater number of Object Categories than the South Wellesleys. Similarities in the sets from the Coast and North Wellesleys reflect shared Object Categories associated with ceremony and personal identity. Similarities between categories present in both island groups, but absent on the coast, are Object Categories associated with subsistence. Object Categories which are present throughout the study area are also artefacts associated with subsistence. 


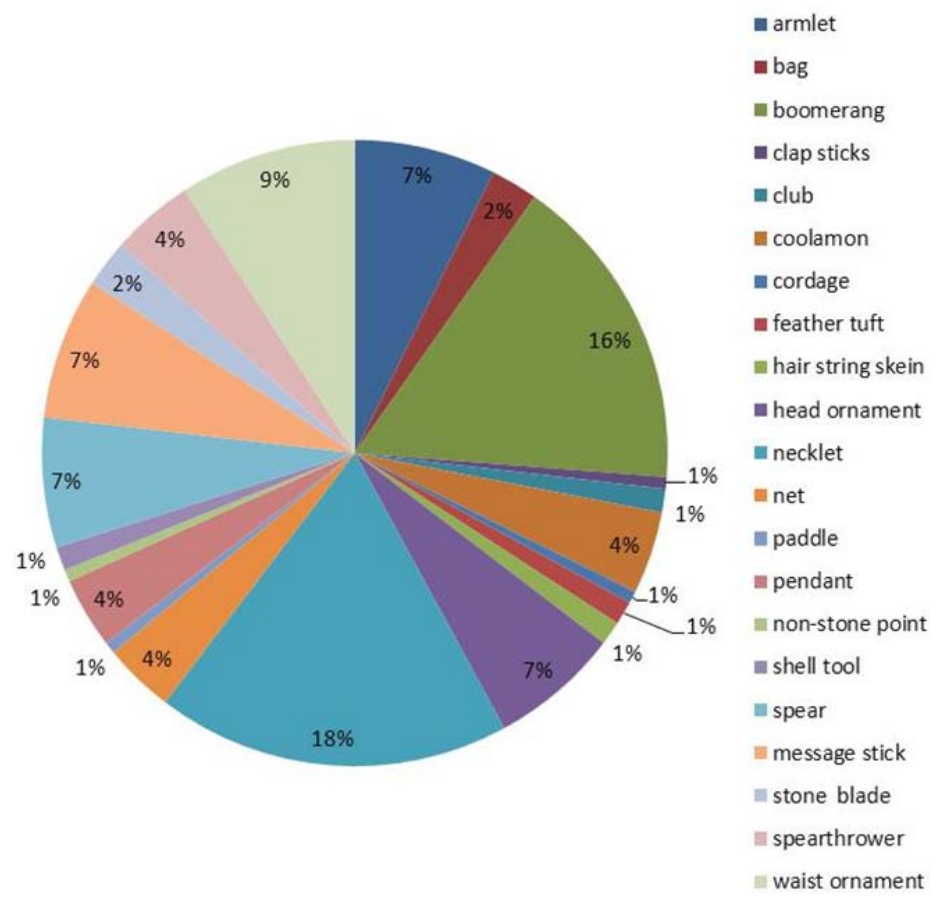

Figure 47. Object Categories in the Mainland Coast region.

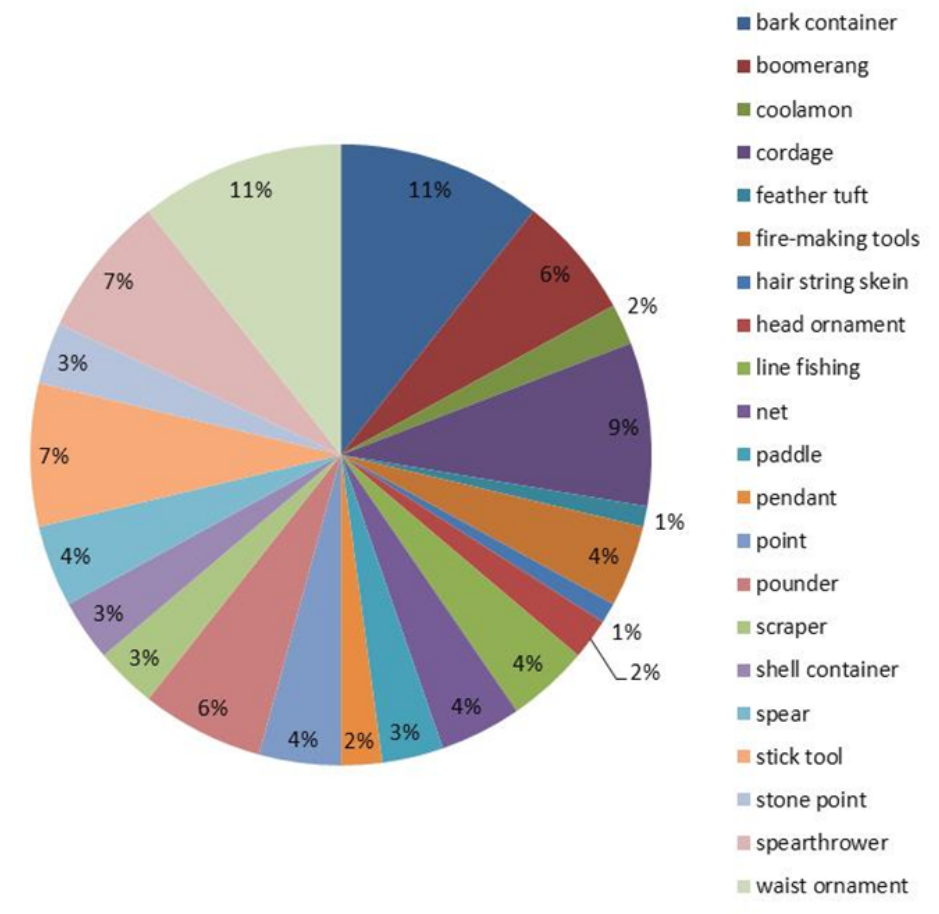

Figure 48. Object Categories in the North Wellesleys.

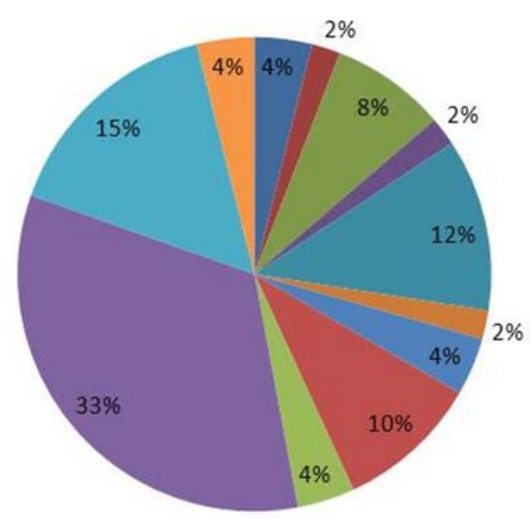

$$
\begin{aligned}
& \text { m cordage } \\
& \text { m fire-making tools } \\
& \text { m fish mandible } \\
& \text { m mixed media bundle } \\
& \text { m net } \\
& \text { = paddle } \\
& \text { m pounder } \\
& \text { m shell containter } \\
& \text { m shell tool } \\
& \text { m spear } \\
& \text { m stick tool } \\
& \text { m spearthrower }
\end{aligned}
$$

Figure 49. Object Categories in the South Wellesleys. 


\section{Object Categories by Language Zone}

As before, the purpose of the next step is to see if material culture differences exist at Object Category level which can be linked to Language Zone. In order to do this, the North Wellesley set is divided into Zone 2 (Lardil: Mornington Island) and Zone 4 (Yangkaal: Forsyth Island). The sets of Zone 1 (Ganggalida: Coast) and Zone 3 (Kaiadilt: Bentinck Island) remain unchanged, as above.

When Lardil and Yangkaal sets are compared it is demonstrated that the Lardil set incorporates 21 Object Categories while the Yangkaal set has only 11 (Figures 50-51). Figure 51 showing Yangkaal Object Categories can be compared to Figure 48 showing North Wellesley Object Categories. 8/11 Yangkaal categories are found in both the Kaiadilt and Lardil sets (cordage, fire-making tools, nets, paddles, pounders, shell containers, stick tools, spear throwers) showing intraisland spatial distributions of a wide range of subsistence-context objects. However, a closer look at a finer-grained level, shows that melon and trumpet shell containers are absent from the Lardil set, making the distribution of these objects restricted to Yangkaal and Kaiadilt sets. The single object in the Lardil shell container category is a modified clam shell. This represents a further example of stylistic affinities between Yangkaal (Forsyth Island) and Kaiadilt (Bentinck Island) sets.

Figures 50-51 quantify the Object Categories of the Lardil (Zone 2: Mornington Island) and Yangkaal (Zone 4: Forsyth Island) and clearly demonstrate material culture differences within the North Wellesley Islands.

In summary, when the North Wellesley material culture data is separated by Language Zone, spatial patterns emerge. The most obvious difference between the sets is the absence of boomerangs and items associated with body ornamention from Forsyth Island. However, cultural links between the Yangkaal set and the mainland is demonstrated in the presence of an undecorated coolamon (a wider Gulf region object). Both sets include pleated bark containers, making this object common to Lardil and Yangkaal sets but absent in the two others. Intraisland spatial patterning is beginning to emerge at Object Category level relating to those items associated with subsistence.

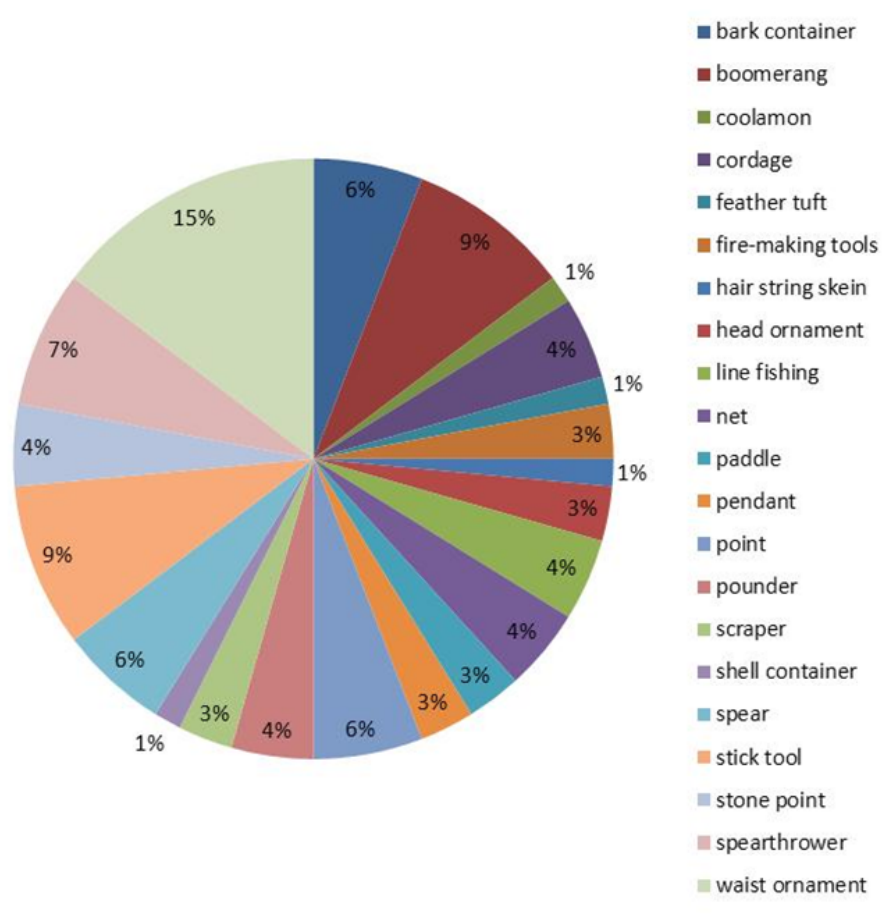

Figure 50. Lardil Object Categories.

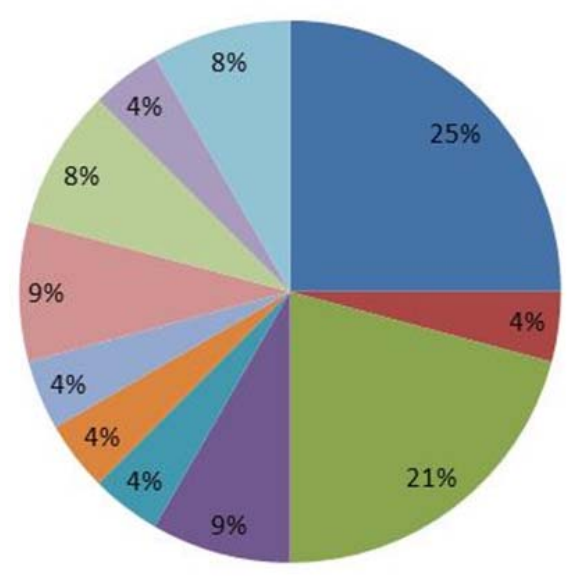

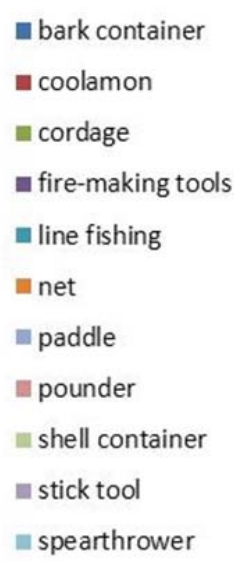

Figure 51. Yangkaal Object Categories. 
Spatial Distribution Patterns of Selected Object Categories (boomerangs, spears, fishing gear)

I now take a selected number of Object Categories boomerangs, spears and fishing gear - in order to look at secondary morphological variables which are identified as Forms and Types.

\section{Distribution of Boomerang Forms and Types}

Boomerangs are assigned both a form and a type (as are all artefacts in the dataset). The form represents the primary morphological feature which, in this case, is the boomerang's shape. Four boomerang forms are identified: curved, shallow curve, asymmetrical and hook. Each boomerang is further assigned a type which represents a secondary morphological trait which in this case is the boomerang's style of decoration. Four types are applicable to this category: painted red with white tip, undecorated, fluted and painted red with white tip, fluted and painted red (Table 6).

Table 6 sets out the forms and types of boomerangs. It shows that the majority of boomerangs are painted red; that curved boomerangs are most likely to be undecorated; that fluted, asymmetrical boomerangs are the most common form/type.

Spatial distributions of boomerang variables can also be quantified.

Boomerangs are present in greater numbers, and in a wider range of forms on the coast than in the North
Wellesleys (Table 7). As noted above, these objects are absent in the South Wellesleys and the Yangkaal Language Zone (Forsyth Island). The most common form on the mainland is asymmetrical which is represented by a single example in the North Wellesley set. The curved and shallow curved forms are the commonest on the islands but less prominent on the mainland. Hook boomerangs, already discussed as a form traded in from the south of the region are not common.

A greater range of boomerang types is found on the mainland (Table 8). Fluting is absent on boomerangs from the North Wellesleys, but decorates the majority of boomerangs from the Mainland Coast. Three different decoration styles are present in the coastal set, but only one in the North Wellesley set. Boomerangs with red pigment alone are a feature of the coast and absent on Mornington Island. Decorated boomerangs found on Mornington Island (none are present on Forsyth Island) are painted red with a white tip, similar, but without fluting, to those from the mainland. The design motif of a white band at the tip of one end of red painted boomerangs on Mornington demonstrates cultural connections with the mainland. Such objects impart social information such as 'I am male,' 'I am an initiated male,' 'I am from Mornington Island' or 'I am a Lardil speaker'.

Table 6. Boomerang forms with types.

\begin{tabular}{|l|c|c|c|c|c|}
\hline \multicolumn{1}{|c|}{ Boomerang Type } & \multicolumn{5}{c|}{ Boomerang Form } \\
\hline & Curved & Shallow Curve & Asymmetrical & Hook & Total \\
\hline Painted Red with White Tip & 4 & 1 & 1 & 0 & $\mathbf{6}$ \\
\hline Undecorated & 7 & 2 & 1 & 0 & $\mathbf{1 0}$ \\
\hline Fluted \& Painted Red with White Tip & 0 & 1 & 4 & 2 & $\mathbf{7}$ \\
\hline Fluted \& Painted Red & 0 & 1 & 9 & 0 & $\mathbf{1 0}$ \\
\hline Total & $\mathbf{1 1}$ & $\mathbf{5}$ & $\mathbf{1 5}$ & $\mathbf{2}$ & $\mathbf{3 3}$ \\
\hline
\end{tabular}

Table 7. Spatial distribution of boomerang forms.

\begin{tabular}{|l|c|c|c|c|c|}
\hline & \multicolumn{5}{c|}{ Boomerang Form } \\
\hline \multicolumn{1}{|c|}{ Boomerang Location } & Curved & Shallow Curve & Asymmetrical & Hook & Total \\
\hline Coast & 8 & 3 & 14 & 2 & 27 \\
\hline North Wellesleys & 3 & 2 & 1 & 0 & $\mathbf{6}$ \\
\hline Total & $\mathbf{1 1}$ & $\mathbf{5}$ & $\mathbf{1 5}$ & $\mathbf{2}$ & $\mathbf{3 3}$ \\
\hline
\end{tabular}

Table 8. Spatial distribution of boomerang types.

\begin{tabular}{|l|c|c|c|c|c|}
\hline & \multicolumn{5}{|c|}{ Boomerang Type } \\
\hline $\begin{array}{c}\text { Boomerang } \\
\text { Location }\end{array}$ & $\begin{array}{c}\text { Painted Red } \\
\text { with } \\
\text { White Tip }\end{array}$ & Undecorated & $\begin{array}{c}\text { Fluted and Painted } \\
\text { Red with } \\
\text { White Tip }\end{array}$ & $\begin{array}{c}\text { Fluted and } \\
\text { Painted Red }\end{array}$ & Total \\
\hline Coast & 2 & 8 & 7 & 10 & $\mathbf{2 7}$ \\
\hline North Wellesleys & 4 & 2 & 0 & 0 & $\mathbf{6}$ \\
\hline Total & $\mathbf{6}$ & $\mathbf{1 0}$ & $\mathbf{7}$ & $\mathbf{1 0}$ & $\mathbf{3 3}$ \\
\hline
\end{tabular}




\section{Distribution of Spear Forms and Types}

As with boomerangs, spears have been assigned a form. Description of the morphology of the spear's functional distal end has been used to classify the spear category by form. I identify nine forms of spear within the set, elaborating on Trigger's (1987:77-78) four forms (1. Pronged, 2. Stone point, 3. Multiple barbed, 4. Wood point 'javelin') (Table 9).

In addition each spear is assigned with one of six different secondary traits, or types, which focus on the production and function of the spear - whether it comprises one or two shafts hafted together, whether it is manufactured to be used with a spear thrower and so on.

Dividing the spears by forms (Table 10), I have plotted the spatial distribution of spear forms (Table 11) (like boomerangs, spears are absent from the Forsyth Island set). The most obvious element of this table suggests that Bentinck Island could be called 'Spear Country'. Spears from Bentinck outnumber those of the other two areas combined. The table also reveals a unique Bentinck Island spear manufacturing style where three spear forms are unique to Bentinck (3 prong/shallow barbs; multiple carved shallow wood barbs; 2 prong/shallow barbs). This style of spear would be particularly effective when used in conjunction with fish traps to acquire marine resources and may be too fragile for hunting large marine animals. Spears with sharply serrated multiple carved wood barbs represent a mainland spear style with a single outlier present on Mornington. The hafted tips of this spear form commonly incorporate painted designs which suggest a more ceremonial, less subsistence social context for that form. Mornington Island is the only place where 'javelin' pointed spears are found. These robust objects would be suitable - along with the large nets present on Mornington - for hunting large marine animals such as dugong and turtle.

11 spears, 10 of which are from Bentinck, were in poor or fragmentary condition. This meant that it was not possible to know if they had been manufactured to be used with a spear thrower. However, the examination of complete spears indicates that mainland and Mornington Island spears were designed to be used with a thrower, but that several Bentinck Island spears appear to have been hand-held (Table 12). Again, this might represent a cultural point of difference in the detail of material culture styles found on Bentinck. While spears throughout the study area are hafted in a way unique to the Burketown region of the Gulf (Figure 40), Bentinck Island spear shafts are hafted using a particular, 'return' knot fastening, using twined vegetable fibre string. While gum fixative is present on certain mainland spears, no gum was used on Mornington or Bentinck spears. A further point of difference within the Bentinck spear set is the addition of black banded designs around the distal shaft.

Table 9. Spear forms as defined in dataset with corresponding types (Trigger 1987).

\begin{tabular}{|c|l|c|}
\hline Spear Form & \multicolumn{1}{|c|}{ Description } & Corresponding Trigger (1987) Spear Type \\
\hline 1 & wood point 'javelin’ & 4 \\
\hline 2 & 3 prong/shallow barbs & 1 \\
\hline 3 & multiple carved shallow wood barbs (1 side) & 3 \\
\hline 4 & multiple carved sharp/serrated wood barbs (1 side) & 3 \\
\hline 5 & stone point & 2 \\
\hline 6 & 2 prong/shallow barbs & 1 \\
\hline 7 & 2 prong (prongs not barbed) & 1 \\
\hline 8 & 2 prong multiple sharp/serrated barbs one side only & 1 \\
\hline 9 & 3 circular rows carved barbs carved into shaft & Not included \\
\hline
\end{tabular}

Table 10. Spear types.

\begin{tabular}{|c|l|}
\hline Type & \multicolumn{1}{c|}{ Description } \\
\hline 1 & 1 shaft for thrower (recessed butt) \\
\hline 2 & 1 shaft hand-held \\
\hline 3 & 2 shafts for thrower (recessed butt) \\
\hline 4 & 2 shafts hand-held \\
\hline 5 & 2 shafts thrower uncertain (broken etc) \\
\hline 6 & 1 shaft thrower uncertain (broken etc) \\
\hline 7 & 1 piece hand-held no hafted point/prong/barbs \\
\hline
\end{tabular}

Table 11. Spatial distribution of spear forms.

\begin{tabular}{|l|c|c|c|c|c|c|c|c|c|c|}
\hline & \multicolumn{9}{|c|}{ Spear Form } & \multicolumn{1}{c|}{} \\
\hline \multicolumn{1}{|c|}{ Spear Location } & $\mathbf{1}$ & $\mathbf{2}$ & $\mathbf{3}$ & $\mathbf{4}$ & $\mathbf{5}$ & $\mathbf{6}$ & $\mathbf{7}$ & $\mathbf{8}$ & $\mathbf{9}$ & Total \\
\hline Coast & 0 & 0 & 0 & 6 & 2 & 0 & 1 & 1 & 1 & $\mathbf{1 1}$ \\
\hline Mornington Island & 3 & 0 & 0 & 1 & 0 & 0 & 0 & 0 & 0 & $\mathbf{4}$ \\
\hline Bentinck Island & 0 & 7 & 6 & 0 & 0 & 4 & 0 & 0 & 0 & $\mathbf{1 7}$ \\
\hline Total & $\mathbf{3}$ & $\mathbf{7}$ & $\mathbf{6}$ & $\mathbf{7}$ & $\mathbf{2}$ & $\mathbf{4}$ & $\mathbf{1}$ & $\mathbf{1}$ & $\mathbf{1}$ & $\mathbf{3 2}$ \\
\hline
\end{tabular}


Table 12. Spatial distribution of spear types.

\begin{tabular}{|l|c|c|c|c|c|c|c|c|}
\hline & \multicolumn{9}{|c|}{ Spear Types } & \\
\hline \multicolumn{1}{|c|}{ Spear Location } & $\mathbf{1}$ & $\mathbf{2}$ & $\mathbf{3}$ & $\mathbf{4}$ & $\mathbf{5}$ & $\mathbf{6}$ & $\mathbf{7}$ & Total \\
\hline Coast & 8 & 0 & 1 & 0 & 0 & 1 & 1 & $\mathbf{1 1}$ \\
\hline Mornington Island & 4 & 0 & 0 & 0 & 0 & 0 & 0 & $\mathbf{4}$ \\
\hline Bentinck Island & 1 & 3 & 2 & 1 & 5 & 5 & 0 & $\mathbf{1 7}$ \\
\hline Total & $\mathbf{1 3}$ & $\mathbf{3}$ & $\mathbf{3}$ & $\mathbf{1}$ & $\mathbf{5}$ & $\mathbf{6}$ & $\mathbf{1}$ & $\mathbf{3 2}$ \\
\hline
\end{tabular}

\section{Distribution of Fishing Gear Forms and Types}

Fishing gear artefacts are sorted into four Object Categories; cordage, nets, line fishing, and paddles. Each of these categories is subdivided by obvious morphological variables. When the spatial distributions of forms or types of each category are explored, further, fine-grained spatial differences can be observed.

Cordage is divided into rope and string. Seven examples of rope exist, all from the North Wellesleys and are present on both Mornington Island (2) and Forsyth Island (5). Perhaps rope cordage in the North Wellesleys may provide further evidence of the exploitation of large marine animals in the North Wellesleys (along with 'javelin' spears and large knotted nets). Examples of string cordage are present in all three geographical zones. Nets types are identified in Table 13.

Throughout the study area all nets are manufactured using knotted, vegetable fibre twined string.

Hand nets with stick handles come in two distinctive shapes. Net Type 1 is only found in the South Wellesleys. Net Types 2 and 3 are present on the mainland and in the North Wellesleys (absent in the South Wellesleys). One example of Type 2 net from Mornington Island (QM QE450) is exceptionally large compared to the other nine examples of hand nets with stick handles. A single example of Net Type 4 originates on Forsyth Island. Therefore, although many style traits are common to nets throughout the study area, inter-regional differences are revealed when net morphology is examined in closer detail.

Line fishing gear is only present in the North Wellesley set with iron hooks attached to lines originating from both Mornington Island and Forsyth Island. No line fishing gear is found in the Bentinck Island set. Presence of iron represents another example of contact between the coastal region and the North Wellesley Island group and is noted by Roth during his report on his second voyage to the Wellesleys in 1903 which states that iron hooks are present in the Burketown region and in the North Wellesleys.

Finally the sample of five raft paddles is divided into two forms. One is a paddle made of mangrove timber where the paddle is produced by beating out the wood to form a 'fan' shaped end. The second form is a carved, elongated oval shape. The 'fan' shaped paddle is represented in the Mainland Coast and South Wellesley sets while examples of the elongated oval form are present from both Mornington and Forsyth Islands.

In summary, although fishing gear artefacts are a feature of the study area, regional style 'specialisation' is visible, which may in turn reflect slight 'local' differences in traditions of marine resource exploitation. Rope cordage, large stick handled nets, line fishing and elongated oval paddles are a feature of the North Wellesleys and absent in the South Wellesleys. Oval shaped hand nets with stick handles are only found in the South Wellesleys.

It may be that a combination of rock-wall fish traps, pronged spears and smallish hand nets represent South Wellesley marine exploitation, while a lesser focus on fish trap/spearing/hand netting took place in the North Wellesleys where large marine animals were hunted using a combination of single point spears, strong rope, large nets, hooks and lines.

Table 13. Net types.

\begin{tabular}{|c|l|}
\hline Type & \multicolumn{1}{|c|}{ Description } \\
\hline 1 & 2 stick handles, oval shape \\
\hline 2 & 2 long stick handles, triangular shape \\
\hline 3 & cylinder/casting string/open one end closed other \\
\hline 4 & rectangular length of netting \\
\hline
\end{tabular}

Spatial Patterns of Selected Materials (human hair, European materials, pigment)

I have selected a range of materials, namely human hair, materials of European/commercial origin and pigment to see the extent to which they are used in the material culture of the region, what items incorporate these materials and whether spatial patterns exist.

\section{Object Categories which include Human Hair by Geographical Zone}

Objects incorporating human hair are not present in the South Wellesleys. Figure 52 sets out the Object Categories where human hair is present and quantifies their presence. It is apparent that this material is present in a larger range of categories from the Mainland Coast than in the North Wellesleys and that by far the largest number of objects are waist ornaments - an object associated with the identification of male initiation. With the single exception of human hair incorporated into a line fishing object from the North Wellesleys, all objects incorporating human hair are associated with personal identification, ceremony or exchange. This material is a feature of items representing personal or group status. 
Object Categories which include European Materials by Geographical Zone

Distribution of the presence of European materials (iron, wool, cotton) reveals a similar pattern to that of human hair (Figure 53). The widest range of Object Categories incorporating these materials is from the Mainland Coast (8) with a reduced number in the North Wellesleys (4). There is also an overlap of six Object Categories where some items within an Object Category incorporate either human hair or European materials (armlet, feather tuft, hair string skein, head ornament, line fishing, necklet). European materials are absent from the South Wellesleys. The social context of these items is similar to those with human hair, namely a focus on objects used by males which are connected either with exchange or personal identity. The distribution demonstrates that socio-cultural connections existed between the mainland and North Wellesleys, and also that for cultural and/or physical reasons, these materials were not part of the material culture of the South Wellesleys.

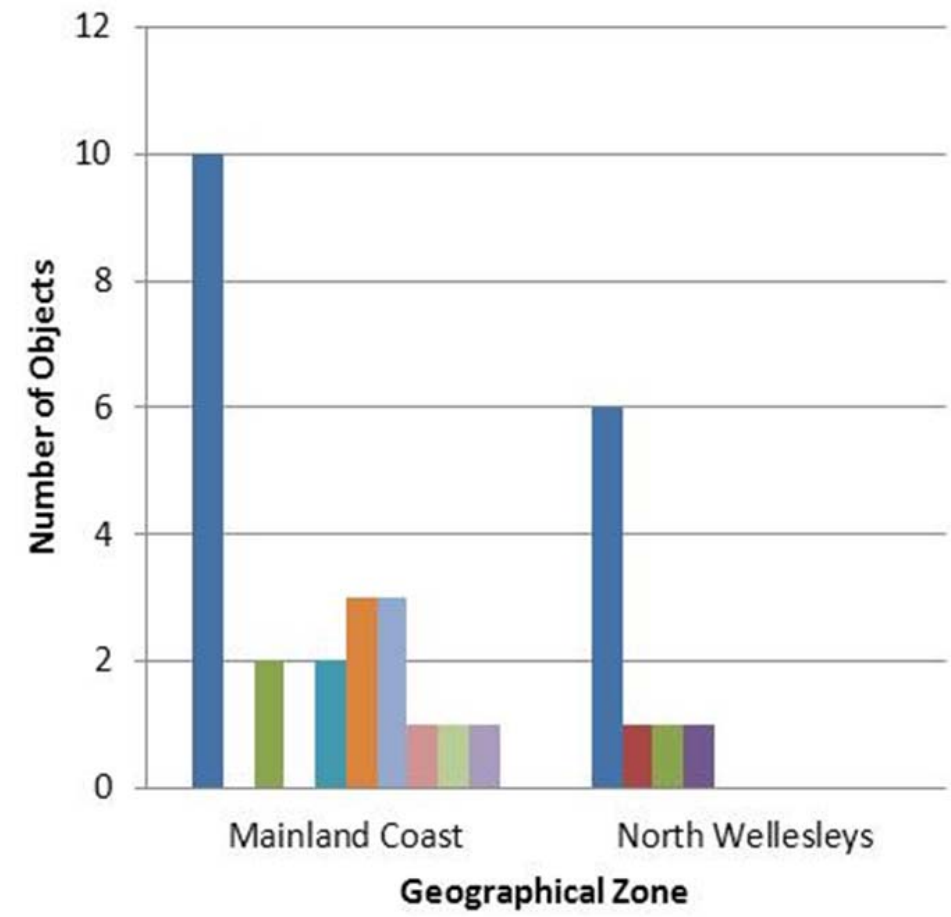

Figure 52. Distribution of Object Categories incorporating human hair.

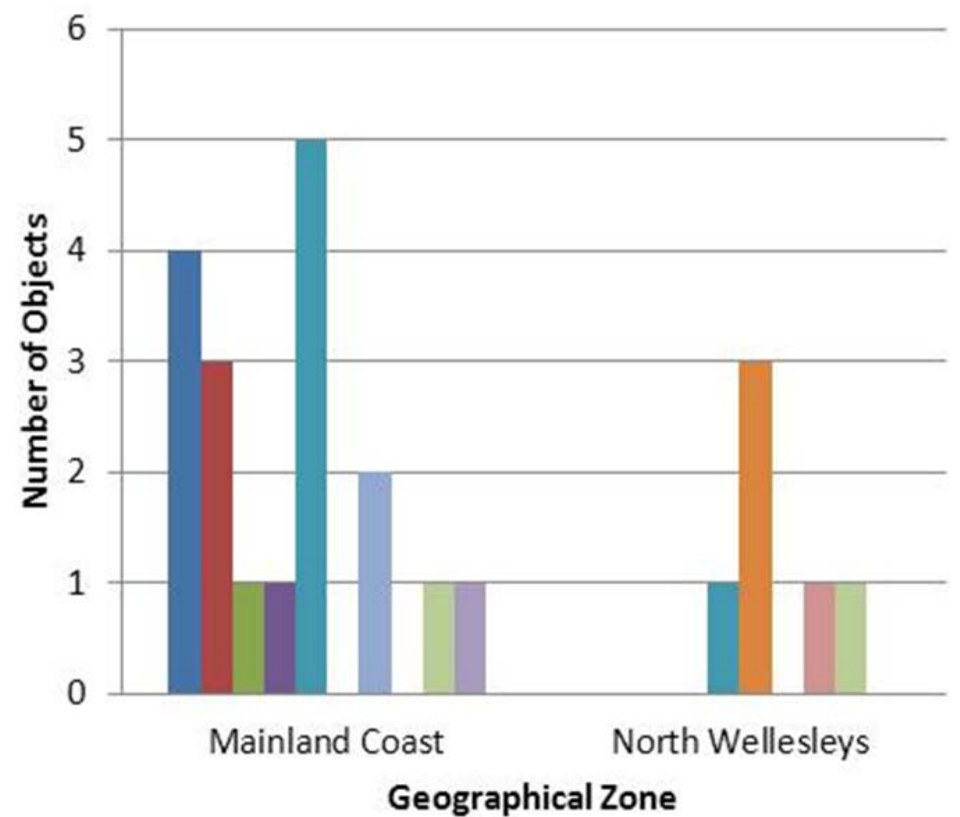

Geographical Zone waist ornament

feather tuft

hair string skein

- line fishing

armlet

abg

nead ornament

necklet

w stone blade

spearthrower armlet

abg

weather tuft

nair sting skein

ㅁ head ornament

- line fishing

necklet

w scraper

in spear

stick

Figure 53. Distribution of Object Categories incorporating European materials. 


\section{Distribution of Object Categories with Pigment}

In the following investigation, all forms of pigment are considered, not just red ochre. The purpose is to identify which Object Categories include pigment, as well as the distribution and quantities of those categories with pigment. Within the study area, black, red, white and yellow pigments are found. Yellow is restricted to the mainland, black is a feature of Bentinck Island spear decoration, red ochre with white is a characteristic of Mainland Coast and North Wellesley boomerangs and head bands and red ochre is common on coolamons, neck, waist and head ornaments, and twined string. Intentionally added pigment, for decorative purposes, is not universal here. Pigment may be added for functional as well as decorative reasons. For example the small shell container from Mornington Island (AM E11843) contained red ochre and the stone points from Mornington bear ochre residues, not ochre decorations. Red ochre mixed with grease found on a range of body ornaments could serve as both a decorative and preservative agent. Intentionally decorated objects are discussed below.

Fourteen Object Categories (106 objects) in the Mainland Coast set incorporate pigment. Thirteen Object Categories (27 objects) in the North Wellesley set incorporate pigment. Three Object Categories (21 objects) from the South Wellesleys have added pigment. In percentage terms pigment is present in $65 \%$ of the Mainland Coast set, $41 \%$ of the South Wellesley set and $29 \%$ of the North Wellesley set (Figure 54).

\section{Object Decoration}

Certain objects incorporate specific decorative embellishments which can be disassociated with the function of the object. These added decorative elements are entered into the 'Decoration' fields of the database and include subcategories of technique, location (where on the object the decoration occurs), colour, motif and motif type. These variables enable finer-grained analyses of stylistic traits. A wide range of enquiries is possible, but I limit the discussion at this point to a general look at selected technique, motif, and colour categories to reveal which objects incorporate these features and in which Geographical Zone they are present.

\section{Fluting Technique}

Fluting - the application of parallel grooves on the surface of a wood object - is a technique with a wide distribution in central Queensland (Gulf, Eyre and Riverine drainage divisions) (Best 2003:151, 156). Roth describes how these linear striations are produced using an instrument he refers to as a gouge or chisel (1904:17, 20, Fig. 101, Plate XIV). This implement is composed of a curved wooden 'handle' to each end of which is attached a stone flake scraper embedded in plant resin cement. Roth (1904:20) writes that the chisel itself was not traded but the fluted objects that were worked with this tool were extensively exchanged. Within the current study area, fluting is found on 24 objects from the Mainland Coast zone. The technique is absent from the North and South Wellesley Islands. The Object Categories which incorporate fluting are boomerangs, clubs, coolamons and spear throwers - all large wooden objects with suitable surfaces on which to decorate with this technique and objects that are known to have been extensively exchanged. Fluting is absent on message sticks.

Table 14. Fluted objects: Mainland coastal zone.

\begin{tabular}{|l|c|}
\hline \multicolumn{1}{|c|}{ Object Category } & \# Objects \\
\hline Boomerangs & 17 \\
\hline Clubs & 1 \\
\hline Coolamons & 4 \\
\hline Throwers & 2 \\
\hline Total & $\mathbf{2 4}$ \\
\hline
\end{tabular}

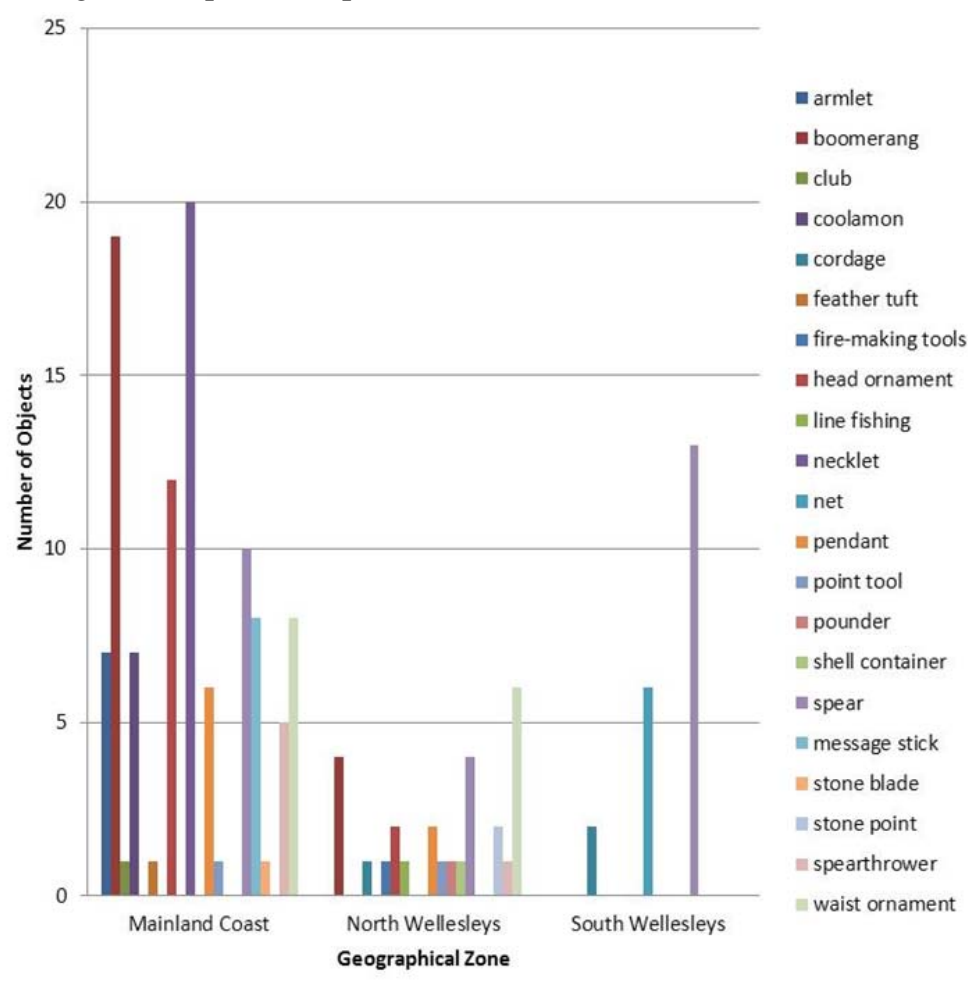

Figure 54. Distribution of Object Categories with added pigment. 


\section{Motifs and Motif Types}

The motif repertory used to embellish certain objects in the set is notable in being made up of a range of linear, straight lines (Table 15). This repertory is limited in its composition. Absent are the numerous arcs and wavy motif forms found on the material culture of other regions of Queensland (Best 2003). Unsurprisingly, the greatest range of motifs and motif types are present on message sticks. Message stick designs are incised into the surface and include the following motifs: arrow, cross, diagonal and the most numerous motif designs are straight line band(s) applied with pigment. Motifs are quantified on a presence or absence basis. For example, when a Bentinck Island spear shaft is decorated with numerous black bands, I have counted the presence of one motif only - in this example Straight - in order to avoid skewing caused by heavily decorated individual objects.

Similarly, the presence of motifs can be quantified by Geographical Zone.

By far the greatest instance and variety of motif decoration is present in the Mainland Coast set (Table 16). This reflects the presence of message sticks in this area as well as pituri bags, boomerangs, coolamons, clubs, and spears, many of which incorporate design motifs.

Straight line motifs which form a banded decoration are the only designs present in the Wellesley Islands. In the North Wellesley's banded decoration is present on spears and painted boomerangs, while in the South Wellesleys, spears are the only embellished objects.

Spears in the three geographical zones commonly incorporate painted decoration although - as with the spear type - the manner of the decoration varies spatially. In the Mainland Coast zone, spears with multiple, carved, serrated wood barbs (Spear Form 4) can include crosshatch motifs as well as zoned straight band decoration using red, white and yellow pigments (Figure 55). Two of the four Mornington Island 'javelin' spears have red and white bands on the shafts (Spear Form 1) while the serrated barb on the single example of Spear Form 4 from Mornington Island (Figure 56) is painted red overall with vertical and horizontal zones delineated by white bands. All but three of the complete spears from Bentinck Island have charred black band decoration on the shafts (Spear Forms 2, 3 and 6) (Figure 57); two (Spear Form 3) are undecorated while the carved barb on one (Spear Form 3) is painted red with a white tip.

In summary, the Mainland Coast objects incorporate a variety of motifs while the motif repertory present in the Wellesley Islands is limited to band decoration. Motifs from the Mainland Coast set are applied to a range of objects using a variety of techniques which includes incising, notching, 'painting', and weaving. Motifs present on objects from the Wellesley Island set are all applied with pigment although the manner in which they are applied and the location on the object is different in the North and South Wellesley artefacts. Throughout the region, spears are commonly decorated, although the type of decoration is spatially distinct. Straight band motifs are a feature of the study area and could be categorised as a diagnostic stylistic trait of the southern Gulf region (Best 2003:156).

\section{Colours}

It has already been established that red pigment is present on many objects in the set. Here I look briefly at coloured motifs, that is to say colour present in an added design as opposed to the overall use of pigment on - for example, a waist ornament.

Again, within the set, spatial differences are evident. The Mainland Coast set incorporates designs in white, red and yellow applied pigments. Pituri bags from this set include blue, green and red bands produced from unpicked European blankets. Red and white only are present on Mornington Island while black is unique to Bentinck Island.

Table 15. Presence of motifs by Object Category.

\begin{tabular}{|c|c|c|c|c|c|c|c|c|c|c|c|}
\hline & \multicolumn{11}{|c|}{ Object Category } \\
\hline Motif & Bag & Boomerang & Club & Coolamon & $\begin{array}{c}\text { Head } \\
\text { Ornament }\end{array}$ & $\begin{array}{c}\text { Message } \\
\text { Stick }\end{array}$ & Pendant & Point & Spear & $\begin{array}{c}\text { Spear } \\
\text { Thrower }\end{array}$ & Total \\
\hline Arrow & 0 & 0 & 0 & 0 & 0 & 1 & 0 & 0 & 0 & 0 & 1 \\
\hline Cross & 0 & 0 & 0 & 0 & 0 & 2 & 0 & 0 & 0 & 0 & 2 \\
\hline Diagonal & 0 & 0 & 0 & 0 & 0 & 6 & 0 & 0 & 0 & 0 & 6 \\
\hline Diamond & 0 & 0 & 0 & 0 & 0 & 4 & 0 & 0 & 0 & 0 & 4 \\
\hline Dots & 0 & 0 & 0 & 0 & 0 & 2 & 0 & 0 & 0 & 0 & 2 \\
\hline Funnel & 0 & 0 & 0 & 0 & 0 & 2 & 0 & 0 & 0 & 0 & 2 \\
\hline Hatching & 0 & 0 & 0 & 0 & 0 & 0 & 0 & 0 & 6 & 0 & 6 \\
\hline Straight & 4 & 12 & 3 & 5 & 1 & 11 & 1 & 1 & 37 & 1 & 76 \\
\hline Tracks & 0 & 0 & 0 & 0 & 0 & 1 & 0 & 0 & 0 & 0 & 1 \\
\hline Zigzag & 0 & 0 & 0 & 0 & 0 & 5 & 0 & 0 & 1 & 0 & 6 \\
\hline Total & 4 & 12 & 3 & 5 & 1 & 34 & 1 & 1 & 44 & 1 & 106 \\
\hline
\end{tabular}


Table 16. Spatial distribution of motifs.

\begin{tabular}{|l|r|r|r|r|}
\hline & \multicolumn{5}{|c|}{ Geographical Zone } \\
\hline \multicolumn{1}{|c|}{ Motif } & Mainland Coast & North Wellesleys & \multicolumn{1}{c|}{ South Wellesleys } & \multicolumn{1}{c|}{ Total } \\
\hline Arrow & 1 & 0 & 0 & $\mathbf{1}$ \\
\hline Cross & 2 & 0 & 0 & $\mathbf{2}$ \\
\hline Diagonal & 6 & 0 & 0 & $\mathbf{6}$ \\
\hline Diamond & 4 & 0 & 0 & $\mathbf{4}$ \\
\hline Dots & 2 & 0 & 0 & $\mathbf{2}$ \\
\hline Funnel & 2 & 0 & 0 & $\mathbf{2}$ \\
\hline Hatching & 6 & 0 & 0 & $\mathbf{6}$ \\
\hline Straight & 56 & 8 & 12 & $\mathbf{7 6}$ \\
\hline Tracks & 1 & 0 & 0 & $\mathbf{1}$ \\
\hline Zigzag & 6 & 0 & 0 & $\mathbf{6}$ \\
\hline Total & $\mathbf{8 6}$ & $\mathbf{8}$ & $\mathbf{1 2}$ & $\mathbf{1 0 6}$ \\
\hline
\end{tabular}

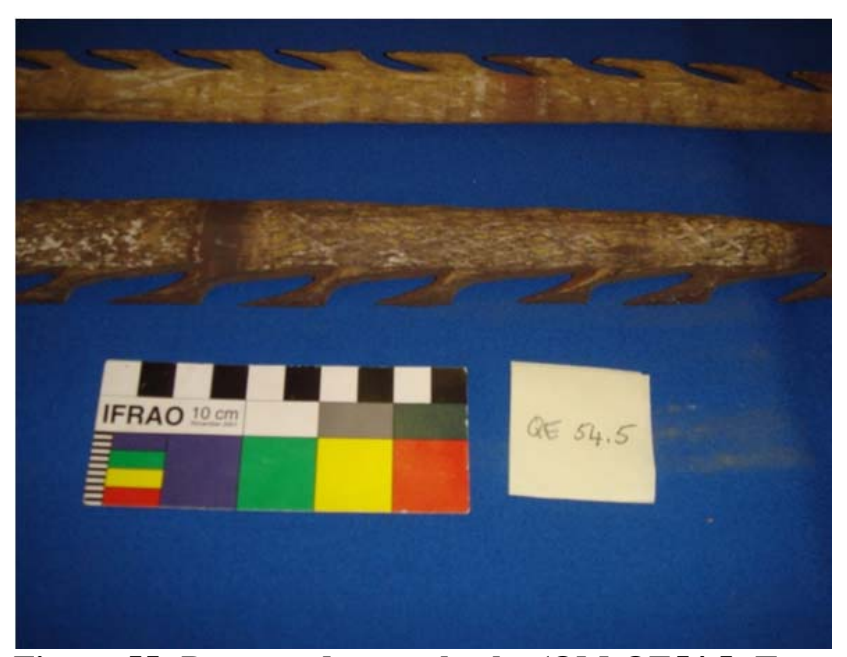

Figure 55. Decorated spear barbs (QM QE54.5, Turn Off Lagoon).

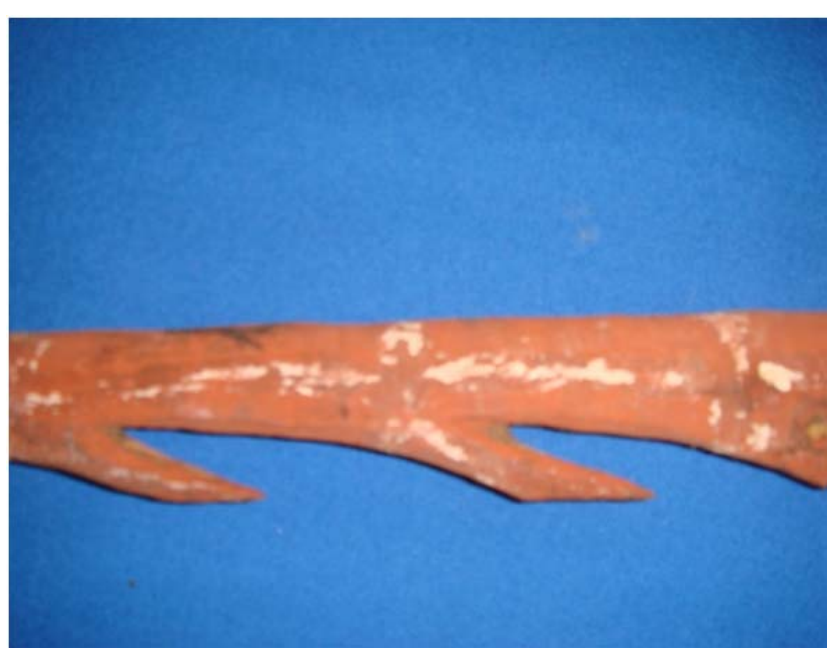

Figure 56. Decorated spear barbs (QM QE1112, Mornington Island).

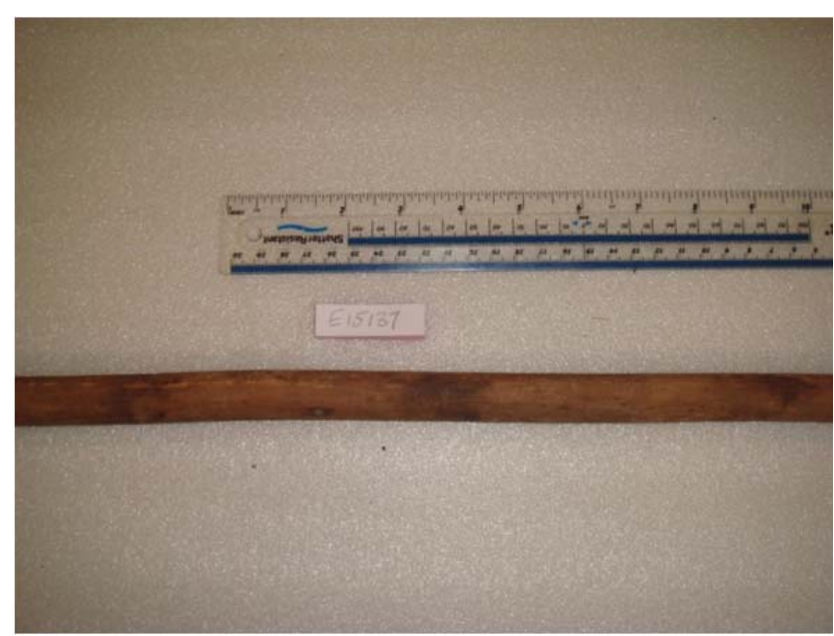

Figure 57. Black bands on spear shaft (AM E15137, Bentinck Island). 


\section{Discussion}

Analysis of portable objects originating from the Wellesley Islands and adjacent Mainland Coast has been carried out to address the following research questions:

- Can the data be said to represent a Saltwater material culture?

- Do spatial stylistic patterns suggest more than one cultural unit within the study area?

- What stylistic traits are common within the area and what are intraregionally unique?

- Can the Wellesley Islands be said to display an 'island style' which is different from a 'mainland style'?

- What are the contexts of those items which are common and those which are spatially bounded?

- What social and environmental factors can be said to affect the answers to the above?

Certain broad regional traits exist which set the data apart from more geographically distant material culture styles. These include the absence of shields (present in the Eyre region to the south) and vegetable fibre baskets (common in the Cape York region to the northeast), and the presence a number of traits including spears used with throwers, spear throwers with cylindrical shaft, a diagnostic hafting technique for spear shafts, knotting technique, widespread use of red pigment, banded motifs, and objects associated with a marine economy such as nets, paddles, and cordage. These broad regional traits could be said to confirm Trigger's (1987) claim for a Saltwater material culture. However, a conclusion from that data is that a Saltwater material culture can be said to represent a Saltwater economy in the study area - namely fisher-hunter-gatherers - and the objects that are associated with that lifeway, but the data do not demonstrate an identifiable Saltwater society or Saltwater culture as clearly a wide range of objects associated with social practices are absent from the South Wellesleys.

Quantitative analysis of the objects reveals distinct spatial distribution patterns within the study area which support the view that within this area, intraregional cultural traditions are visible at a finer-grained (Object Category, materials, decoration) level. A primary aim of these investigations is to identify similarities and differences between material culture styles of:

- The Mainland Coast and the Wellesley Islands

- The Mainland Coast and the North Wellesley Islands

- The North Wellesley Islands and the South Wellesley Islands

- The South Wellesley Islands and the Mainland Coast

- $\quad$ The Lardil, Yangkaal and Kaiadilt

\section{The Mainland Coast and the Wellesley Islands: Differences}

Artefacts from the coastal set demonstrate that a wider range of Object Categories, materials, styles and decorative motifs are present compared to those from the islands. Items and styles which are present on the coast but absent on the islands include message sticks, cylindrical spear throwers with added peg, stone point spears, pituri bags, hook boomerangs, fluted coolamons, stone blade knives, arm ornaments, neck ornaments, clap sticks, yellow pigment, fluting, gum resin and cement fixative, and the addition of twined string to the butt end of spears.

\section{The Mainland Coast and the North Wellesley Islands: Similarities}

The data reveal a range of styles are shared between the Mainland Coast and North Wellesley Islands but are absent in the South Wellesley Islands. These include painted boomerangs with white tips, waist ornaments, head ornaments, feather tufts, bound and wound pendants, macropod tooth decoration on headbands, multiple carved serrated wood barb spears, nets with no stick handles, small point tools, scraper tools ('planes') with metal blades, human hair string, red and white applied decoration and iron.

\section{The North Wellesley Islands and the South Wellesley Islands: Similarities and Differences}

None of the items listed above as being shared with the Mainland Coast and the North Wellesleys are present in the South Wellesleys. Items present in both the North and South Wellesleys include fire-making tools, pounders, 'fighting' sticks, 'digging' sticks, shell containers, and fishing nets. Unique to the North Wellesleys are line fishing, iron fish hooks, 'javelin' point spears, rope, large nets with stick handles, clam shell container, pleated bark containers and heavy wood pounders with integrated handles. Unique to the South Wellesleys are three spear forms - 2-prong spears with shallow barbs on one side, 3prong spears with shallow barbs carved on one side of the prong and multiple carved shallow wood barb spears, fish mandible artefacts, bark torches, trumpet shell containers, cylindrical pounders, black band decoration applied to spear shafts, technique of tying two spear shafts together with returned diagonal string knot. The data do not support Memmott et al.'s (2006) assertion that pleated bark containers are common to the material culture of North and South Wellesley Islands.

\section{The South Wellesley Islands and the Mainland Coast: Similarities}

Similarities between these two sets are limited to panregional traits including the presence of spears, paddles, cordage, nets, and spearthrowers. At a slightly finergrained level, nets with stick handles, cylindrical spear throwers with integrated carved peg, and fan-shaped paddles are present in both the Mainland Coast and South Wellesley Island sets. Both sets also include forms of pronged spears and spears with multiple carved barbs, however there are differences in the secondary morphological traits of these spears in that the Bentinck Island pronged spears have less sharp barbs while the multiple carved barb spears are undecorated. Likewise, although nets with stick handles are common to both sets, the forms of these nets differ. The nets from the Mainland Coast set have long handles and are triangular in shape while those from Bentinck Island have shorter handles and are more oval in shape (Figures 58-59). 


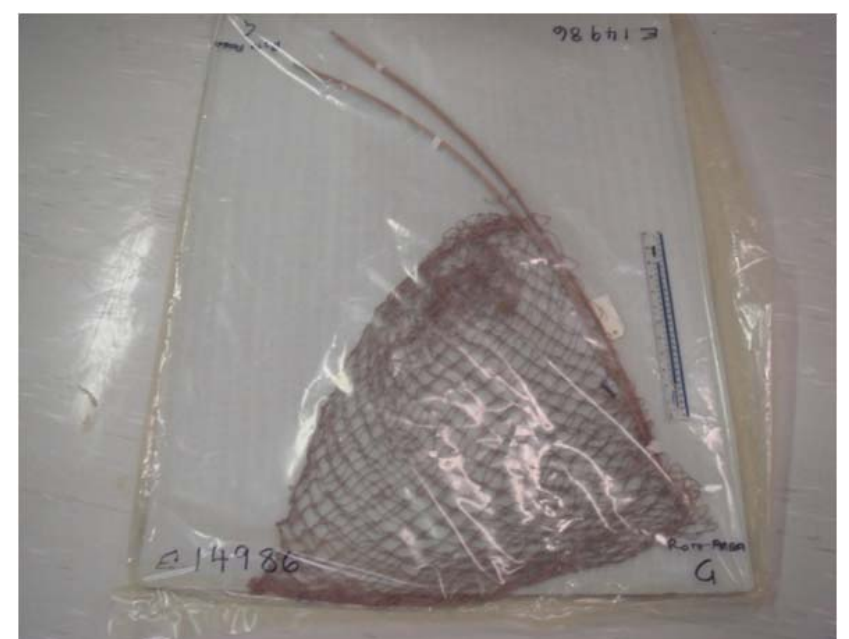

Figure 58. Net with stick handle (AM E14986, Burketown).

\section{Lardil, Yangkaal and Kaiadilt}

When the material culture assemblages of Mornington Island (Lardil, North Wellesleys), Forsyth Island (Yangkaal, North Wellesleys) and Bentinck Island (Kaiadilt, South Wellesleys) are reviewed some interesting spatial continuities and discontinuities are demonstrated.

Perhaps most surprising, is the absence of any type of object associated with personal ornament, or body decoration from the Yangkaal and Kaiadilt sets. Similarly an absence of boomerangs links the sets as well as the presence of pierced shell containers.

Objects common to both Lardil and Kaiadilt sets, but absent in the Yangkaal set are long 'fighting' sticks, shorter 'digging sticks', and the presence of spears.

Geographically proximate, it is unsurprising that the Lardil and Yangkaal sets share a range of common artefacts which are absent from the Kaiadilt set. These include 'cast nets' (nets without stick handles), oval shaped paddles, hook and line fishing, iron, vegetable fibre rope, large ovate wood pounders with integrated handle, fire sticks, and pleated bark containers.

In summary, the data show a far greater diversity of material culture styles in the Mainland Coast set; a significant quantity of shared traits within the Mainland Coast and the North Wellesley sets and a distinctly different group of objects in the South Wellesleys.

\section{Interpretation}

Although this study focuses on the style of portable objects it is set within known facts such as the existence of extensive exchange networks linking the Burketown area with neighbours to the south; the relative proximity of Mornington Island and the mainland via 'stepping stone' islands; the occurrence of shared initiation practices between Mornington Island and the mainland; a marine-based economy throughout the study area; different systems of social organisation and land-use in the North and South Wellesley Island groups; the relative geographical isolation of Bentinck Island; a more varied floral and faunal resource base present on Mornington Island than on Bentinck Island, including macropods and dingoes; and different languages on the adjacent coastal

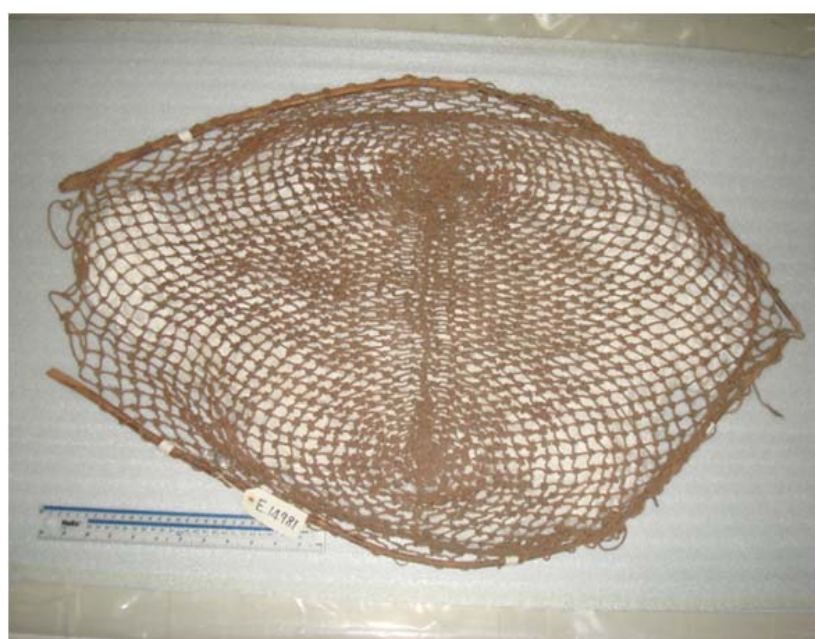

Figure 59. Net with stick handle (AM E14982, Bentinck Island).

mainland and Mornington, Forsyth, and Bentinck Islands. Against this background, the differences and similarities that have been demonstrated within the material culture can be looked at with the view to assess the part played by social and/or environmental factors in the spatial distribution of material culture style.

Social and environmental factors which affect the distribution of artefacts and the style of artefacts are numerous. They will include issues such as availability of resources, subsistence practices, physical communication or physical isolation. These in turn will facilitate or hinder the exchange of objects, materials, traditions and ideas. Within the study area degrees of spatial patterning are observable. Variations may be extreme and demonstrated through the absence of a particular category, such as European materials from the South Wellesleys. In other instances, variations may be shown through differences within a particular Object Category, such as spear forms.

Although social and environmental factors are likely to operate in parallel, social factors heavily influence the composition of the dataset.

Exchange networks described in Roth's bulletins connected communities within the Gulf drainage division and beyond. The composition of the Mainland Coast set includes a range of objects and styles which formed part of this network. These include pituri bags, hook boomerangs, clubs, stone knives and a wide range of personal adornment. All these objects are associated with personal identity, status and ceremony rather than subsistence. Message sticks, which are absent from the Wellesley Islands, are another manifestation of mainland community connections.

The male initiation practices shared between the Mainland Coast and North Wellesleys are responsible for a range of objects involving personal status such as body ornament, and weapons (boomerangs) which are completely absent in the South Wellesleys. The absence of this range of objects is likely to be a reason behind twentieth century observations on the 'impoverished' nature of the material culture of the South Wellesleys (e.g Tindale 1977). I do not see the material culture of the South Wellesleys as impoverished. It would seem that the material culture of Bentinck Island deals efficiently with 
intensification of marine resource exploitation, high population densities, access to restricted materials and a 'secular' social tradition (as compared with that of Mornington Island). There is no evidence of either objects or materials exchanged from the mainland to Bentinck Island. The shared nature of social practices as well as relative physical proximity may account for greater social communication between the Mainland Coast and North Wellesley groups resulting in the presence of a range of items either influenced by coastal styles (coolamons, boomerangs) or directly exchanged articles, such as European materials. Comparisons between the North Wellesley Island objects from Mornington and Forsyth islands suggest differences in social organisation and initiation practices on Forsyth Island (absence of body ornaments and boomerangs).

\section{Conclusion}

The predictions set out at the start of this study have been demonstrated by the data. These are that:

- $\quad$ Objects associated with personal identity are bounded geographically

- Objects associated with ceremony are bounded geographically

- $\quad$ Objects associated with subsistence are less bounded geographically

- Objects associated with exchange traverse their culture area

A range of objects connected with personal identity such as body ornaments and weapons have limited distributions. A large quantity of items associated with body decoration, are present in the Mainland Coast and North Wellesley sets (but absent on Forsyth and Bentinck Islands). However, within their limited general geographical distribution (Mainland Coast and Mornington Island) subsets exist. That is to say that a wider range of items of personal adornment is present on the Mainland Coast than on Mornington, where arm ornaments and neck ornaments are absent. Likewise a larger range of boomerang styles are similarly distributed.

Personal identity forms a component of ceremony and many items which are associated with personal identity are also connected with ceremony. For example human hair string waist ornaments, which have a Mainland Coast and Mornington Island distribution, can be worn by men just before and following the first initiation ceremony (Roth 1897:112-113, 118, 170, 172, 1901, 1903). It is known that the extent of the mainland practice of subincision, which forms the second male initiation, included the North Wellesleys (Memmott 2010) but not the South Wellesleys (for a description of initiation practices on the Gulf mainland, see Roth 1897:169-180).

The material culture of the study area is exemplified and unified by a limited range of artefacts. These include spears, spear throwers, nets, cordage and paddles. Banded decoration, knotting and the application of red pigment are also a feature of the region. Pan-regional objects are associated with subsistence. However, geographical style subsets exist at an intraregional level. Variations in the spatial distribution of the form and types of the above objects are demonstrated by the data.
A number of materials, objects and styles formed part of an extensive and well-documented mainland exchange network (see Roth 1897). Items associated with exchange include hook boomerangs, fluted objects, spears, stone knives, pituri and pituri bags. These items which are found in the Burketown (adjacent coastal) area are unlikely to have been made locally, but would have originated from beyond the study area, but still within the identified culture area of the Gulf drainage division.

In summary I conclude that objective quantification of pre-1916 museum data broadly confirm the work of Trigger (1987), Memmott (2010) and Memmott et al. (2006) in that they reveal a loosely connected regional style present within a restricted range of artefacts, as well as confirm that quantifiable differences are evident between the material culture of the North and South Wellesley Islands.

However, within the study region, three stylistic subunits or culture units are present. The differences between them are emphatic. The Mainland Coast set is by far the most varied in terms of numbers of Object Categories, materials and decoration. The Mornington Island set includes a sizeable range of artefacts which are either identical or influenced by the Mainland Coast set. The items concerned are those connected with personal identity, status and ceremony. Finally the Bentinck Island set has many unique features, which support the proposal of a generally isolated community which evolved its own social organisation (see Evans 1995).

It would be useful if these findings were compared and correlated with data from other disciplines such as archaeology and linguistics to form part of a wider enquiry on the way island populations in general, and the Wellesley Islands in particular are influenced by social and environmental factors.

Of wider interest would be to establish the physical boundaries of the loosely connected regional style identified here and by Trigger (1987). This would involve comparing the current data with that to the east (Cape York) to the south (southern Gulf and Eyre drainage divisions) and to see how far to the northwest of the Gulf region they persist. A number of objects present in the Wellesley Islands but absent from the adjacent Mainland Coast, are found in Cape York. These include pleated bark containers and heavy wood pounders.

Although imperfect, Queensland artefacts from museum collections that were collected during the early contact period and date prior to the major cultural disruptions which followed, provide a valuable resource. The findings of this study broadly correlate with the contemporary writings of Roth. Stylistic boundaries revealed by this study, were subsequently blurred in the Wellesleys following the setting up of the mission on Mornington Island and the later removal of the population from Bentinck Island to Mornington Island in 1948. Coastal populations were affected by the establishment of a mission at Doomadgee in 1933 and the movement of people inland which followed.

\section{Supplementary Information}

Supplementary information for this article is available at http://www.library.uq.edu.au/ojs/index.php/qar/. 


\section{Acknowledgements}

This research was supported under the Australian Research Council's (ARC) Discovery Projects funding scheme (project number DP0663047). We acknowledge the Kaiadilt, Lardil, Yangkaal and Gangalidda Traditional Owners of the Wellesley Islands as partners in this research project. The Gulf Region Aboriginal Corporation RNTBC collaborated in establishing the research framework for this project.

I would like to thank Professors Paul Memmott and Ian Lilley of The University of Queensland for asking me to carry out this study. Funding for the data collection and database design was provided by the ARC grant under the directorship of Professor Paul Memmott. The study would have been impossible without the support, cooperation, dedication and expertise of the museum staff at the Australian Museum, the British Museum and the Queensland Museum. In particular I would like to thank Stan Florek of the Anthropology Research Section, Australian Museum; Jill Hasell, Collections Manager, Oceania, Department of Africa, Oceania and the Americas, British Museum; and Trish Barnard, Senior Curator, Cultures and Histories at the Queensland Museum. The Archaeological Computing Research Group at Southampton University was responsible for the database design. My thanks to David Wheatley for the original design structure and in particular to Tom Brughmans for the detailed work and support that was given on the final database setup. Assistance with marine species identification was provided by Associate Professor Sean Ulm and Dr Dan Rosendahl (James Cook University). Annette Oertle (James Cook University) redrew the motifs in Appendix F.

\section{References}

Best, A. 2003 Regional Variation in the Material Culture of Hunter Gatherers: Social and Ecological Approaches to Ethnographic Objects from Queensland, Australia. BAR International Series 1149. Oxford: Archaeopress.

Clarke, D.L. 1968 Analytical Archaeology. London: Methuen.

Evans, N. 2005 East across a narrow sea: Micro-colonization and synthetic prehistory in the Wellesley Islands, northern Australia. In O. Toshiki (ed.), Linguistics, Archaeology and the Human Past, pp.9-39. Occasional Paper 1. Kyoto: Research Institute for Humanity and Nature.

Hamlyn-Harris, R. 1918 On messages and "message sticks" employed among the Queensland Aborigines. Memoirs of the Queensland Museum 5:13-36.

Hodder, I. 1982 Symbols in Action: Ethnoarchaeological Studies of Material Culture. Cambridge: Cambridge University Press.

Howitt, A.W. 1904 The Native Tribes of South East Australia. London: MacMillan.

Keogh, L. 2011 Dubiosa pituri: A natural history. Historical Records of Australian Science 22:199-214.

Khan, K. 2003 Catalogue of the Roth Collection of Aboriginal Artefacts from North Queensland. Vol. 3. Technical Reports of the Australian Museum 17. Sydney: Australian Museum.

Kroeber, A.L. 1947 Cultural and Natural Areas of Native North America. Los Angeles: University of California Press.

Lubar, S. and W.D. Kingery 1993 The History of Things: Essays on Material Culture. Washington, D.C.: Smithsonian Institution Press.

MacIntyre, J.N. 1920 White Australia: The Empty North, the Reasons and Remedy. Sydney: W.C. Penfold.

Memmott, P. 1982 The South Wellesley Islands and the Kaiadilt: A History and Analysis of the Significance of the
Land and its People. Unpublished manuscript, Aboriginal Data Archive, School of Architecture, University of Queensland.

Memmott, P. 2010 Material Culture of the North Wellesley Islands. Research Report Series 7. Brisbane: Aboriginal and Torres Strait Islander Unit, The University of Queensland.

Memmott, P., N. Evans, R. Robins and I. Lilley 2006 Understanding isolation and change in island human populations through a study of indigenous cultural patterns in the Gulf of Carpentaria. Transactions of the Royal Society of South Australia 130:29-47.

Memmott, P., R. Robins and E. Stock 2008 What exactly is a fish trap? Methodological issues for the study of Aboriginal intertidal rock wall fish traps, Wellesley Islands region, Gulf of Carpentaria, Australia. In J. Conolly and M. Campbell (eds), Comparative Island Archaeologies, pp.47-67. Oxford: Archaeopress.

Morphy, H. 1977 'Too Many Meanings': An Analysis of the Artistic System of the Yolngu of North-East Arnhem Land. Unpublished PhD thesis, Australian National University, Canberra.

Peterson, N. 1975 Hunter-gatherer territoriality: The perspective from Australia. American Anthropologist 77:53-69.

Peterson, N. 1976 The natural and cultural areas of Aboriginal Australia: A preliminary analysis of population groupings with adaptive significance. In N. Peterson (ed.), Tribes and Boundaries in Australia, pp.50-71. Social Anthropology Series 10. Canberra: Institute of Australian Aboriginal Studies.

Robins, R. 1990 A re-evaluation of the role of material cultural studies in museums. COMA 23:25-30.

Robins, R.P., E.C. Stock and D.S. Trigger 1998 Saltwater country, Saltwater people: Geomorphological, anthropological and archaeological investigations of coastal lands in the Gulf Country of Queensland. Memoirs of the Queensland Museum, Cultural Heritage Series 1(1):75-125.

Rosendahl, D. 2012 The Way it Changes Like the Shoreline and the Sea: The Archaeology of the Sandalwood River, Mornington Island, Southeast Gulf of Carpentaria, Australia. Unpublished PhD thesis, School of Architecture, The University of Queensland, Brisbane.

Roth, W.E. 1897 Ethnological Studies among the North-WestCentral Queensland Aborigines. Brisbane: Edmund Gregory

Roth, W.E. 1901 The Carpentaria blacks: The Wellesley Islands. Visit by Dr Roth. The Observer (Brisbane) 24 August 1901.

Roth, W.E. 1902 Games, Sports and Amusements. North Queensland Ethnography Bulletin 4. Brisbane: Government Printer.

Roth, W.E. 1903 Third Visit to the Wellesley Islands June 11-24 June 1903, Unpublished report.

Roth, W.E. 1904 Domestic Implements, Arts and Manufactures. North Queensland Ethnography Bulletin 7. Brisbane: Government Printer.

Roth, W.E. 1905 Government, Morals and Crime. North Queensland Ethnography Bulletin 8. Brisbane: Government Printer.

Roth, W.E. 1909 Fighting Weapons. North Queensland Ethnography Bulletin 13. Sydney: Records of the Australian Museum. 
Roth, W.E. 1910 Transport and Trade. North Queensland Ethnography Bulletin 14. Sydney: Records of the Australian Museum.

Tindale, N.B. 1949 Large biface implements from Mornington Island, Queensland and from south Western Australia. Records of the South Australia Museum 9:157-163.

Tindale, N.B. 1962 Geographical knowledge of the Kaiadilt people of Bentinck Island, Queensland. Records of the South Australia Museum 14:259-296.

Tindale, N.B. 1974 Aboriginal Tribes of Australia: Their Terrain, Environmental Controls, Distribution, Limits and Proper Names. Berkeley: University of California Press.

Tindale, N.B. 1977 Further report on the Kaiadilt people of Bentinck Island, Gulf of Carpentaria, Queensland. In J. Allen, J. Golson and R. Jones (eds), Sunda and Sahul: Prehistoric Studies in Southeast Asia, Melanesia and Australia, pp.247-273. London: Academic Press.

Trigger, D.S. 1987 Inland, coast and islands: Traditional Aboriginal society and material culture in a region of the southern Gulf of Carpentaria. Records of the South Australian Museum 21(2):69-84.
Ulm, S., N. Evans, D. Rosendahl, P. Memmott and F. Petchey 2010 Radiocarbon and linguistic dates for occupation of the South Wellesley Islands, northern Australia. Archaeology in Oceania 45(1):39-43.

Wiessner, P. 1983 Style and social information in Kalahari San projectile points. American Antiquity 48:253-276.

Wiessner, P. 1984 Reconsidering the behavioural basis for style: A case study among the Kalahari San. Journal of Anthropological Archaeology 3:190-234.

Wobst, H.M. 1977 Stylistic behaviour and information exchange. In C.E. Cleland (ed.), For the Director: Research Essays in Honor of James B. Griffin, pp.317-342. Anthropological Papers 61. Ann Arbor, MI: Museum of Anthropology, University of Michigan.

Wobst, H.M. 1999 Style in archaeology or archaeologists in style. In E.S. Chilton (ed.), Material Meanings: Critical Approaches to the Interpretation of Material Culture, pp.93107. Salt Lake City: University of Utah Press. 


\section{Appendix A. Composition of the dataset.}

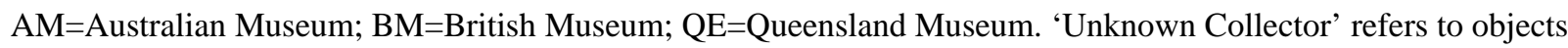
donated to museums by donors who did not necessarily collect the objects (see Tables 1-2).

\begin{tabular}{|c|c|c|c|}
\hline Accession No. & Collector & Geographical Zone & Object Category \\
\hline BM Q73 Oc18 & A.C. Gregory & 1=Mainland Coast & paddle \\
\hline BM 9125 & R.O. Burke \& W.J. Wills & 1=Mainland Coast & stone blade \\
\hline AM E11840 & Charles Hedley & 2=North Wellesleys & bark container \\
\hline AM E11842 & Charles Hedley & 2=North Wellesleys & bark container \\
\hline AM E11858 & Charles Hedley & 2=North Wellesleys & cordage \\
\hline AM E11844 & Charles Hedley & $2=$ North Wellesleys & fire-making tools \\
\hline AM E11848 & Charles Hedley & $2=$ North Wellesleys & pounder \\
\hline AM E11845 & Charles Hedley & 2=North Wellesleys & scraper \\
\hline AM E11843 & Charles Hedley & 2=North Wellesleys & shell container \\
\hline AM E11832 & Charles Hedley & 3=South Wellesleys & fire-making tools \\
\hline AM E11825 & Charles Hedley & 3=South Wellesleys & net \\
\hline AM E11834 & Charles Hedley & 3=South Wellesleys & mixed media bundle \\
\hline AM E11823 & Charles Hedley & 3=South Wellesleys & shell container \\
\hline AM E11822 & Charles Hedley & 3=South Wellesleys & shell container \\
\hline AM E11827 & Charles Hedley & 3=South Wellesleys & shell tool \\
\hline AM E11826 & Charles Hedley & 3=South Wellesleys & shell tool \\
\hline AM E11831 & Charles Hedley & 3=South Wellesleys & spear \\
\hline AM E11830 & Charles Hedley & 3=South Wellesleys & spear \\
\hline AM E11829 & Charles Hedley & 3=South Wellesleys & spear \\
\hline AM E11821 & Charles Hedley & 3=South Wellesleys & stick tool \\
\hline AM E11836 & Charles Hedley & 3=South Wellesleys & stick tool \\
\hline QE 765 & Constable Martin & 1=Mainland Coast & boomerang \\
\hline QE 769 & Constable Martin & 1=Mainland Coast & boomerang \\
\hline QE 767 & Constable Martin & 1=Mainland Coast & boomerang \\
\hline QE 766 & Constable Martin & 1=Mainland Coast & boomerang \\
\hline QE 776 & Constable Martin & 1=Mainland Coast & coolamon \\
\hline QE 775 & Constable Martin & 1=Mainland Coast & coolamon \\
\hline QE 15-773 & Constable Martin & 1=Mainland Coast & head ornament \\
\hline QE 50.6 & Constable Martin & 1=Mainland Coast & necklet \\
\hline QE 772 & Constable Martin & 1=Mainland Coast & waist ornament \\
\hline QE 49-1 & Constable W.E. Smith & 1=Mainland Coast & armlet \\
\hline QE 49.2 & Constable W.E. Smith & 1=Mainland Coast & armlet \\
\hline QE 33.1 QE 33.2 & Constable W.E. Smith & 1=Mainland Coast & clap sticks \\
\hline QE 51 & Constable W.E. Smith & 1=Mainland Coast & coolamon \\
\hline QE 40.1 & Constable W.E. Smith & 1=Mainland Coast & feather tuft \\
\hline QE 48.2 & Constable W.E. Smith & 1=Mainland Coast & head ornament \\
\hline QE 48.1 & Constable W.E. Smith & 1=Mainland Coast & head ornament \\
\hline QE 48.3 & Constable W.E. Smith & 1=Mainland Coast & head ornament \\
\hline QE 48.4 & Constable W.E. Smith & 1=Mainland Coast & head ornament \\
\hline QE 50.10 & Constable W.E. Smith & 1=Mainland Coast & necklet \\
\hline QE 50.9 & Constable W.E. Smith & 1=Mainland Coast & necklet \\
\hline QE 50.8 & Constable W.E. Smith & 1=Mainland Coast & necklet \\
\hline QE 50.7 & Constable W.E. Smith & 1=Mainland Coast & necklet \\
\hline QE 50.4 & Constable W.E. Smith & 1=Mainland Coast & necklet \\
\hline QE 43 & Constable W.E. Smith & 1=Mainland Coast & necklet \\
\hline QE 50.3 & Constable W.E. Smith & 1=Mainland Coast & necklet \\
\hline QE 50.2 & Constable W.E. Smith & 1=Mainland Coast & necklet \\
\hline QE 50.1 & Constable W.E. Smith & 1=Mainland Coast & necklet \\
\hline QE 50.5 & Constable W.E. Smith & 1=Mainland Coast & necklet \\
\hline QE 771 & Constable W.E. Smith & 1=Mainland Coast & necklet \\
\hline QE 42.1 & Constable W.E. Smith & 1=Mainland Coast & necklet \\
\hline QE 42.2 & Constable W.E. Smith & 1=Mainland Coast & necklet \\
\hline QE 52.1 & Constable W.E. Smith & 1=Mainland Coast & shell tool \\
\hline QE 52.2 & Constable W.E. Smith & 1=Mainland Coast & shell tool \\
\hline QE 54.5 & Constable W.E. Smith & 1=Mainland Coast & spear \\
\hline QE 54.1 & Constable W.E. Smith & 1=Mainland Coast & spear \\
\hline QE 54.6 & Constable W.E. Smith & 1=Mainland Coast & spear \\
\hline QE 54.4 & Constable W.E. Smith & 1=Mainland Coast & spear \\
\hline QE 54.2 & Constable W.E. Smith & 1=Mainland Coast & spear \\
\hline QE 53.2 & Constable W.E. Smith & 1=Mainland Coast & spear \\
\hline QE 53.3 & Constable W.E. Smith & 1=Mainland Coast & spear \\
\hline QE 54.3 & Constable W.E. Smith & 1=Mainland Coast & spear \\
\hline
\end{tabular}




\begin{tabular}{|c|c|c|c|}
\hline Accession No. & Collector & Geographical Zone & Object Category \\
\hline QE 36.2 & Constable W.E. Smith & 1=Mainland Coast & stick \\
\hline QE 34 & Constable W.E. Smith & 1=Mainland Coast & stick \\
\hline QE 35 & Constable W.E. Smith & 1=Mainland Coast & stick \\
\hline QE 36.1 & Constable W.E. Smith & 1=Mainland Coast & stick \\
\hline QE 55-4 & Constable W.E. Smith & 1=Mainland Coast & thrower \\
\hline AM E32081 & Dr W. Chisholm & 1=Mainland Coast & net \\
\hline AM E32083 & Dr W. Chisholm & 1=Mainland Coast & stone blade \\
\hline AM E32082 & Dr W. Chisholm & 1=Mainland Coast & stone blade \\
\hline QE 16/1931 & J.N. MacIntyre & 1=Mainland Coast & stick \\
\hline QE 928 & J.N. MacIntyre & 1=Mainland Coast & stick \\
\hline QE 929 & J.N. MacIntyre & 1=Mainland Coast & stick \\
\hline QE 930 & J.N. MacIntyre & 1=Mainland Coast & stick \\
\hline QE 438 & Mornington Island Mission & 2=North Wellesleys & boomerang \\
\hline QE 450 & Mornington Island Mission & 2=North Wellesleys & net \\
\hline QE 4561 & Mornington Island Mission & $2=$ North Wellesleys & paddle \\
\hline QE 9926 & Mornington Island Mission & $2=$ North Wellesleys & thrower \\
\hline QE 9927 & Mornington Island Mission & $2=$ North Wellesleys & thrower \\
\hline QE 1121 & Robert Hall & 2=North Wellesleys & bark container \\
\hline QE 1120 & Robert Hall & $2=$ North Wellesleys & bark container \\
\hline QE 1110 & Robert Hall & 2=North Wellesleys & boomerang \\
\hline QE 1108 & Robert Hall & $2=$ North Wellesleys & boomerang \\
\hline QE 1109 & Robert Hall & 2=North Wellesleys & boomerang \\
\hline QE 1099 & Robert Hall & $2=$ North Wellesleys & feather tuft \\
\hline QE 1100 & Robert Hall & $2=$ North Wellesleys & head ornament \\
\hline QE 1111 & Robert Hall & 2=North Wellesleys & line fishing \\
\hline QE 1102 & Robert Hall & $2=$ North Wellesleys & net \\
\hline QE 1104 & Robert Hall & 2=North Wellesleys & paddle \\
\hline QE 1119 & Robert Hall & 2=North Wellesleys & pounder \\
\hline QE 1105 & Robert Hall & 2=North Wellesleys & spear \\
\hline QE 1107.1 & Robert Hall & 2=North Wellesleys & spear \\
\hline QE 1112 & Robert Hall & $2=$ North Wellesleys & spear \\
\hline QE 1107.2 & Robert Hall & $2=$ North Wellesleys & spear \\
\hline QE 1115 & Robert Hall & 2=North Wellesleys & stick tool \\
\hline QE 1114 & Robert Hall & 2=North Wellesleys & stick tool \\
\hline QE 1113 & Robert Hall & $2=$ North Wellesleys & thrower \\
\hline QE 1098 & Robert Hall & 2=North Wellesleys & waist ornament \\
\hline QE 1101 & Robert Hall & 2=North Wellesleys & waist ornament \\
\hline QE 1097 & Robert Hall & $2=$ North Wellesleys & waist ornament \\
\hline QE 1096 & Robert Hall & $2=$ North Wellesleys & waist ornament \\
\hline BM 1901 12-21.16 & R. Christison & 1=Mainland Coast & stick \\
\hline BM 1901 12-21.19 & R. Christison & 1=Mainland Coast & stick \\
\hline QE 6022 & Stephen Buhot & 1=Mainland Coast & necklet \\
\hline QE 6276 & Unknown & 1=Mainland Coast & armlet \\
\hline QE 1800-1 & Unknown & 1=Mainland Coast & armlet \\
\hline QE 1800-3 & Unknown & 1=Mainland Coast & armlet \\
\hline QE 1799-1 & Unknown & 1=Mainland Coast & armlet \\
\hline QE 1800-2 & Unknown & 1=Mainland Coast & armlet \\
\hline QE 1799-3 & Unknown & 1=Mainland Coast & armlet \\
\hline BM 5250 & Unknown & 1=Mainland Coast & club \\
\hline BM +5231 & Unknown & 1=Mainland Coast & coolamon \\
\hline BM +5233 & Unknown & 1=Mainland Coast & coolamon \\
\hline BM +5232 & Unknown & 1=Mainland Coast & coolamon \\
\hline AM E17647 & Unknown & 1=Mainland Coast & cordage \\
\hline BM +5243 & Unknown & 1=Mainland Coast & head ornament \\
\hline BM 5238 & Unknown & 1=Mainland Coast & head ornament \\
\hline BM 5237 & Unknown & 1=Mainland Coast & head ornament \\
\hline BM +5245 & Unknown & 1=Mainland Coast & necklet \\
\hline BM +5244 & Unknown & 1=Mainland Coast & necklet \\
\hline BM +5241 & Unknown & 1=Mainland Coast & necklet \\
\hline BM +5239 & Unknown & 1=Mainland Coast & necklet \\
\hline BM +5242 & Unknown & 1=Mainland Coast & necklet \\
\hline BM +5246 & Unknown & 1=Mainland Coast & pendant \\
\hline BM +5247 & Unknown & 1=Mainland Coast & pendant \\
\hline BM +5248 & Unknown & 1=Mainland Coast & pendant \\
\hline AM E17645 & Unknown & 1=Mainland Coast & stone blade \\
\hline BM +5234 & Unknown & 1=Mainland Coast & waist ornament \\
\hline BM +5235 & Unknown & 1=Mainland Coast & waist ornament \\
\hline
\end{tabular}




\begin{tabular}{|c|c|c|c|}
\hline Accession No. & Collector & Geographical Zone & Object Category \\
\hline BM +5236 & Unknown & 1=Mainland Coast & waist ornament \\
\hline BM 5240 & Unknown & 1=Mainland Coast & waist ornament \\
\hline QE E445 & Unknown & 2=North Wellesleys & cordage \\
\hline QE 11458 & Unknown & 2=North Wellesleys & hair string skein \\
\hline QE E449 & Unknown & 2=North Wellesleys & stick tool \\
\hline QE 439 & Unknown & $2=$ North Wellesleys & stick tool \\
\hline AM E14723 & W.E. Roth & 1=Mainland Coast & armlet \\
\hline AM E14722 & W.E. Roth & 1=Mainland Coast & armlet \\
\hline AM E14742 & W.E. Roth & 1=Mainland Coast & armlet \\
\hline AM E14741 & W.E. Roth & 1=Mainland Coast & armlet \\
\hline AM E14258 & W.E. Roth & 1=Mainland Coast & boomerang \\
\hline AM E14234 & W.E. Roth & 1=Mainland Coast & boomerang \\
\hline AM E14256 & W.E. Roth & 1=Mainland Coast & boomerang \\
\hline AM E14228 & W.E. Roth & 1=Mainland Coast & boomerang \\
\hline AM E14261 & W.E. Roth & 1=Mainland Coast & boomerang \\
\hline AM E14245 & W.E. Roth & 1=Mainland Coast & boomerang \\
\hline AM E14244 & W.E. Roth & 1=Mainland Coast & boomerang \\
\hline AM E14257 & W.E. Roth & 1=Mainland Coast & boomerang \\
\hline AM E14262 & W.E. Roth & 1=Mainland Coast & boomerang \\
\hline AM E14236 & W.E. Roth & 1=Mainland Coast & boomerang \\
\hline AM E14259 & W.E. Roth & 1=Mainland Coast & boomerang \\
\hline AM E14225 & W.E. Roth & 1=Mainland Coast & boomerang \\
\hline AM E14237 & W.E. Roth & 1=Mainland Coast & boomerang \\
\hline AM E14235 & W.E. Roth & 1=Mainland Coast & boomerang \\
\hline AM E14233 & W.E. Roth & 1=Mainland Coast & boomerang \\
\hline AM E14249 & W.E. Roth & 1=Mainland Coast & boomerang \\
\hline AM E14251 & W.E. Roth & 1=Mainland Coast & boomerang \\
\hline AM E14242 & W.E. Roth & 1=Mainland Coast & boomerang \\
\hline AM E14260 & W.E. Roth & 1=Mainland Coast & boomerang \\
\hline AM E14248 & W.E. Roth & 1=Mainland Coast & boomerang \\
\hline AM E14199 & W.E. Roth & 1=Mainland Coast & boomerang \\
\hline AM E14192 & W.E. Roth & 1=Mainland Coast & boomerang \\
\hline AM E14250 & W.E. Roth & 1=Mainland Coast & boomerang \\
\hline AM E15049 & W.E. Roth & 1=Mainland Coast & club \\
\hline AM E13359 & W.E. Roth & 1=Mainland Coast & coolamon \\
\hline AM E14393 & W.E. Roth & 1=Mainland Coast & feather tuft \\
\hline AM E14638 & W.E. Roth & 1=Mainland Coast & hair string skein \\
\hline AM E14637 & W.E. Roth & 1=Mainland Coast & hair string skein \\
\hline AM E14572 & W.E. Roth & 1=Mainland Coast & head ornament \\
\hline AM E14724 & W.E. Roth & 1=Mainland Coast & head ornament \\
\hline AM E14573 & W.E. Roth & 1=Mainland Coast & head ornament \\
\hline AM E14571 & W.E. Roth & 1=Mainland Coast & head ornament \\
\hline AM E14473 & W.E. Roth & 1=Mainland Coast & necklet \\
\hline AM E14474 & W.E. Roth & 1=Mainland Coast & necklet \\
\hline AM E14592 & W.E. Roth & 1=Mainland Coast & necklet \\
\hline AM E14591 & W.E. Roth & 1=Mainland Coast & necklet \\
\hline AM E14543 & W.E. Roth & 1=Mainland Coast & necklet \\
\hline AM E14587 & W.E. Roth & 1=Mainland Coast & necklet \\
\hline AM E14595 & W.E. Roth & 1=Mainland Coast & necklet \\
\hline AM E14590 & W.E. Roth & 1=Mainland Coast & necklet \\
\hline AM E14594 & W.E. Roth & 1=Mainland Coast & necklet \\
\hline AM E14985 & W.E. Roth & 1=Mainland Coast & net \\
\hline AM E14962 & W.E. Roth & 1=Mainland Coast & net \\
\hline AM E14986 & W.E. Roth & 1=Mainland Coast & net \\
\hline AM E14968 & W.E. Roth & 1=Mainland Coast & net \\
\hline AM E14967 & W.E. Roth & 1=Mainland Coast & net \\
\hline AM E14718 & W.E. Roth & 1=Mainland Coast & pendant \\
\hline AM E14717 & W.E. Roth & 1=Mainland Coast & pendant \\
\hline AM E14719 & W.E. Roth & 1=Mainland Coast & pendant \\
\hline AM E13891 & W.E. Roth & 1=Mainland Coast & point \\
\hline AM E15101 & W.E. Roth & 1=Mainland Coast & spear \\
\hline AM E15106 & W.E. Roth & 1=Mainland Coast & spear \\
\hline AM E15100 & W.E. Roth & 1=Mainland Coast & spear \\
\hline AM E13416 & W.E. Roth & 1=Mainland Coast & stick \\
\hline AM E13419 & W.E. Roth & 1=Mainland Coast & stick \\
\hline AM E14379 & W.E. Roth & 1=Mainland Coast & thrower \\
\hline AM E14373 & W.E. Roth & 1=Mainland Coast & thrower \\
\hline
\end{tabular}




\begin{tabular}{|c|c|c|c|}
\hline Accession No. & Collector & Geographical Zone & Object Category \\
\hline AM E14381 & W.E. Roth & 1=Mainland Coast & thrower \\
\hline AM E14378 & W.E. Roth & 1=Mainland Coast & thrower \\
\hline AM E14369 & W.E. Roth & 1=Mainland Coast & thrower \\
\hline AM E14632 & W.E. Roth & 1=Mainland Coast & waist ornament \\
\hline AM E14634 & W.E. Roth & 1=Mainland Coast & waist ornament \\
\hline AM E14631 & W.E. Roth & 1=Mainland Coast & waist ornament \\
\hline AM E14684 & W.E. Roth & 1=Mainland Coast & waist ornament \\
\hline AM E14635 & W.E. Roth & 1=Mainland Coast & waist ornament \\
\hline AM E14683 & W.E. Roth & 1=Mainland Coast & waist ornament \\
\hline AM E14647 & W.E. Roth & 1=Mainland Coast & waist ornament \\
\hline AM E14649 & W.E. Roth & 1=Mainland Coast & waist ornament \\
\hline AM E14720 & W.E. Roth & 1=Mainland Coast & waist ornament \\
\hline AM E14716 & W.E. Roth & 1=Mainland Coast & waist ornament \\
\hline AM E13329 & W.E. Roth & 2=North Wellesleys & bark container \\
\hline AM E13330 & W.E. Roth & $2=$ North Wellesleys & bark container \\
\hline AM E13333 & W.E. Roth & 2=North Wellesleys & bark container \\
\hline AM E13328 & W.E. Roth & 2=North Wellesleys & bark container \\
\hline AM E13332 & W.E. Roth & 2=North Wellesleys & bark container \\
\hline AM E13334 & W.E. Roth & 2=North Wellesleys & bark container \\
\hline AM E14270 & W.E. Roth & $2=$ North Wellesleys & boomerang \\
\hline AM E14271 & W.E. Roth & 2=North Wellesleys & boomerang \\
\hline AM E13361 & W.E. Roth & 2=North Wellesleys & coolamon \\
\hline AM E11360 & W.E. Roth & 2=North Wellesleys & coolamon \\
\hline AM E14756 & W.E. Roth & 2=North Wellesleys & cordage \\
\hline AM E14755 & W.E. Roth & $2=$ North Wellesleys & cordage \\
\hline AM E14754 & W.E. Roth & 2=North Wellesleys & cordage \\
\hline AM E14757 & W.E. Roth & $2=$ North Wellesleys & cordage \\
\hline AM E14759 & W.E. Roth & 2=North Wellesleys & cordage \\
\hline AM E14758 & W.E. Roth & 2=North Wellesleys & cordage \\
\hline AM E13798 & W.E. Roth & $2=$ North Wellesleys & fire-making tools \\
\hline AM E13796 & W.E. Roth & $2=$ North Wellesleys & fire-making tools \\
\hline AM E13797 & W.E. Roth & 2=North Wellesleys & fire-making tools \\
\hline AM E14549 & W.E. Roth & 2=North Wellesleys & head ornament \\
\hline AM E13882 & W.E. Roth & 2=North Wellesleys & line fishing \\
\hline AM E13880 & W.E. Roth & 2=North Wellesleys & line fishing \\
\hline AM E13881 & W.E. Roth & 2=North Wellesleys & line fishing \\
\hline AM E14966 & W.E. Roth & 2=North Wellesleys & net \\
\hline AM E14963 & W.E. Roth & 2=North Wellesleys & net \\
\hline AM E13464 & W.E. Roth & 2=North Wellesleys & paddle \\
\hline AM E13697 & W.E. Roth & 2=North Wellesleys & pendant \\
\hline AM E13698 & W.E. Roth & $2=$ North Wellesleys & pendant \\
\hline AM E13907 & W.E. Roth & 2=North Wellesleys & point \\
\hline AM E13906 & W.E. Roth & $2=$ North Wellesleys & point \\
\hline AM E13897 & W.E. Roth & 2=North Wellesleys & point \\
\hline AM E13896 & W.E. Roth & 2=North Wellesleys & point \\
\hline AM E13475 & W.E. Roth & $2=$ North Wellesleys & pounder \\
\hline AM E13474 & W.E. Roth & 2=North Wellesleys & pounder \\
\hline AM E13472 & W.E. Roth & $2=$ North Wellesleys & pounder \\
\hline AM E13473 & W.E. Roth & 2=North Wellesleys & pounder \\
\hline AM E13944 & W.E. Roth & 2=North Wellesleys & scraper \\
\hline AM E13943 & W.E. Roth & 2=North Wellesleys & scraper \\
\hline AM E13343 & W.E. Roth & 2=North Wellesleys & shell container \\
\hline AM E13345 & W.E. Roth & 2=North Wellesleys & shell container \\
\hline AM E13925 & W.E. Roth & 2=North Wellesleys & stick tool \\
\hline AM E13924 & W.E. Roth & 2=North Wellesleys & stick tool \\
\hline AM E13929 & W.E. Roth & 2=North Wellesleys & stick tool \\
\hline AM E13491 & W.E. Roth & $2=$ North Wellesleys & stone point \\
\hline AM E13494 & W.E. Roth & 2=North Wellesleys & stone point \\
\hline AM E13489 & W.E. Roth & 2=North Wellesleys & stone point \\
\hline AM E14384 & W.E. Roth & 2=North Wellesleys & thrower \\
\hline AM E14386 & W.E. Roth & 2=North Wellesleys & thrower \\
\hline AM E14387 & W.E. Roth & $2=$ North Wellesleys & thrower \\
\hline AM E14385 & W.E. Roth & $2=$ North Wellesleys & thrower \\
\hline AM E14628 & W.E. Roth & 2=North Wellesleys & waist ornament \\
\hline AM E14709 & W.E. Roth & 2=North Wellesleys & waist ornament \\
\hline AM E14711 & W.E. Roth & 2=North Wellesleys & waist ornament \\
\hline AM E14712 & W.E. Roth & 2=North Wellesleys & waist ornament \\
\hline
\end{tabular}




\begin{tabular}{|c|c|c|c|}
\hline Accession No. & Collector & Geographical Zone & Object Category \\
\hline AM E14682 & W.E. Roth & 2=North Wellesleys & waist ornament \\
\hline AM E14710 & W.E. Roth & 2=North Wellesleys & waist ornament \\
\hline QE 1921.1 & W.E. Roth & 3=South Wellesleys & cordage \\
\hline QE 1921.2 & W.E. Roth & 3=South Wellesleys & cordage \\
\hline AM E13868 & W.E. Roth & 3=South Wellesleys & fish mandible \\
\hline AM E13867 & W.E. Roth & 3=South Wellesleys & fish mandible \\
\hline AM E13966 & W.E. Roth & 3=South Wellesleys & fish mandible \\
\hline AM E13865 & W.E. Roth & 3=South Wellesleys & fish mandible \\
\hline AM E14979 & W.E. Roth & 3=South Wellesleys & net \\
\hline AM E14982 & W.E. Roth & $3=$ South Wellesleys & net \\
\hline AM E14981 & W.E. Roth & 3=South Wellesleys & net \\
\hline AM E14976 & W.E. Roth & 3=South Wellesleys & net \\
\hline AM E14980 & W.E. Roth & 3=South Wellesleys & net \\
\hline AM E13462 & W.E. Roth & 3=South Wellesleys & paddle \\
\hline AM E13479 & W.E. Roth & 3=South Wellesleys & pounder \\
\hline AM E13477 & W.E. Roth & 3=South Wellesleys & pounder \\
\hline AM E13344 & W.E. Roth & 3=South Wellesleys & shell container \\
\hline AM E13346 & W.E. Roth & 3=South Wellesleys & shell container \\
\hline AM E13347 & W.E. Roth & $3=$ South Wellesleys & shell container \\
\hline AM E15138 & W.E. Roth & 3=South Wellesleys & spear \\
\hline AM E15141 & W.E. Roth & $3=$ South Wellesleys & spear \\
\hline AM E15142 & W.E. Roth & 3=South Wellesleys & spear \\
\hline AM E15140 & W.E. Roth & 3=South Wellesleys & spear \\
\hline AM E15147 & W.E. Roth & 3=South Wellesleys & spear \\
\hline QE 2492 & W.E. Roth & 3=South Wellesleys & spear \\
\hline AM E15144 & W.E. Roth & $3=$ South Wellesleys & spear \\
\hline AM E15146 & W.E. Roth & $3=$ South Wellesleys & spear \\
\hline AM E15145 & W.E. Roth & 3=South Wellesleys & spear \\
\hline AM E15148 & W.E. Roth & 3=South Wellesleys & spear \\
\hline AM E15137 & W.E. Roth & 3=South Wellesleys & spear \\
\hline AM E15139 & W.E. Roth & $3=$ South Wellesleys & spear \\
\hline AM E15135-001 & W.E. Roth & 3=South Wellesleys & spear \\
\hline AM E15136 & W.E. Roth & 3=South Wellesleys & spear \\
\hline AM E15008 & W.E. Roth & 3=South Wellesleys & stick tool \\
\hline AM E14272 & W.E. Roth & 3=South Wellesleys & stick tool \\
\hline AM E15010 & W.E. Roth & 3=South Wellesleys & stick tool \\
\hline AM E13476 & W.E. Roth & $3=$ South Wellesleys & stick tool \\
\hline AM E13478 & W.E. Roth & 3=South Wellesleys & stick tool \\
\hline AM E15009 & W.E. Roth & 3=South Wellesleys & stick tool \\
\hline AM E14383 & W.E. Roth & 3=South Wellesleys & thrower \\
\hline AM E14382 & W.E. Roth & 3=South Wellesleys & thrower \\
\hline BM 97-637 & William E. Finucane & 1=Mainland Coast & bag \\
\hline BM 97-636 & William E. Finucane & 1=Mainland Coast & bag \\
\hline BM Q80 Oc691 & William E. Finucane & 1=Mainland Coast & bag \\
\hline BM 97-634 & William E. Finucane & 1=Mainland Coast & bag \\
\hline QE 4051 & Clement Lindley Wragge & 1=Mainland Coast & thrower \\
\hline
\end{tabular}


Appendix B. Data entry form showing data variables.

\begin{tabular}{|c|c|c|}
\hline Data Section & Data Variable & Glossary of Data Variable \\
\hline Museum Record & $\begin{array}{l}\text { Accession Number } \\
\text { Date of Acquisition } \\
\text { Collector } \\
\text { Donor } \\
\text { Provenance } \\
\text { Geographical Zone } \\
\text { Language Zone } \\
\text { Cultural Group }\end{array}$ & $\begin{array}{l}\text { Unique museum record number } \\
\text { Date that the object was acquired by the } \\
\text { museum } \\
\text { Name of original collector } \\
\text { Donor to museum } \\
\text { Origin of object: region or area of } \\
\text { Queensland } \\
\text { Three zones - Mainland Coast/North } \\
\text { Wellesley/South Wellesley } \\
\text { Four zones, numbered 1-4 representing } \\
\text { Language Groups - Ganggalida, Lardil, } \\
\text { Kaiadilt, Yangkaal } \\
\text { Cultural group linked to this zone as per } \\
\text { Language Zone }\end{array}$ \\
\hline Object Record & $\begin{array}{l}\text { Condition } \\
\text { Social Context } \\
\text { Male/Female } \\
\text { Object Group } \\
\text { Object Category } \\
\text { Object Form } \\
\text { Object Type }\end{array}$ & $\begin{array}{l}\text { Condition of the object (e.g. are elements } \\
\text { missing or broken) } \\
\text { Broad category - 'subsistence', 'ritual', } \\
\text { 'body decoration' etc } \\
\text { One or the other (or unknown) } \\
\text { Highest level category - 'tools', } \\
\text { 'weapons' etc (after Khan 2003) } \\
\text { e.g. spear, shell container (see Appendix } \\
\text { C) } \\
\text { Primary morphological trait of object (e.g. } \\
\text { hook) } \\
\text { Secondary morphological trait of object } \\
\text { (e.g. fluted and painted) }\end{array}$ \\
\hline Object Manufacture & $\begin{array}{l}\text { Visible number of Components } \\
\text { Material } \\
\text { Material Type } \\
\text { Presence of European Materials }\end{array}$ & $\begin{array}{l}\text { Number of visible component parts } \\
\text { Manufacturing material (e.g. wood, } \\
\text { vegetable fibre) } \\
\text { Type of material (e.g. ficus (wood) grass } \\
\text { (vegetable fibre)) } \\
\text { Are European materials recorded as } \\
\text { present? Y/N }\end{array}$ \\
\hline Object Dimensions (cm) & $\begin{array}{l}\text { Length } \\
\text { Width } \\
\text { Depth } \\
\text { Diameter } \\
\text { Circumference }\end{array}$ & $\begin{array}{l}\text { Overall length of object } \\
\text { Overall width of object } \\
\text { Overall depth of object } \\
\text { Diameter (e.g. armband) } \\
\text { Circumference of (e.g. spear shaft) }\end{array}$ \\
\hline Object Decoration & $\begin{array}{l}\text { Design Condition } \\
\text { Summary of Main Design Components } \\
\text { Design Techniques } \\
\text { Design Location } \\
\text { Colour } \\
\text { Motif } \\
\text { Motif Type }\end{array}$ & $\begin{array}{l}\text { Condition of design elements (e.g. faded) } \\
\text { Predominant designs (e.g. zigzags, wavy } \\
\text { lines) } \\
\text { Techniques with which design is applied } \\
\text { (e.g. painting, incising) } \\
\text { Location on object of particular design } \\
\text { motif or decorative technique } \\
\text { Colour of pigments only, not materials } \\
\text { Category of motif (e.g. arc, diamond) (see } \\
\text { Appendix F) } \\
\text { Type of (e.g. arc, diamond) (see Appendix } \\
\text { F) }\end{array}$ \\
\hline Images & $\begin{array}{l}\text { Photograph } \\
\text { Sketch }\end{array}$ & $\begin{array}{l}\text { Photograph of object } \\
\text { Scan or photograph of sketch }\end{array}$ \\
\hline
\end{tabular}


Appendix C. Object Categories.

\begin{tabular}{|l|l|}
\hline \multicolumn{1}{|c|}{ Object Category } & \\
\hline armlet & arm ornament \\
\hline bag & bag or basket \\
\hline bark container & shallow container of bark \\
\hline boomerang & boomerang \\
\hline clap sticks & pair of sticks to sound beat \\
\hline club & throwing stick \\
\hline coolamon & hollowed wooden container \\
\hline cordage & rope/string etc \\
\hline feather tuft & feather tuft hair decoration \\
\hline fire-making tools & fire-making tools \\
\hline fish mandible & barracuda mandible \\
\hline hair string skein & human hair string skein \\
\hline head ornament & head ornament \\
\hline line fishing & gear used in line fishing \\
\hline mixed media bundle & mixed media bundle \\
\hline necklet & neck ornament \\
\hline net & items of twined string netting \\
\hline paddle & raft/canoe paddle \\
\hline pendant & ornament hung from neck \\
\hline point & needle shaped tool, not stone \\
\hline pounder & wooden pounding object \\
\hline scraper & scraper \\
\hline shell container & container made from shell \\
\hline shell tool & unpierced shell \\
\hline spear & spears \\
\hline stick & message stick \\
\hline stick tool & cylindrical wooden tool \\
\hline stone blade & stone knife \\
\hline stone point & 'oyster pick' \\
\hline thrower & spear thrower \\
\hline waist ornament & waist ornament \\
\hline & \\
\hline
\end{tabular}


Appendix D. Object forms. Form numbers correspond to those in Best (2003). Note that not all forms used in Best (2003) are encountered in the study area and are omitted from this table.

\begin{tabular}{|c|c|c|}
\hline Object Category & Form & Description \\
\hline armlet & 0 & other \\
\hline armlet & 1 & rigid \\
\hline armlet & 2 & soft \\
\hline bag & 0 & other \\
\hline bag & 2 & pituri \\
\hline bark container & 0 & other \\
\hline bark container & 1 & pleated ends shallow bark container \\
\hline boomerang & 0 & other \\
\hline boomerang & 1 & curved, round tips \\
\hline boomerang & 2 & shallow curve, round tips \\
\hline boomerang & 3 & asymmetrical curve, round tips \\
\hline boomerang & 4 & hook \\
\hline clap sticks & 0 & other \\
\hline clap sticks & 1 & cylindrical \\
\hline club & 0 & other \\
\hline club & 1 & 'grenade' or 'pineapple' head \\
\hline club & 2 & 2 prong/fluted/painted \\
\hline coolamon & 0 & other \\
\hline coolamon & 1 & undecorated \\
\hline coolamon & 2 & decorated \\
\hline cordage & 0 & other \\
\hline cordage & 1 & vegetable fibre rope \\
\hline cordage & 2 & coil of vegetable fibre string \\
\hline feather tuft & 0 & other \\
\hline feather tuft & 1 & bunch of feathers tied with human hair string \\
\hline feather tuft & 2 & bunch feathers bound with gum resin \\
\hline feather tuft & 3 & feathers tied with vegetable fibre \\
\hline fire-making tools & 0 & other \\
\hline fire-making tools & 1 & fire stick(s) \\
\hline fire-making tools & 2 & bark strip 'torch' \\
\hline fish mandible & 0 & other \\
\hline fish mandible & 1 & barracuda mandible \\
\hline hair string skein & 0 & other \\
\hline hair string skein & 1 & human hair string \\
\hline head ornament & 0 & other \\
\hline head ornament & 1 & fine mesh forehead band with ties \\
\hline head ornament & 2 & circlets tied flat with spacer stiches \& with ties \\
\hline head ornament & 3 & multiple strands of string held together by cloth \\
\hline head ornament & 4 & iron circlet with macropod teeth pendants \\
\hline head ornament & 5 & bound single strand over human hair with ties \\
\hline line fishing & 0 & other \\
\hline line fishing & 1 & hook \& line \\
\hline line fishing & 2 & rod \& line \\
\hline line fishing & 3 & rod, line \& hook \\
\hline mixed media bundle & 1 & bark/string/fish mandible bundle \\
\hline necklet & 0 & other \\
\hline necklet & 1 & single strand \\
\hline necklet & 2 & double strand \\
\hline necklet & 3 & multiple strand \\
\hline necklet & 4 & shell pendant on single strand \\
\hline net & 0 & other \\
\hline net & 1 & knotted twined vegetable fibre string \\
\hline paddle & 0 & other \\
\hline paddle & 1 & fan shape blade \\
\hline paddle & 2 & elongated oval shape blade \\
\hline pendant & 0 & other \\
\hline pendant & 1 & cigar shape \\
\hline pendant & 2 & macropod teeth \\
\hline point & 0 & other \\
\hline point & 1 & bone 'awl' 'needle' \\
\hline point & 2 & wood 'awl' 'needle'” \\
\hline pounder & 0 & other \\
\hline pounder & 1 & integrated handle \\
\hline pounder & 2 & thick stick shape wider at centre \\
\hline
\end{tabular}




\begin{tabular}{|c|c|c|}
\hline Object Category & Form & Description \\
\hline scraper & 0 & other \\
\hline scraper & 1 & wooden handled 'plane' with iron blade \\
\hline scraper & 2 & wooden handled 'plane’ iron blade missing \\
\hline shell container & 0 & other \\
\hline shell container & 1 & pierced spiral shell container \\
\hline shell container & 2 & unpierced spiral shell container \\
\hline shell container & 3 & not spiral shell \\
\hline shell tool & 1 & modified, unpierced \\
\hline shell tool & 2 & unmodified \\
\hline spear & 0 & other \\
\hline spear & 1 & wood point 'javelin' \\
\hline spear & 2 & 3 prong/shallow barbs \\
\hline spear & 3 & multiple carved shallow wood barbs (1 side) \\
\hline spear & 4 & multiple carved sharp/serrated wood barbs (1 side) \\
\hline spear & 5 & stone point \\
\hline spear & 6 & 2 prong/shallow barbs \\
\hline spear & 7 & 2 prong (prongs not barbed) \\
\hline spear & 8 & 2 prong multiple sharp/serrated barbs one side only \\
\hline spear & 9 & 3 circular rows carved barbs carved into shaft \\
\hline stick & 0 & other \\
\hline stick & 1 & round rod \\
\hline stick & 2 & oval rod \\
\hline stick & 3 & flat rod \\
\hline stick & 4 & rectangular rod \\
\hline stick tool & 0 & other \\
\hline stick tool & 1 & multipurpose $>25<100 \mathrm{~cm}$ \\
\hline stick tool & 2 & $>100 \mathrm{~cm}$ fighting/digging \\
\hline stone blade & 0 & other \\
\hline stone blade & 1 & knife blade \\
\hline stone blade & 2 & knife blade with handle grip \\
\hline stone blade & 3 & with sheath \& handle grip \\
\hline stone point & 0 & none \\
\hline stone point & 1 & ‘tear drop’ shape \\
\hline thrower & 0 & other \\
\hline thrower & 1 & cylindrical, integrated peg \\
\hline thrower & 2 & cylindrical, added peg \\
\hline waist ornament & 0 & other \\
\hline waist ornament & 1 & human hair belt, 1st initiate \\
\hline waist ornament & 2 & fringed skirt with ties/pigment \\
\hline waist ornament & 3 & fringed skirt with ties \\
\hline waist ornament & 4 & fringed tassel/loop \\
\hline waist ornament & 5 & fringed tassel/pigment/loop \\
\hline waist ornament & 6 & tied bunch feathers \\
\hline waist ornament & 7 & circlets tied flat with spacer stitches \& with ties \\
\hline waist ornament & 8 & human hair tassel \& multistrand circlet \\
\hline
\end{tabular}


Appendix E. Object types.

\begin{tabular}{|c|c|c|}
\hline Object Category & Type & Description \\
\hline armlet & 0 & other \\
\hline armlet & 1 & plaited cane \\
\hline armlet & 2 & bound/wound \\
\hline armlet & 3 & bound/wound/fringing \\
\hline armlet & 4 & bound/wound/pendant decoration \\
\hline armlet & 5 & bound/wound/cane/pigment \\
\hline armlet & 6 & bound/wound/cane \\
\hline armlet & 7 & bound/wound/pigment \\
\hline bag & 0 & other \\
\hline bag & 1 & closed weave, soft, handle \\
\hline bag & 2 & closed weave, soft, no handle \\
\hline bark container & 0 & none \\
\hline bark container & 1 & knotted bark fibre string \\
\hline boomerang & 0 & other \\
\hline boomerang & 1 & painted red with white tip \\
\hline boomerang & 2 & undecorated \\
\hline boomerang & 3 & fluted \& painted red with white tip \\
\hline boomerang & 4 & fluted \& painted red \\
\hline clap sticks & 0 & none \\
\hline club & 0 & other \\
\hline coolamon & 0 & other \\
\hline coolamon & 1 & painted \\
\hline coolamon & 2 & painted \& fluted \\
\hline coolamon & 3 & undecorated \\
\hline cordage & 0 & none \\
\hline feather tuft & 0 & none \\
\hline feather tuft & 1 & feathers modified \\
\hline feather tuft & 2 & feathers unmodified \\
\hline fire-making tools & 0 & other \\
\hline fire-making tools & 1 & twirling stick(s) \\
\hline fire-making tools & 2 & hand-held torch \\
\hline fish mandible & 0 & none \\
\hline hair string skein & 0 & other \\
\hline hair string skein & 1 & wound over vegetable fibre string \\
\hline hair string skein & 2 & wound over commercial cotton cloth \\
\hline head ornament & 0 & other \\
\hline head ornament & 1 & with pigment \\
\hline head ornament & 2 & with pigment \& macropod teeth \\
\hline line fishing & 0 & none \\
\hline line fishing & 1 & iron hook \\
\hline mixed media bundle & 0 & other \\
\hline necklet & 0 & none \\
\hline necklet & 1 & bound \& wound \\
\hline necklet & 2 & bound \& wound \& ochred \\
\hline necklet & 3 & grass bugle beads \\
\hline necklet & 4 & seed beads \\
\hline net & 0 & other \\
\hline net & 1 & 2 stick handles oval shape \\
\hline net & 2 & 2 long stick handles triangular shape \\
\hline net & 3 & cylinder/casting string/open one end closed other \\
\hline net & 4 & rectangular length of netting \\
\hline paddle & 0 & none \\
\hline pendant & 0 & other \\
\hline pendant & 1 & bound/wound/pigmented \\
\hline pendant & 2 & pigmented macropod teeth set in gum tied on string \\
\hline point & 0 & other \\
\hline pounder & 0 & none \\
\hline pounder & 1 & ovate \\
\hline pounder & 3 & cylindrical \\
\hline scraper & 0 & none \\
\hline shell container & 0 & other \\
\hline shell container & 1 & melo/baler shell \\
\hline shell container & 2 & Syrinx arianus trumpet shell \\
\hline shell container & 3 & modified clam shell \\
\hline shell tool & 0 & other \\
\hline
\end{tabular}




\begin{tabular}{|l|c|l|}
\hline \multicolumn{1}{|c|}{ Object Category } & Type & \\
\hline shell tool & 1 & species unidentified \\
\hline shell tool & 2 & Polymesoda coaxans (mud clam) \\
\hline spear & 0 & none \\
\hline spear & 1 & 1 shaft for thrower (recessed butt) \\
\hline spear & 2 & 1 shaft hand-held \\
\hline spear & 3 & 2 shafts for thrower (recessed butt) \\
\hline spear & 4 & 2 shafts hand-held \\
\hline spear & 5 & 2 shafts thrower uncertain (broken etc) \\
\hline spear & 6 & 1 shaft thrower uncertain (broken etc) \\
\hline spear & 7 & 1 piece hand-held no hafted point/prong/barbs \\
\hline stick & 0 & other \\
\hline stick & 1 & blunt ends \\
\hline stick & 2 & tapered ends \\
\hline stick & 3 & pointed ends \\
\hline stick tool & 0 & none \\
\hline stick tool & 1 & pointed both ends \\
\hline stick tool & 2 & pointed one end \\
\hline stick tool & 3 & incised grip pointed both ends \\
\hline stick tool & 4 & incised grip pointed one end \\
\hline stick tool & 5 & boomerang shaped \\
\hline stick tool & 6 & waisted form, point one end \\
\hline stone blade & 0 & other \\
\hline stone blade & 1 & flake with central ridge, flat back \\
\hline stone point & 0 & other \\
\hline thrower & 0 & none \\
\hline thrower & 1 & twine bound proximal end \\
\hline thrower & 2 & added decoration on shaft \& twine proximal end \\
\hline waist ornament & 0 & other \\
\hline waist ornament & 1 & multistrand \\
\hline waist ornament & 2 & fully encircling waist \\
\hline waist ornament & 3 & female public cover \\
\hline waist ornament & 4 & male pubic cover \\
\hline waist ornament & 5 & multistrand with spacer stitches \\
\hline & & \\
\hline
\end{tabular}


Appendix F. Motifs. Motif type numbers correspond to those in Best (2003). Note that not all motifs used in Best (2003) are encountered in the study area and are omitted from this table.

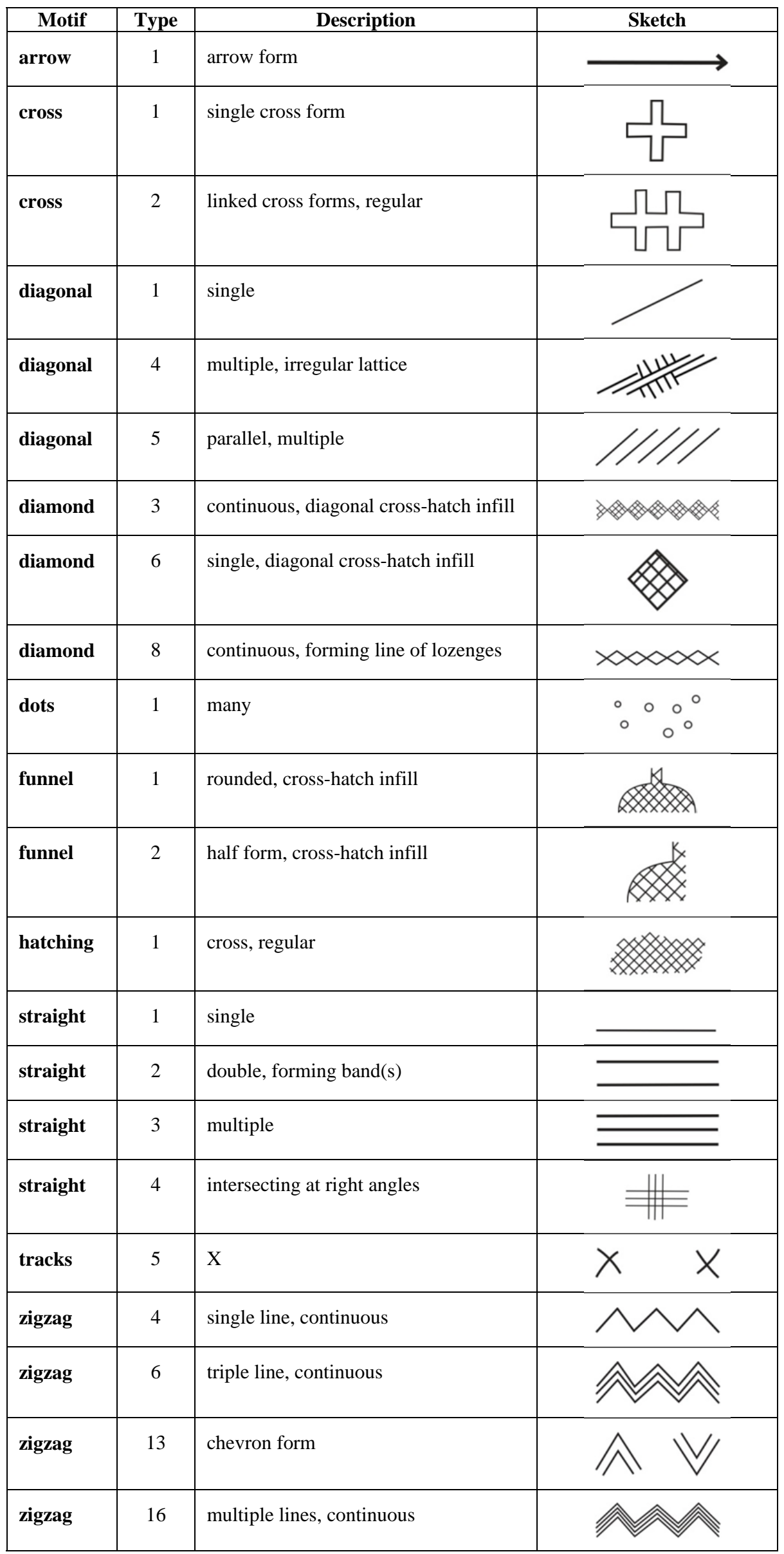

